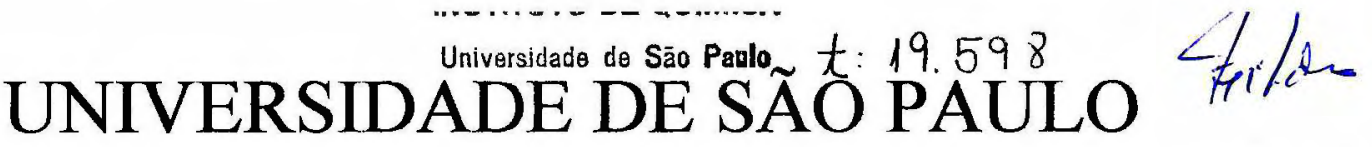 INSTITUTO DE QUÍMICA
}

\section{Estudos eletroquímicos envolvendo eletrodos modificados por metaloporfirinas e aplicação na determinação de nitrato $\left(\mathrm{NO}_{3}^{-}\right)$e nitrito $\left(\mathrm{NO}_{2}^{-}\right)$}

José Roberto Caetano da Rocha Dissertação de Mestrado

\section{Prof. Dr. Mauro Bertotti \\ Orientador}




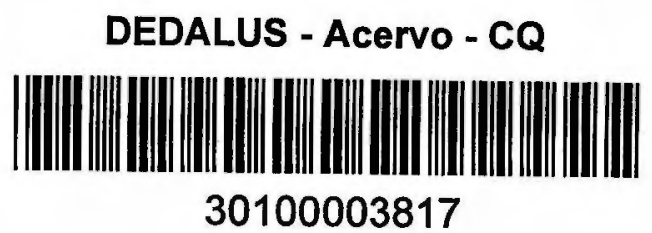

Ficha Catalogrảifica

Elaborada pela Divisão de Biblioteca e

Documentação do Conjunto das Quimicas da USP.

\section{R672e}

Rocha, José Roberto Caetano da

Estudos eletroquímicos envolvendo eletrodos modificados por metaloporfirinas e aplicaça na determinaça de nitrato $\left(\mathrm{NO}_{3}{ }^{\prime}\right)$ e nitrito $\left(\mathrm{NO}_{2}{ }^{-}\right.$)! Jose Roberto Caetano da Rocha, -. Sao Paulo.2001.

$93 \mathrm{p}$.

Dissertação (mestrado) - Instituto de Quimica da Universidade de Sao Paulo. Departamento de Quimica Fundamental.

Orientador: Bertotti. Mauro

1. Amperometria : Química analftica 2, Eletrodo : Fisicoquimica 3. Nitrito: Quimica analitica: Inotganica 1 . T. II. Bertotti. Mauro. orientador. 
BIBLIOTECA

INSTITUTO DE QUIMICA

Unlversidade de São Panlo

Estudos Eletroquímícos Envolvendo Eletrodos Modificados por Metaloporfirinas e Aplicaf̧ão na Determinação de Nitrato $\left(\mathrm{NO}_{3}{ }^{-}\right)$e Nitrito $\left(\mathrm{NO}_{2}^{-}\right)^{-1}$.

\section{JOSÉ ROBERTO CAETANO DA ROCHA}

DISSERTAÇÃO DE MESTRADO SUBMETIDA AO INSTITUTO DE QUÍMICA DA UNIVERSIDADE DE SÃo PAULO COMO PARTE DOS REQUISITOS NECESSÁRIOS À OBTENÇÃo DO

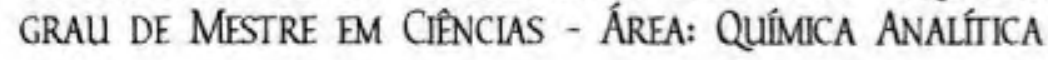

Aprovado por:

Prof. Dr. MAURO BERTOTTI

(Orientador e Presidente)

Prof. Dr. SILVIA HELENA PIRES SERRANO

IQ - USP

Prof. Dr. SÉRGIO ANTONIO SPINOLA MACHADO

IQSC - USP 
"Hay hombres que luchan un dia y son buenos Hay outros que luchan um año y son mejores Hay quienes luchan muchos años y son muy buenos Pero hay los que luchan toda la vida Esos son los imprescindibles".

(Bertold Brecht) 
Dedico este trabalho à minha esposa, TEREZA. A quem agradeço pelo amor, companheirismo e paciência, demonstrados a cada instante. 
À minha mãe, Mercedes, pelo constante incentivo.

Aos meus filhos, Roberta e Leandro, a quem amo muito. 


\section{AGRADECIMENTOS}

A Deus.

Ao Prof. Dr. Mauro Bertotti que além de orientador é um grande amigo e com quem consegui os conhecimentos necessários para que este momento se tornasse realidade.

Ao Prof. Dr. Lúcio Angnes pelas conversas, auxílios, dignidade de suas ações e co-orientação valiosa.

Ao Prof. Dr. Sérgio Massaro pelas contribuições relacionadas ao meio ambiente e a vida. Estas, muito contribuíram para minha formação profissional, pessoal e ética.

À Prof ${ }^{\mathrm{a}}$. Dra. Maura Vicenza Rossi quem primeiramente me recebeu no Instituto de Química e a quem eu declaro meu maior respeito.

Ao Prof. Antônio Machado Fonseca Neto que me apresentou os primeiros conceitos de Química Analítica.

Aos Profs. Drs. Henrique Eisi Toma e Koiti Araki por contribuírem de forma significativa na conclusão deste trabalho.

Aos Profs. Drs. Peter Wilhelm Tiedemann, Reiko Isuyama e Vera Lúcia Pardini pelos conhecimentos cedidos na área de educação em química.

Ao Prof. Dr. Roberto Tokoro pelo convivio, conhecimentos transmitidos e pela amizade.

Aos Profs. Drs. Claudimir Lúcio do Lago, Ivano Gebhart Rolf Gutz, Jorge César Masini, Maria Encarnación Vásquez Suárez Iha, Koshun Tha, Roy Edward Bruns, Silvia Helena Pires Serrano pelo incentivo e conhecimentos transmitidos.

Aos colegas de laboratório Alexandra, Audrei, Denise, Dennys, Fernanda, Luis, Nilton, Thiago, Tiago, Vânia pelos momentos bons e descontraídos que passamos juntos.

Aos colegas do laboratório comum Andrea, Giseli, Marco Antônio, Socorro, Sofia (in memorian) pelos papos e constante ajuda.

Aos colegas da analítica Adriana, Alberto, Carlos, Cristiane, Daniela, Dôra, Dosil, Eduardo, Flávia, Flávio, Francisco, Gilberto, Heliara, Heron, Laerte, José Carlos, Paulo Cesar, Renato, Sílvio, Vicente pela amizade e pelas conversas. 
Ao Prof. Dr. Gianluca Camillo Azzellini e seus alunos Marcela e Rodrigo pelos auxílios e dúvidas sanadas.

À todos os professores das Faculdades Osvaldo Cruz que, de alguma forma, me induziram para este caminho.

Aos professores e funcionários do Instituto de Química pelo excelente convivio.

Aos meus amigos - professores do município de Ribeirão Pires Angélica, Elizabeth, Claudimir, Edilson, Enilda, Jorge que muito me incentivaram e em especial à Maria Aparecida, Maria Clara, Rosângela Panace e Sônia que além do incentivo me concederam suas amizades.

Aos professores Alba, Ana Néri, Beth, Claudia, Cristina, Olívia, Sônia, Valdir e Vera Lúcia pela amizade e pelo incentivo.

Aos técnicos Alexandre, Roberto e Wilson pelos constantes auxílios.

Às secretárias da Química Analítica, Célia e Marlene, pela presteza de seus serviços e constantes bate papos.

Às funcionárias Lúcia e Luciana que sempre foram muito prestativas.

À todos os funcionários da Seção de Pós Graduação pela forma eficaz e bondosa como realizam os seus trabalhos.

À Cristina e Fumie que muito contribuíram para que eu conseguisse maiores informações nos diversos congressos.

Aos meus irmãos, João Donizetti, Inês, Odete e Ricardo; às minhas cunhadas, Esmênia e Luzia, e a minha sogra, Mafrizia (in memorian), pelo incentivo e apoio.

Ao meu pai, João (in memorian), por instigar-me a fazer algo diferente.

À todos que de alguma forma colaboraram no desenvolvimento deste trabalho.

Ao CNPq, CAPES, FAPESP e Pró Reitoria de Pós Graduação da USP pelo suporte financeiro.

P.S. Peço desculpas se por acaso tenha esquecido de agradecer alguém. 


\section{RESUMO}

O presente trabalho inclui duas etapas da pesquisa. Na primeira fase do projeto, a oxidação eletroquímica do nitrito em eletrodo de carbono vítreo modificado com um filme obtido eletrostaticamente de Co-TRP/Zn-TPPS, foi investigada em $\mathrm{pH} 4,7$. Um aumento de corrente foi detectado em $0,75 \mathrm{~V}$, cujo máximo foi proporcional à concentração do íons nitrito, exibindo uma dependência inversa com a espessura do filme. A velocidade de transferência de carga foi avaliada por cronoamperometria, sendo que a velocidade de difusão da carga eletroquímica através do filme é mais alta do que a velodicade de difusão do íon em solução. O processo catalítico envolvendo a oxidação do íon nitrito no filme de pares de depósitos alternados foi também investigado com as técnicas da voltametria cíclica e de disco rotativo. Em concentrações relativamente baixas de substrato, o processo mediado foi tratado como um sub-caso, SR, na notação de Saveant, permitindo o cálculo da constante de velocidade para a reação de troca na interface filme-solução, sendo que tal valor foi estimado em $3,4 \times 10^{3} \mathrm{dm}^{3} \mathrm{~mol}^{-1} \mathrm{~s}^{-1}$.

$\mathrm{Na}$ segunda parte da investigação, a potencialidade analítica do eletrodo modificado foi confirmada por experimentos de injeção em fluxo usando solução carregadora tampão $\mathrm{pH} 4,7$. Devido à atividade catalítica da camada imobilizada, a determinação de nitrito foi realizada em potencial menos positivo do que aqueles obtidos em eletrodos polidos $(0,75 \mathrm{~V}$ vs. $\mathrm{Ag} / \mathrm{AgCl})$ e os dados obtidos demostraram o melhor desempenho do eletrodo modificado, indicando excelente repetibilidade e maior sensibilidade.

$\mathrm{Na}$ condição experimental otimizada, o nitrito foi determinado na configuração FIA com limite de deteç̧ão de $0,1 \mu \mathrm{mol} \mathrm{L}^{-1} \mathrm{e}$ a faixa analítica de aplicabilidade do método foi de 1 a $1000 \mu \mathrm{mol} \mathrm{L^{-1 }}$. Nitrato também foi quantificado após sua redução estequiométrica a nitrito pela passagem da solução através da coluna de cádmio/cobre. Ambos analitos foram quantificados em água mineral e amostras de saliva e os resultados foram concordantes com aqueles obtidos usando método oficial. 


\section{ABSTRACT}

This present work includes two research steps. In the first step the electrochemical oxidation on nitrite on a glassy carbon disc electrode, modified with an electrostatically assembled film of tetraruthenated cobalt porphyrin/(mesotetra(4-sulphonatephenyl)porphyrinate zinc(II), was investigated at $\mathrm{pH}=4.7 . \quad \mathrm{A}$ current enhancement was observed by using the modified electrode, the signal being proportional to the concentration of nitrite ions and exhibiting an inverse dependence with the film thickness. The charge transfer rate was evaluated by chronoamperometry, showing that the rate of diffusion of electrochemical charge through the film is higher than the rate of diffusion of substrates in solution. The catalytic process involving the oxidation of the nitrite ions at the bilayered film was also investigated based on cyclic and rotating disc voltammetry. At relatively low substrate concentrations the mediated process has been dealt with in terms of the SR sub-case in Saveant's notation, allowing the calculation of the rate constant for the cross-exchange reaction at the film-solution interface as $3.4 \times 10^{3} \mathrm{dm}^{3} \mathrm{~mol}^{-1} \mathrm{~s}^{-1}$.

In the second part the analytical potentiality of the modified electrode was studied by flow injection experiments carried out by using a $\mathrm{pH} 4.7$ buffer as carrier solution. Owing to the catalytic activity of the immobilized layer, the determination of nitrite was performed at less positive potentials $(0.75 \mathrm{~V}$ versus $\mathrm{Ag} / \mathrm{AgCl})$ and the data obtained showed a better performance indicated by both an excellent repeatability and increased sensitivity.

At the optimized experimental condition, nitrite was determined in the FIA configuration with a limit of detection of $0.1 \mu \mathrm{mol} \mathrm{L}^{-1}$. Nitrate was also quantified after its stoichiometric reduction to nitrite by passing the solution through a cadmium/copper column. Both analytes were quantified in mineral water and saliva samples and the results were in agreement with the ones obtained by using an official method. 
Agradecimentos

Resumo I

Abstract II

Índice $\quad$ III

Índice das Figuras $\quad$ VI

Índice das Tabelas $\quad$ XI

Abreviaturas, Símbolos e Definições $\quad$ XII

1. OBJETIVOS 1

2. INTRODUÇÃO 2

2.1. Nitrato e Nitrito 2

2.2. Técnicas Eletroanalíticas 5

2.2.1. Cronoamperometria 6

2.2.2. Voltametria Cíclica 6

2.2.3. Amperometria 8

2.3. Análise por Injeção em Fluxo (FIA) 9

2.4. Eletrodos Modificados $\quad 12$

2.5. Porfirinas 13

2.6. Redução do Nitrato a Nitrito 18

3. PARTE EXPERIMENTAL

3.1. Reagentes $\quad 20$

3.2. Soluções $\quad 21$

3.3. Aparelhagem 21

3.4. Esquemas das Aparelhagens 23

3.4.1. Ensaios em sistema estacionário $\quad 23$

3.4.2. Ensaios em sistema FIA para determinação de nitrito 24

3.4.3. Ensaios em sistema FLA para determinação de nitrato em pH 9,I 25 
3.4.4. Ensaios em sistema FLA para determinação de $\mathrm{NO}_{3}{ }^{-}$em $\mathrm{pH} 4,5$. 25

3.4.5. Ensaios em sistema FIA para determinação de nitrato em $\mathrm{pH} 8$.

3.5. Coluna redutora de $\mathrm{Cd} / \mathrm{Cu}$

3.5.1. Preparo da coluna $\quad 27$

3.5.2. Rendimento da coluna 28

3.6. Procedimento de Desproteneização 28

3.7. Procedimento de Extração 29

4. RESULTADOS E DISCUSSÃO 30

4.1. Procedimento de Imobilização de Depósitos Alternados de Co-TRP/Zn- 30 TPPS na Superfície do Eletrodo

4.2. Estudos Preliminares 31

4.2.1. Variação na Velocidade de Varredura . 31

4.2.2. Equação de Cottrell

4.2.3. Ensaios preliminares utilizando o par Co-TRP/Zn-TPPS 35

4.2.4. Eletrodo Modificado com outras Porfirinas 37

4.2.4.1. $\mathrm{ZnTBzPyP}\left(\mathrm{ClO}_{4}\right)_{4}$

4.2.4.2. $\mathrm{ZnTMeOBzPyP}\left(\mathrm{ClO}_{4}\right)_{4}$

4.3. Caracterização do Eletrodo Modificado 39

4.3.1. Ensaios com Pares de Depósitos Alternados de Co-TRP/Zn-TPPS 39

4.3.2. Número de Depósitos Alternados de Co-TRP/Zn-TPPS 41

4.3.3. Homogeneidade e Permeabilidade do filme Co-TRP/Zn-TPPS 47

4.3.4. Envenenamento da Superficie do Eletrodo de Carbono Vitreo $\quad 50$

4.3.5. Quantidade de Agente Modificador $\quad 52$

4.3.6. Estabilidade do eletrodo modificado 53

4.3.7. Estudo do processo de transferência de elétrons no eletrodo 54 modificado

4.4 Determinação da Constante de Velocidade Referente à Oxidação do $\mathrm{NO}_{2}^{-} \quad 60$ no Eletrodo Modificado 
4.5. Coeficiente de Difusão do $\mathrm{NO}_{2}{ }^{-}$

4.6. Ensaios Quantitativos

4.6.1. Determinação de Nitrito em Tampão $p H$ 4,7

4.6.2. Determinação de Nitrito e Nitrato em Tampão pH 9, 1

4.6.3. Determinação de Nitrato com Acerto de $p H$

4.6.4. Solução Tampão pH 4,7 X Solução Acetato $p H 8$

4.6.5. Resultados Obtidos Utilizando Solução Acetato (pH 8)

4.6.5.1. Determinação de Nitrato e Nitrito em $\mathrm{pH} 8$

4.6.5.2. Repetibilidade e Linearidade do Método em $\mathrm{pH} 8$ 70

4.6.5.3. Preparo das Amostras Reais

4.6.5.4. Resultados das Amostras Reais

5. CONCLUSÕES

75

6. PERSPECTIVAS FUTURAS

80

7. REFERÊNCIAS BIBLIOGRÁFICAS 


\section{ÍNDICE DAS FIGURAS}

Figura

Pág.

1 Esquema do ciclo do nitrogênio na natureza 2

2 Voltamograma cíclico de um sistema reversível.

3 Voltamograma cíclico de um sistema irreversível.

4 Esquema básico de um sistema de análise por injeção em fluxo 10 (FIA).

5 Comparação da mistura e condição de dispersão em sistema 11 estacionário e sistema de injeção em fluxo

6 Esquema do controle da dispersão do constituinte de interesse 12 em função do tempo.

7 Estruturas dos grupamentos pirrol, porfina e complexo $\mathrm{Fe}^{2+}-14$ porfina.

8 Estrutura do complexo ferro-porfirina ou simplesmente heme. 14

9 Esquema do processo de transporte de oxigênio pela 15 hemoglobina.

10 Estrutura da clorofila $a$, o principal pigmento da clorofila. 16

11 Estrutura da $\alpha, \beta, \gamma, \delta$-meso-tetrakis-fenilporfirina. 17

12 Estrutura da porfirina catiônica Co-TRP e da porfirina aniônica 18 Zn-TPPS.

13 Célula eletroquímica para trabalhos em sistema FIA. 23

14 Esquema para ensaios em sistema estacionário. 24

15 Esquema para ensaios em sistema FIA para determinação de 24 nitrito $\mathrm{pH} 4,7$.

16 Esquema para ensaios em sistema FIA para determinação de 25 nitrato em $\mathrm{pH} 9,1$. 
17 Esquema para ensaios em sistema FIA para determinação de 26 nitrato com acerto de $\mathrm{pH} \approx 4,5$.

18 Esquema para ensaios em sistema FIA para determinação de 26 nitrato em $\mathrm{pH} 8,0$.

19 Fiagrama para determinar a redução de nitrato a nitrito.

20 Esquema do processo de recobrimento da superficie do eletrodo. 30

21 Voltamogramas cíclicos para estudo da variação da velocidade 31 de varredura.

22 Dependência da corrente de pico catódica em função da 32 velocidade de varredura.

23 Cronoamperograma obtido em sol. de ferricianeto de potássio.

24 Aplicação da equação de Cottrell, utilizando a análise de dados da figura 23 (I vs. $\mathrm{t}^{-1 / 2}$ ).

25 Voltamogramas cíclicos obtidos com eletrodo de carbono vítreo 35 modificado em solução sem perclorato de sódio.

26 Voltamogramas cíclicos obtidos com eletrodo de carbono vítreo 36 modificado em solução com perclorato de sódio.

27 Voltamogramas cíclicos obtidos em solução tampão acetato de 40 sódio/ácido acético $0,1 \mathrm{~mol} / \mathrm{L}(\mathrm{pH} \mathrm{4,7)}$ contendo perclorato de sódio $0,2 \mathrm{~mol} / \mathrm{L}$ e $1 \mathrm{mmol} / \mathrm{L}$ de $\mathrm{NO}_{2}^{-}$, utilizando-se eletrodo de carbono vítreo polido e eletrodo de carbono vítreo modificado com 1 par de depósito alternado de Co-TRP/Zn-TPPS.

28 Provável esquema de mediação para a intensificação do sinal de corrente quando da oxidação de nitrito em eletrodo modificado com Co-TRP/Zn-TPPS.

29 Voltamogramas cíclicos registrados utilizando $1,3,5,7,10 \mathrm{e}$ 15 pares de depósitos alternados de Co-TRP/Zn-TPPS em eletrodo de carbono vítreo. 
30 Dependência de $\Delta \mathrm{I}$ (corrente de pico na presença de $\mathrm{NO}_{2}^{-}{ }^{-} 44$ corrente de pico na ausência de $\mathrm{NO}_{2}{ }^{-}$) em função do número de pares de depósitos alternados.

31 Gráfico que apresenta as curvas de intensidade de corrente em 46 função da quantidade de depósitos alternados de porfirinas.

32 Injeções sucessivas de $1 \mathrm{mmol} / \mathrm{L}$ de $\mathrm{NO}_{2}^{-}$utilizando eletrodo de carbono vítreo modificado com 1 par de depósito alternado de Co-TRP/Zn-TPPS e em eletrodo polido.

33 Voltamogramas cíclicos para estudo da permeabilidade do 48 eletrodo modificado.

34 Voltamogramas cíclicos alterando a velocidade de varredura e a concentração do nitrito.

35 Voltamogramas cíclicos sucessivos para estudo do 51 envenenamento do eletrodo de carbono vítreo polido.

36 Injeções sucessivas de solução $1 \mathrm{mmol} / \mathrm{L}$ de nitrito em eletrodo de carbono vítreo polido.

37 Voltamograma cíclico utilizado para o cálculo da carga (Q).

38 Voltamogramas cíclicos para o estudo da estabilidade do eletrodo modificado com Co-TRP/Zn-TPPS.

39 Cronoamperograma realizado em sol. tampão $\mathrm{pH} \mathrm{4,7}$ contendo $0,2 \mathrm{~mol} / \mathrm{L}$ de $\mathrm{NaClO}_{4}$ utilizando eletrodo de carbono vítreo modificado com 1 par de depósito alternado de Co-TRP/ZnTPPS e análise dos dados da figura $37 \mathrm{~A}$, I vs $\mathrm{t}^{-1 / 2}$.

40 Voltamogramas cíclicos obtidos com velocidades de rotação 56 $100,400,900,1600,2500,3600$ e $4900 \mathrm{rpm}$ em sol. tampão acetato de sódio/ácido acético $(\mathrm{pH} \mathrm{4,7)}$ contendo $0,2 \mathrm{~mol} / \mathrm{L}$ de $\mathrm{NaClO}_{4}$ com concentração final de $\mathrm{Na}_{4}\left[\mathrm{Fe}(\mathrm{CN})_{6}\right] 0,1 ; 0,5 ; 1 ; 5$ e $10 \mathrm{mmol} / \mathrm{L}$. 
41 Gráfico de I vs. $\omega^{1 / 2}$ obtido através de dados da figura 40.

42 Voltamogramas cíclicos obtidos com velocidades de rotação 58 $100,400,900,1600,2500,3600$ e 4900 rpm em sol. tampão acetate de sódio/ácido acético contendo $0,2 \mathrm{~mol} / \mathrm{L}$ de $\mathrm{NaClO}_{4}$ com concentração final de $\mathrm{NaNO}_{2} 1,2,3,4$ e $5 \mathrm{mmol} / \mathrm{L}$.

43 Gráficos de I vs. $\omega^{1 / 2}$ e $\Gamma^{-1}$ vs. $\omega^{-1 / 2}$ obtidos a partir de dados do voltamograma cíclico da figura 42.

44 Gráfico de coeficientes lineares vs. $C^{-1}$, sendo que os coeficientes lineares foram obtidos através da regressão linear da figura 42B.

45 Resposta amperométrica em fluxo para obtenção da curva analítica para nitrito.

46 Curva analítica para nitrito em $\mathrm{pH} 4,7$.

47 Fiagramas obtidos para determinar a repetibilidade do método de determinação de nitrito $\mathrm{pH} 4,7$.

48 Resposta amperométrica em fluxo após passagem da amostra 64 pela coluna redutora de $\mathrm{Cd} / \mathrm{Cu}$ para obtenção da curva analítica para nitrito $\mathrm{pH} 9,1$.

49 Resposta amperométrica em fluxo após passagem da amostra 65 pela coluna redutora de $\mathrm{Cd} / \mathrm{Cu}$ para obtenção da curva analítica para nitrato $\mathrm{pH} 9,1$.

50 Curva analítica para nitrito em $\mathrm{pH} 9,1$.

51 Curva analítica para nitrato em $\mathrm{pH} 9,1$.

52 Fiagrama obtido para determinar a repetibilidade do método de 66 determinação de nitrito em pH 9,1.

53 Fiagrama obtido para determinar a repetibilidade do método de determinação de nitrato em $\mathrm{pH} 9,1$.

54 Resposta amperométrica obtida com acerto de $\mathrm{pH}$ para 4,5 após 68 passagem da amostra pela coluna redutora $\mathrm{de} \mathrm{Cd} / \mathrm{Cu}$. 
55 Resposta amperométrica para comparar os resultados em solução 69 tampão pH 4,7 e em solução acetato pH 8.

56 Resposta amperométrica em fluxo passando pela coluna redutora 70 de $\mathrm{Cd} / \mathrm{Cu}$ para obtenção da curva analítica para nitrato $\mathrm{pH} 8$.

57 Curva analítica para nitrato em $\mathrm{pH} 8$. 71

58 Resposta amperométrica em fluxo para obtenção da curva 72 analítica para nitrito $\mathrm{pH} 8$.

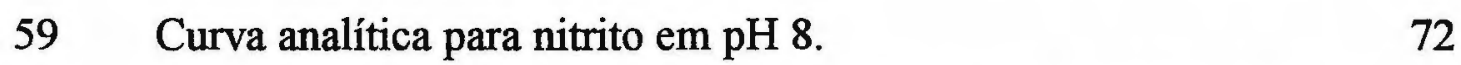

60 Fiagramas obtidos para determinar a repetibilidade do método de 73 determinação de nitrito $\mathrm{pH} 8$.

61 Curva para demosntrar a linearidade do método 74

62 Gráfico que compara os métodos de Griess e amperométrico 76 utilizando os resultados obtidos com a determinação de nitrato. 


\section{ÍNDICE DAS TABELAS}

Tabela

Pág.

1 Dados extraídos dos voltamogramas cíclicos da figura 29, onde

$\mathrm{I}_{\mathrm{k}}=$ intensidade de corrente obtida em solução tampão contendo nitrito, $\mathrm{I}_{\mathrm{d}}=$ intensidade de corrente obtida em solução tampão sem nitrito e $\Delta I=I_{k}-I_{d}$.

2 Dados da média aritmética das intensidades de corrente obtidas através de 3 injeções sucessivas de solução tampão acetato de sódio/ácido acético $0,1 \mathrm{~mol} / \mathrm{L}$ contendo perclorato de sódio 0,2 $\mathrm{mol} / \mathrm{L}$ e $1 \mathrm{mmol} / \mathrm{L}$ de $\mathrm{NO}_{2}^{-}$no fluxo carregador. Utilizando diferentes quantidades de depósitos alternados de Co-TRP/ZnTPPS e aplicando diferentes potenciais ao eletrodo de trabalho.

3 Valores de potencial de pico da onda anódica $\left(\mathrm{E}_{\mathrm{pa}}\right)$ e potencial de 50 pico da onda catódica $\left(\mathrm{E}_{\mathrm{pc}}\right)$, obtidos da figura 33 .

4 Resultados da concentração de nitrato e nitrito, obtidos por meio 75 de ensaios espectrofotométricos e amperométricos em amostras de água mineral e de saliva.

5 Resultados da concentração de nitrato e nitrito, obtidos por meio de ensaios espectrofotométricos e amperométricos em amostra de carne curada.

6 Valores dos desvios encontrados entre o método de Griess e o amperométrico. 


\section{ABREVIATURAS, SÍMBOLOS E DEFINIÇÕES}

$\mathbf{a}$

A

A

b

C

C

$\mathrm{C}_{0}$

$\mathrm{C}_{\max }$

Co-TRP

D

D

$\Delta \mathrm{E}$

$\Delta I$

E. Coli

$\mathrm{E}_{\mathrm{f}}$

$\mathrm{E}_{\mathrm{i}}$

$\mathrm{E}_{\mathrm{pa}}$

$E_{p c}$

ETE

F

FIA

$\Gamma$

h

I

$\mathrm{I}_{\mathrm{d}}$
Coeficiente linear.

Área.

Área da superfície do eletrodo.

Coeficiente angular.

Concentração da substância eletroativa.

Concentração do constituinte após a injeção no fluxo.

Concentração original do constituinte.

Concentração máxima do constituinte após a injeção no fluxo.

$\mu$-meso(tetrapiridyl)

porfirinato

de

cobalto(III)

tetrakis[bis(bipiridina)-(cloro) rutênio (II)].

Coeficiente de Dispersão.

Coeficiente de Difusão.

Diferença entre $E_{p a}$ e $E_{p c}$.

$\mathrm{I}_{\mathrm{k}}-\mathrm{I}_{\mathrm{d}}$

Escherichia coli.

Potencial final.

Potencial inicial.

Potencial de pico anódico.

Potencial de pico catódico.

Estação de Tratamento de Esgotos.

Constante de Faraday.

Análise por Injeção em Fluxo (do inglês, Flow Injection Analysis).

Quantidade de agente modificador que recobre a superfície do eletrodo.

Altura

Intensidade de corrente.

Intensidade de corrente obtida através da varredura em solução tampão contendo nitrito. 
I $\quad$ Intensidade de corrente obtida através da varredura em solução tampão sem nitrito.

$\mathrm{I}_{\mathrm{L}} \quad$ Intensidade de corrente limite.

$\mathrm{I}_{\mathrm{pa}} \quad$ Intensidade de corrente de pico anódico.

$\mathrm{I}_{\mathrm{pc}} \quad$ Intensidade de corrente de pico catódico.

$\mathrm{I}_{\mathrm{t}} \quad$ Intensidade de corrente no instante $\mathrm{t}$.

k Constante de velocidade

Me Metal.

$\mathrm{Me}^{++} \quad$ Íon metálico.

MetHb Metaemoglobina.

n Número de elétrons envolvidos.

Ni-TRP $\mu$-meso(tetrapiridyl) porfirinato de Níquel(III) tetrakis[bis(bipiridina)(cloro) rutênio (II)].

Q Carga envolvida no processo anódico.

$\omega \quad$ Velocidade de rotação.

u Viscosidade.

t Tempo.

$\mathrm{t}_{0} \quad$ Tempo inicial.

Zn-TPPS meso-tetra(4-sulfonatofenil) porfirinato de zinco (II). 


\section{OBJETIVOS}

Desenvolver um procedimento amperométrico em fluxo utilizando eletrodos modificados com porfirina tetrarrutenada para a determinação de nitrato e nitrito em amostras sintéticas e em águas naturais.

Elucidar, utilizando eletrodo rotativo disco-anel, o mecanismo envolvendo a oxidação anódica do nitrito nos eletrodos modificados. 


\section{INTRODUÇÃO Universidado de Săo Paalo}

2 - INTRODUÇÃO - 2

\subsection{Nitrato e Nitrito}

Nitrato e nitrito são utilizados como aditivos para conservar carnes e seus derivados, isto porque estes sais contribuem para (a) a intensificação do sabor e da coloração rosa nos produtos embutidos, (b) na prevenção contra sabor rançoso destes alimentos e (c) para inibir o desenvolvimento da bactéria Clostridium botulinum que se forma no interior ou sobre produtos alimentícios de origem animal [1].

O nitrogênio, que é o elemento central da estrutura do nitrato e do nitrito, apresenta-se dissolvido na água em várias formas dependendo do nível de oxidação deste elemento. $\mathrm{O}$ nitrato é a forma mais oxidada e portanto mais estável do nitrogênio nas condições existentes em águas superficiais.

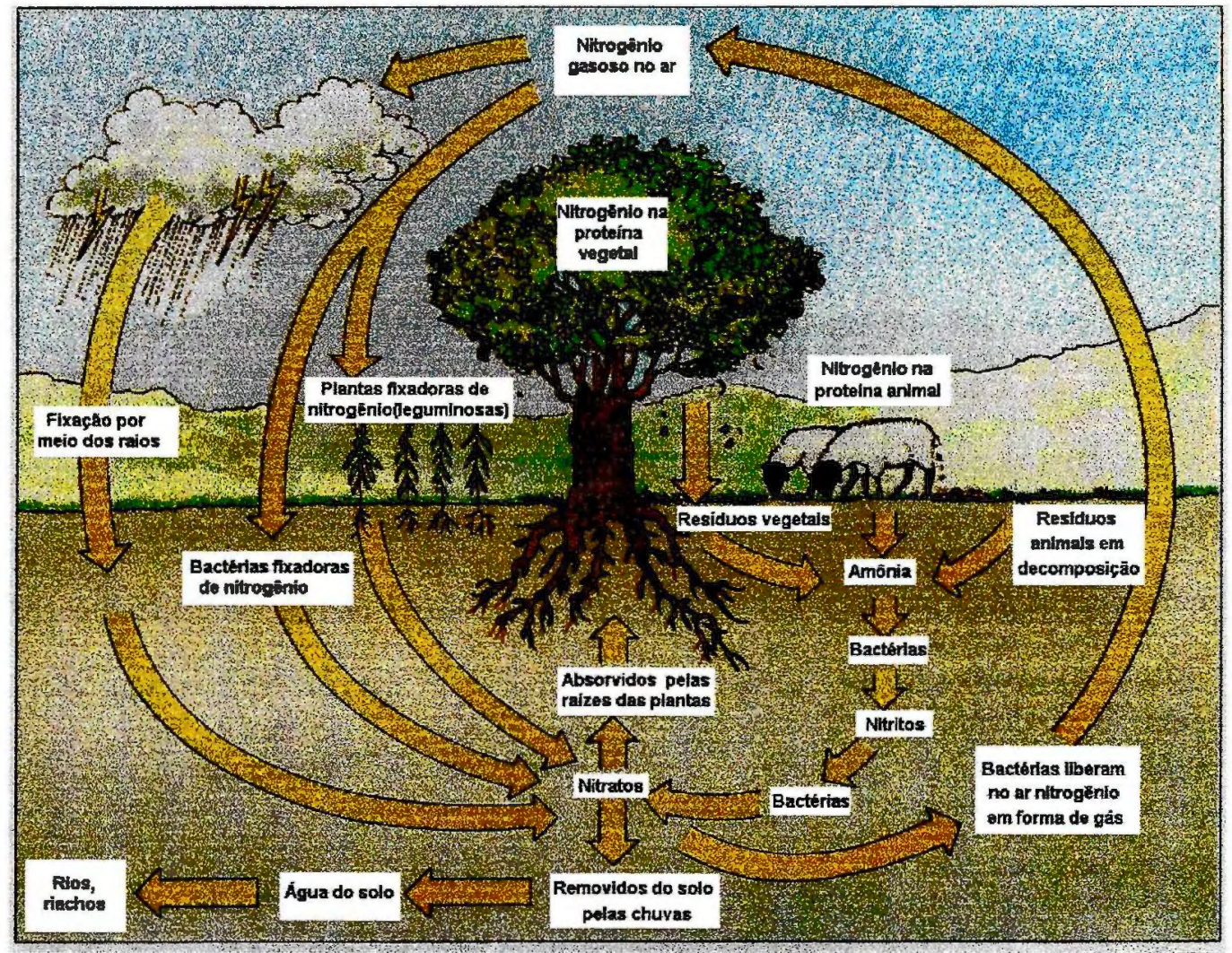

Figura 1 - Esquema do ciclo do nitrogênio na natureza [2].

Devido à sua estreita relação com o ciclo da vida, as concentrações de nitrato dissolvido em água são fortemente influenciadas pelas atividades das 
plantas e dos animais, conforme pode ser observado na figura 1 , onde está representado o ciclo do nitrogênio. As bactérias - nitrosomonas e nitrobacter possuem um papel preponderante na relação do nitrato nas águas visto que elas convertem íons em que o átomo de nitrogênio apresenta número de oxidação menor para nitrato.

Existem casos documentados - principalmente em bebês - de envenenamentos sérios e ocasionalmente fatais devido à ingestão de água de poços contendo nitrato em concentração maior do que $220 \mu \mathrm{mol} / \mathrm{L}$ (expressos em N) [3], devido à formação da metaemoglobina (MetHb). Em bebês o nitrito $\left(\mathrm{NO}_{2}{ }^{-}\right)$formado a partir de nitrato ou ingerido in loco faz com que a hemoglobina seja oxidada a MetHb e nesta forma não é capaz de se combinar com o oxigênio.

Níveis de 1 a $2 \%$ e de 2 a $5 \%$ de MetHb são encontrados no sangue de adultos e de bebês respectivamente. Em concentrações menores de 5\% de MetHb não existem indicações óbvias da toxicidade desta substância. Contudo, em níveis de 5 até $10 \%$ de MetHb os sinais clínicos da sua toxicidade começam a aparecer.

Para bebês, nitrato apresenta risco considerável de toxicidade comparando com os prováveis riscos para os adultos. Os fatores que predispõem os bebês para a formação da MetHb incluem:

1. O aparelho gástrico não está desenvolvido suficientemente e desta forma não é capaz de produzir a quantidade necessária de ácido gástrico para a digestão dos alimentos. Isto faz com que o $\mathrm{pH}$ do aparelho gástrico fique entre 5 e 7 permitindo o desenvolvimento de bactérias, especialmente a Escherichia coli (E. coli), que reduzem o nitrato a nitrito o qual posteriormente é absorvido pelo aparelho circulatório.

2. Os altos níveis de hemoglobina fetal em bebês. Esta forma de hemoglobina é mais suscetível à oxidação para a MetHb do que a hemoglobina adulta.

3. A menor capacidade enzimática de reduzir a MetHb a hemoglobina. 


$$
\text { 2- INTRODUÇÃo - } 4
$$

Pesquisas revelam que níveis acima de $440 \mu \mathrm{mol} / \mathrm{L}$ de $\mathrm{NO}_{3}{ }^{-}$(expressos em N) resultam em elevada frequiência de metemoglobinemia em bebês, porém não entre adultos. Conseqüentemente, a norma utilizada de $220 \mu \mathrm{mol} / \mathrm{L}$ de $\mathrm{NO}_{3}{ }^{-}$ (expressos em $\mathrm{N}$ ) foi principalmente estabelecida para previnir a ocorrência de elevados níveis de $\mathrm{MetHb}$ em bebês. Em concentrações duas vezes maior do que o estabelecido como condenatório os adultos ainda estão protegidos quanto a este tipo de anomalia [1].

A toxicidade do nitrito é bem conhecida e na forma de sal seco a dose letal mínima é de $0,2 \mathrm{mg} / \mathrm{Kg}$ de peso corpóreo [4]. O nitrito quando presente na água de consumo humano tem um efeito mais rápido e pronunciado do que o nitrato. Sua concentração nos mananciais de água bruta deve ser inferior a $30 \mu \mathrm{mol} / \mathrm{L}$ (expressos como nitrogênio) [3].

Outro fator da toxicidade do nitrato e do nitrito é a formação de nitrosaminas. O nitrato é convertido a nitrito pela bactéria $E$. coli na flora intestinal e posteriormente ocorre a reação - em meio ácido - do nitrito com aminas secundárias provenientes de alimentos ou contidas em medicamentos formando as nitrosaminas - compostos estes mutagênicos e carcinogênicos [5-6]:
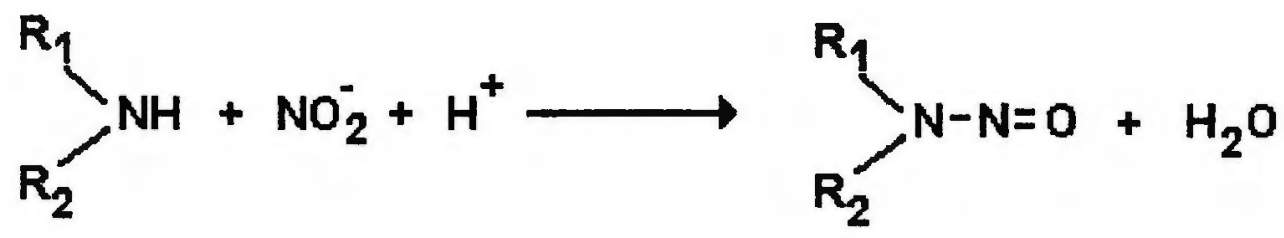

Nitrosaminas são potentes carcinógenos produzindo câncer numa variedade de órgãos incluindo o figado, aparelho respiratório, rim, bexiga, esôfago, estômago, aparelho gastrointestinal e pâncreas [1-7].

Por todos estes fatores, a determinação quantitativa de nitrato $\left(\mathrm{NO}_{3}{ }^{-}\right)$e nitrito $\left(\mathrm{NO}_{2}{ }^{-}\right)$constitui-se em problema analítico de contínuo interesse, em face às implicações ambientais da presença destes analitos em níveis mais elevados do que aqueles estabelecidos na legislação nacional e internacional vigente. $O$ procedimento analítico mais conhecido para a determinação de nitrito é o método 
de Griess que se basea-se na diazotização do reagente $\alpha$-naftilamina em meio ácido [8]. Procedimentos espectrofotométricos - como este - estão bem estabelecidos na literatura [9-10] mas a maioria envolve a utilização de reagentes caros e, às vezes, carcinogênicos. Outras desvantagens relacionadas aos métodos óticos consistem nos problemas cinéticos derivados da lenta formação do composto colorido e da gradual perda de coloração devido à decomposição do azo-composto, embora tais dificuldades possam ser experimentalmente contornadas nos processos em fluxo não consistindo em fator limitante para as quantificações desejadas. Neste contexto, o desenvolvimento de procedimento eletroanalítico para determinação de nitrato $\left(\mathrm{NO}_{3}{ }^{-}\right)$e nitrito $\left(\mathrm{NO}_{2}{ }^{-}\right)$apresenta-se como alternativa de interesse principalmente devido à simplicidade, baixo custo da instrumentação se comparado com aparelhos de absorção atômica, cromatográficos entre outros e pela possibilidade de atingir-se baixos limites de detecção.

\subsection{Técnicas Eletroanalíticas}

Dentre as múltiplas técnicas de análises, as eletroanalíticas destacam-se pela ampla faixa dinâmica de concentração e pela elevada sensibilidade proporcionada. As principais limitações são a baixa seletividade e as interferências de espécies que têm afinidade pela superfície do eletrodo, promovendo, desta forma, o bloqueio do sinal analítico ou o aparecimento de sinais indesejados.

Historicamente as primeiras aplicações eletroanalíticas foram realizadas com eletrodos gotejantes de mercúrio que, por terem sua superficie renovada continuamente, eram considerados ideais. Entretanto suas características exigiam que só se trabalhasse na região de potenciais negativos, onde o processo de oxidação da maioria das espécies orgânicas não ocorre. Já na década de 50 , pesquisadores passaram a explorar a utilização de eletrodos sólidos, dentre os quais os de grafite, ouro, platina e, a seguir, os de carbono vítreo. Tais eletrodos possibilitaram que se trabalhasse em uma faixa de potencial mais ampla. 
Paralelamente, a instrumentação e o desenvolvimento de novos métodos eletroanalíticos ampliaram os limites de deteç̧ão de forma significativa [11].

Verifica-se ainda que, com o interfaciamento da instrumentação eletroanalítica, a aquisição de dados é fácil e cômoda $\mathrm{e}$, desta forma, esta prática tem atraído profissionais de outras áreas para trabalharem com estas técnicas [12].

Neste trabalho utilizou-se três técnicas eletroanalíticas: Voltametria Cíclica, Cronoamperometria e Amperometria.

\subsubsection{Cronoamperometria}

Com esta técnica é possível observar a representação gráfica da equação de Cottrell. Para tanto aplica-se inicialmente um valor de potencial, ao eletrodo de trabalho, em que o substrato não seja eletroativo. Em seguida dá-se um pulso de potencial, que é suficiente para provocar a reação do substrato no eletrodo e mede-se a corrente resultante em função do tempo.

\subsubsection{Voltametria Cíclica}

A voltametria cíclica tornou-se uma ferramenta muito popular para estudos de reações eletroquímicas. Para utilizar-se a técnica, aplica-se um potencial inicial (Ei) o qual é variado linearmente em função do tempo até um potencial final $\left(\mathrm{E}_{\mathrm{f}}\right)$, a partir do qual inverte-se o sentido da varredura, até retornar ao valor do potencial inicial $\left(\mathrm{E}_{\mathrm{i}}\right)$. Registrando o gráfico da corrente em função do potencial aplicado obtém-se, como resultado, um voltamograma cíclico, a exemplo daquele apresentado na Figura 2, onde observa-se o pico anódico obtido pela oxidação do substrato $\left[\mathrm{Fe}(\mathrm{CN})_{6}\right]^{4}$, que perdeu elétrons e formou o íon $\left[\mathrm{Fe}(\mathrm{CN})_{6}\right]^{3-}$. Em seguida, quando inverte-se o sentido de varredura de potencial, observa-se o pico catódico obtido pela redução do íon $\left[\mathrm{Fe}(\mathrm{CN})_{6}\right]^{3-}$, que ganhou elétrons gerando $\left[\mathrm{Fe}(\mathrm{CN})_{6}\right]^{4-}$. 


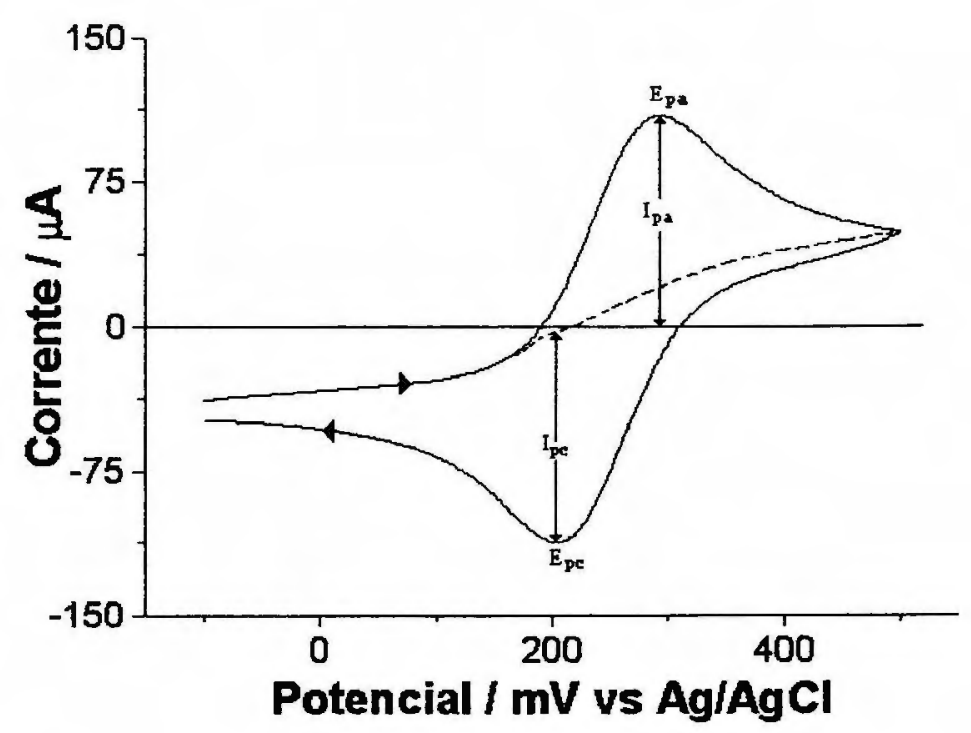

Figura 2 - Voltamograma cíclico de um sistema reversível. Solução de Ferrocianeto de Potássio $1 \mathrm{mmol} / \mathrm{L}$ e $\mathrm{KCl} 0,1 \mathrm{~mol} / \mathrm{L}$. Velocidade de varredura $=50 \mathrm{mV} / \mathrm{s}$. Área do eletrodo $=0,07 \mathrm{~cm}^{2}$.

Pela observação destes voltamogramas cíclicos verifica-se outros parâmetros importantes, tais como a magnitude das correntes de pico catódico $\left(\mathrm{I}_{\mathrm{pc}}\right)$ e anódico $\left(\mathrm{I}_{\mathrm{pa}}\right)$, bem como os respectivos potenciais de pico catódico $\left(\mathrm{E}_{\mathrm{pc}}\right)$ e anódico $\left(\mathrm{E}_{\mathrm{pa}}\right)$ [13].

Este tipo de técnica também fornece informações a respeito da reversibilidade de um par redox. Como a reversibilidade eletroquímica está associada à troca rápida de elétrons das espécies redox com o eletrodo, quanto menor for a diferença registrada entre os potenciais de pico anódico e catódico maior será a idealidade deste par redox. Já a intensidade de corrente dos picos anódico e catódico será igual, desde que não haja reação química acoplada, por exemplo. Quando observa-se a Figura 3 nota-se a presença do pico anódico, enquanto que o pico catódico não aparece, visto que este processo é irreversível. 


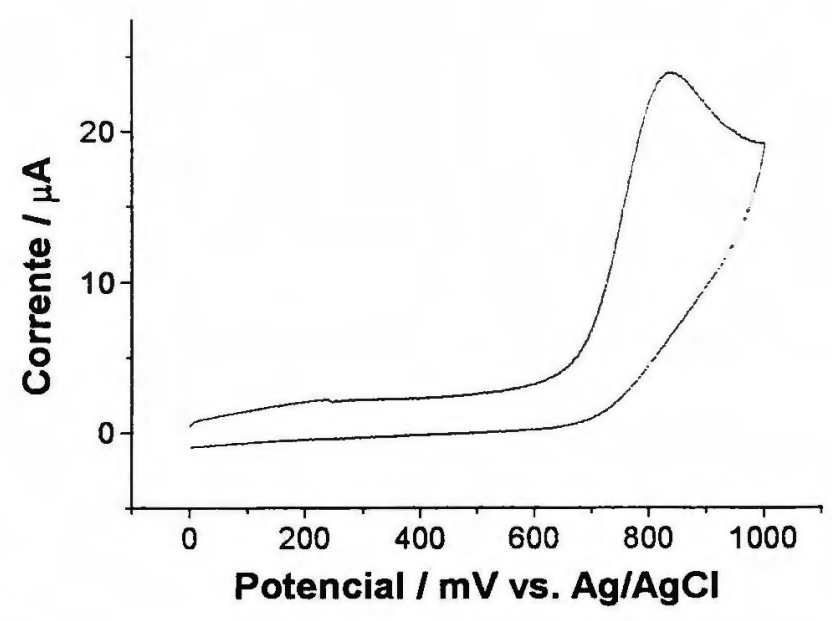

Figura 3 - Voltamograma cíclico de um sistema irreversível. Solução tampão acetato/ácido acético $0,1 \mathrm{~mol} / \mathrm{L}$ contendo perclorato de sódio 0,2 $\mathrm{mol} / \mathrm{L}$ com concentração final de $1 \mathrm{mmol} / \mathrm{L}$ de nitrito. Velocidade de varredura $=50 \mathrm{mV} / \mathrm{s}$.

Apesar das informações importantes que podem ser obtidas com o auxílio desta técnica, quando pretende-se quantificar baixas concentrações de analito ela é pouco favorável, visto que durante a varredura de potencial, ao sinal faradaico soma-se a componente capacitiva, que torna-se muito significativa frente às baixas correntes geradas pelo processo faradaico principalmente a altas velocidade de varredura.

É importante ressaltar ainda que nos voltamogramas cíclicos produzidos é possível observar a intensificação do sinal de corrente, bem como a antecipação do sinal analítico, isto se for produzida alguma alteração proposital na superfície do eletrodo.

\subsubsection{Amperometria}

$\mathrm{Na}$ amperometria mede-se a corrente quando aplica-se um potencial constante à célula de trabalho e uma importante aplicação da técnica está relacionada à utilização de sensores eletroquímicos. 
Um sensor voltamétrico registra vários pontos no perfil de correntepotencial, ou ainda numa região escolhida desta curva, um sensor amperométrico nada mais é do que um sensor voltamétrico mantido em um potencial fixo [17].

Os eletrodos hidrodinâmicos aumentam a sensibilidade, melhoram a repetibilidade e desta forma diminuem os limites de detecção. Por estes fatores torna-se vantajoso acoplar aos sensores amperométricos em sistemas em fluxo visto que além de terem maior sensibilidade também permitem maior repetibilidade nos resultados [17-18].

\subsection{Análise por Injeção em Fluxo (FIA)}

O procedimento de análise por injeção em fluxo (FIA, proveniente do inglês Flow Injection Analysis) baseia-se na introdução de uma amostra líquida em uma solução carregadora monosegmentada[19]. Existem diversas vantagens em utilizar-se este procedimento analítico e dentre elas destacam-se: repetibilidade dos resultados; minimização do consumo de amostras e de reagentes visto que o fluxo de amostragem é maior, ou seja maior quantidade de análises em tempo menor e além do que procedimentos como pré-separação, préconcentração, precipitações, entre outros poderem ser realizados "on line" [20].

O esquema de um sistema de análise por injeção em fluxo (FIA) pode ser observado na figura 4. A solução carregadora é impulsionada até o detector por gravidade ou, ainda, utilizando uma bomba peristáltica. A amostra é introduzida na solução carregadora pelo injetor que tem uma alça de amostragem que é preenchida succionando a amostra por uma seringa hipodérmica ou sistema similar.

A representação gráfica típica é denominada de fiagrama e este apresenta proporcionalidade direta entre a altura (h) ou área (A) dos picos com a concentração da amostra [21]. Devido à facilidade, praticidade e comodidade prefere-se trabalhar com a altura do pico. 


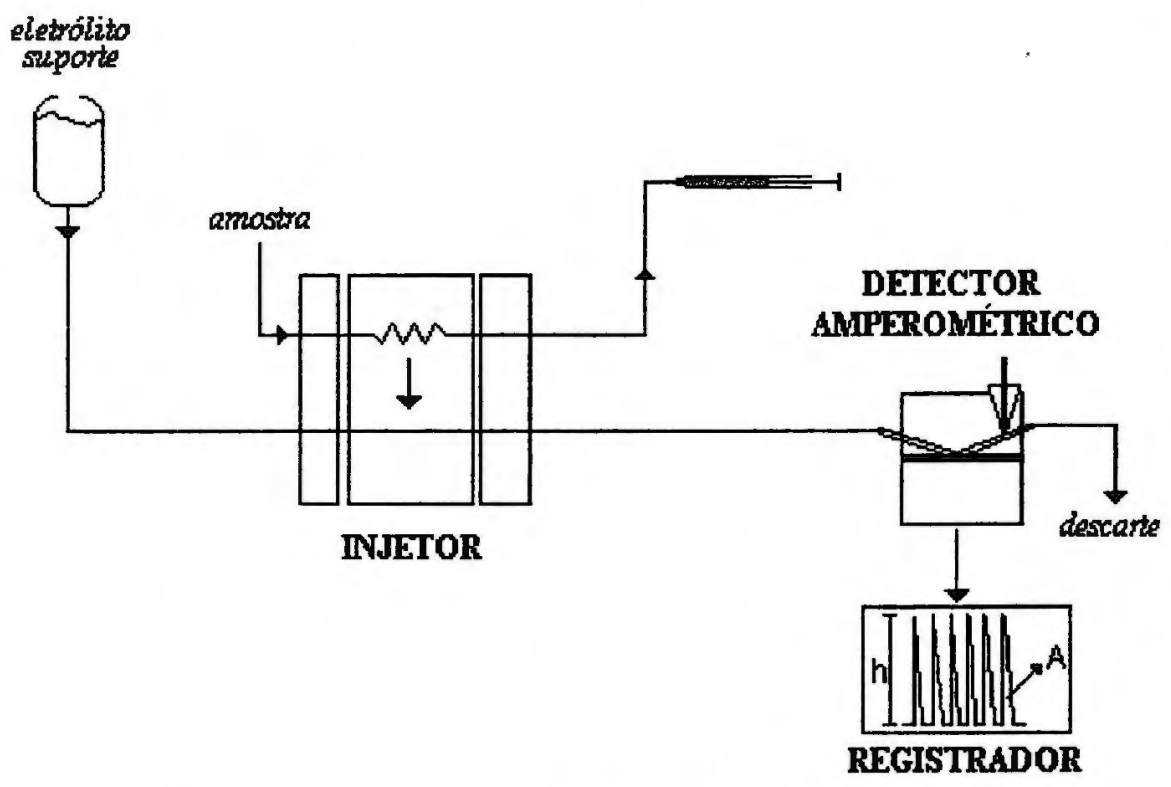

Figura 4 - Esquema básico de um sistema de análise por injeção em fluxo (FIA), cujo registro típico apresenta proporcionalidade direta entre a altura(h) ou área (A) com a concentração da amostra.

Quando da injeção da amostra forma-se uma zona que é transportada para um detector que mede continuamente absorbância, corrente em um eletrodo ou outros parâmetros físicos que sofrem alteração quando da passagem desta zona de amostragem pelo detector em fluxo [22].

O mais importante fenômeno fisico na manipulação da amostra, ou zona de reagente em um fluxo contínuo não segmentado, é a zona de dispersão e, nestes sistemas, a amostra ou zona de reagente pode ser manipulada para se obter um requerido grau de dispersão. A dispersão da amostra é, por isso, controlada e pode ser obtida para satisfazer diferentes objetivos analíticos. A dispersão da amostra no reagente ou solvente não é um processo exclusivo para o processo ou sistema FIA. Em processos analíticos por batelada ou outros métodos de análise em fluxo existe a dispersão, porém pode-se perceber pela figura 5 que no sistema FIA a dispersão é reprodutiva e controlada. Tal fato não ocorre em um sistema estacionário, onde a dispersão é caótica, ou seja sem direção definida [23]. 


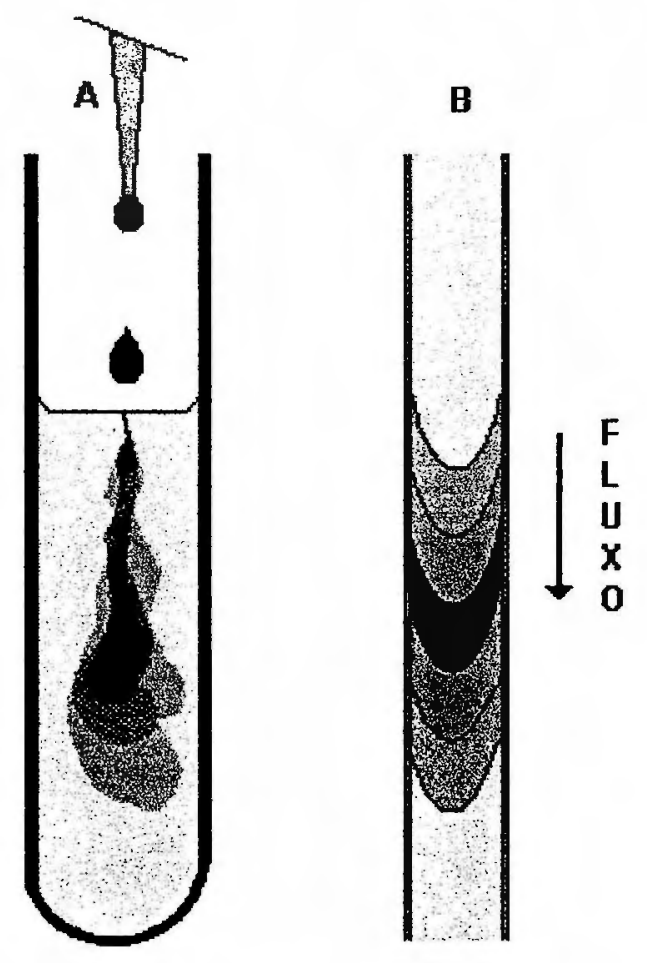

Figura 5 - Comparação da mistura e condição de dispersão em (A) sistema estacionário e (B) sistema de injeção em fluxo [23].

Segundo Ruzicka e Hansen o coeficiente de dispersão pode ser calculado através da equação 1 , onde $\mathrm{D}$ é o coeficiente de dispersão, $\mathrm{C}_{0}$ é a concentração original do constituinte de interesse e $\mathrm{C}$ é a concentração do mesmo constituinte após a injeção.

$$
\mathrm{D}=\mathrm{C}_{0} / \mathrm{C}
$$

Por conveniência a dispersão da amostra é considerada limitada ou pequena quando o valor do coeficiente de dispersão (D) estiver entre 1 e 3 , média quando o valor do coeficiente de dispersão (D) estiver entre 3 e 10 ou grande quando o valor do coeficiente de dispersão (D) for maior do que 10 [24] e estes dados podem ser entendidos observando a figura 6 . 


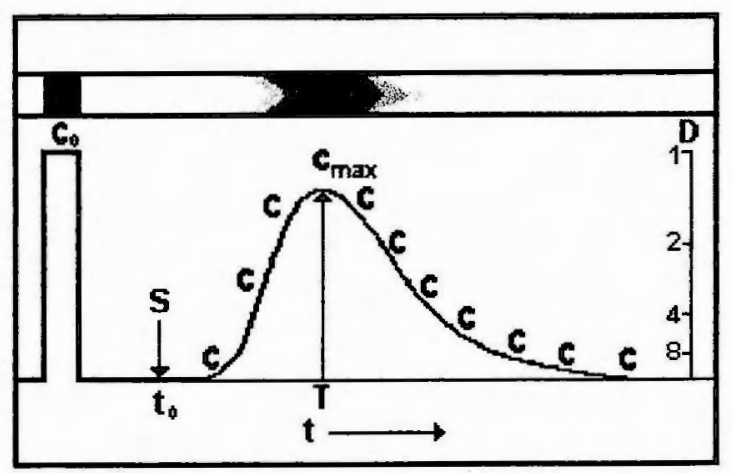

Figura 6 - Controle da dispersão do constituinte de interesse em função do tempo. $\mathrm{C}_{0}$ é a concentração do constituinte de interesse antes da injeção no sistema em fluxo. C são as diversas concentrações do constituinte de interesse ao longo do tempo após a injeção na solução carregadora. $\mathrm{S}$ é o constituinte de interesse sendo injetado no tempo inicial $\left(t_{0}\right) . C_{\max }$ é a concentração máxima obtida após a injeção do constituinte de interesse no sistema em fluxo e D é o coeficiente de dispersão do constituinte de interesse [25].

A dispersão ocorre por vários fatores sendo os principais: volume da amostra, velocidade do fluxo carregador, proporção da velocidade do fluxo existente entre a solução carregadora e a amostra, dimensões geométricas e configuração dos diferentes componentes do sistema, viscosidade dos líquidos utilizados e temperatura.

O controle destes parâmetros faz com que o sistema apresente picos mais definidos e desta forma existe a possibilidade de se quantificar o constituinte de interesse em concentrações cada vez menores, principalmente quando empregam-se outras técnicas acopladas ao sistema [23-26].

\subsection{Eletrodos Modificados}

Numerosos compostos como o nitrito possuem cinética de reação lenta na superfície dos eletrodos normalmente utilizados (platina e carbono vítreo) fazendo com que a oxidação ou redução destes substratos ocorram em potenciais muito elevados e, muitas vezes, promovendo um sinal de corrente pouco intenso [27]. Para tanto torna-se necessária a modificação da superfície do eletrodo com alguma substância que intensifique o sinal de corrente observado. 
A alteração intencional das características da supe fície de um eletrodo, pela imobilização de um agente adequado - por adsorção, por recobrimento físico ou por ligação de espécies específicas - faz com que este sensor ofereça maiores recursos para determinações eletroanalíticas [28]. O resultado desejado com a técnica de modificação do eletrodo consiste em bloquear o acesso direto ao eletrodo inibindo alguns processos e promovendo outros [29-30]. A habilidade de manipular as propriedades dos eletrodos pode levar a uma variedade de efeitos atrativos dentre os quais a eletrocatálise, a prevenção de envenenamento da superficie do eletrodo, a seletividade e a pré-concentração [31-32].

Devido às diversas tecnologias existente atualmente, a modificação de eletrodos é um campo muito vasto. Para a modificação do eletrodo podem ser utilizados metais eletrodepositados [33], óxidos [34-35], espécies orgânicas que são adsorvidas [36], metaloporfirinas [37-38], enzimas [39], DNA [40-41], filmes poliméricos [42-43] entre uma infinidade de substâncias.

\subsection{Porfirinas}

As porfirinas formam uma importante classe de compostos que a princípio podem parecer derivados de quatro unidades de pirrol ligadas pelos átomos $\alpha$ por pontes $\mathrm{CH}$ (metino). Porém na realidade elas derivam-se de um sistema aromático muito estável do qual o membro mais simples é conhecido como porfina [44].

Uma característica marcante das porfirinas é a facilidade com a qual estas formam quelatos com ions metálicos. O metal fixa-se rigidamente no espaço deixado pelos quatros átomos de nitrogênio do sistema planar.

Estes compostos são fortemente coloridos e esta coloração depende de alguns fatores, entre eles estão os grupos substituintes e o átomo central. Algumas porfirinas parcialmente reduzidas são verdes [45]. 


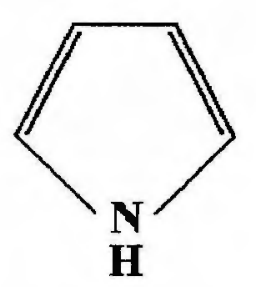

(A)

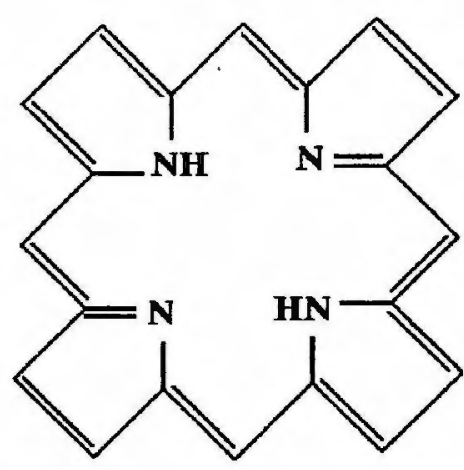

(B)

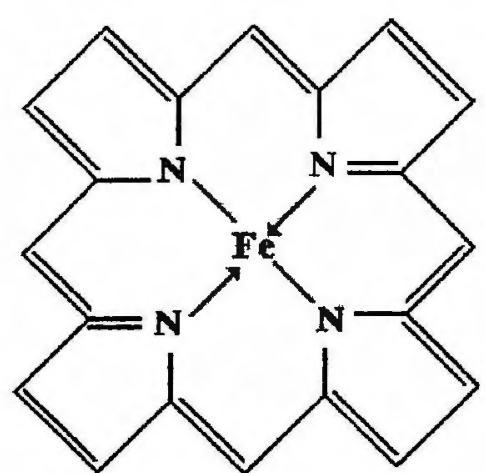

(C)

Figura 7 - Estruturas dos grupamentos (A) pirrol, (B) porfina e (C) complexo $\mathrm{Fe}^{2+}$-porfina.

O sistema porfirínico é importante porque forma as unidades básicas do pigmento vermelho do sangue, a hemoglobina, e do pigmento verde das plantas, a clorofila, sendo estas talvez as duas porfirinas mais importantes.

No caso da hemoglobina esta possui uma porção protéica chamada globina e um complexo ferro-porfirina chamado heme [46].

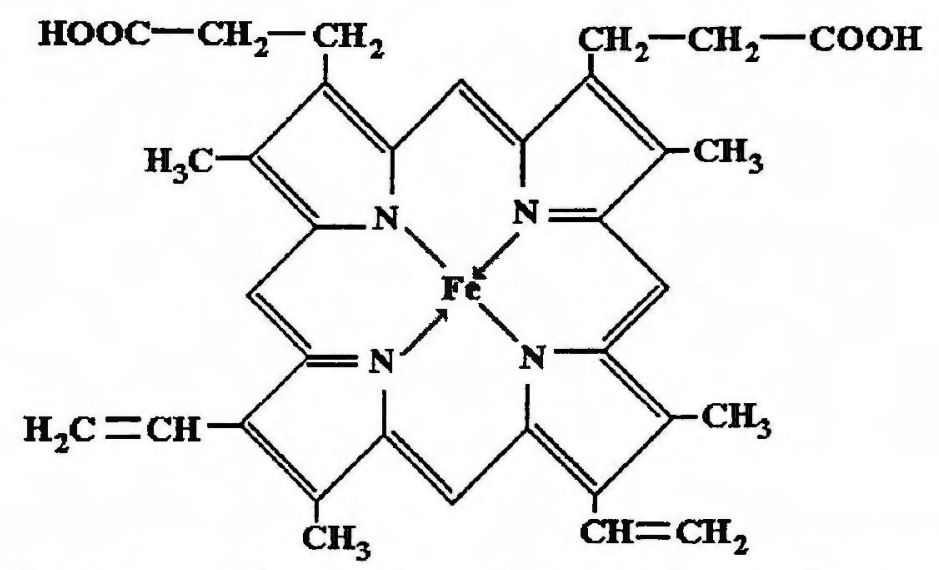

Figura 8 - Estrutura do complexo ferro-porfirina ou simplesmente heme [47].

O átomo de ferro da heme está no estado de oxidação +2 . A função da hemoglobina no sangue é transportar oxigênio até os tecidos. $O$ transporte é feito por meio do complexo ferroso hexacoordenado, no qual o átomo de ferro de uma unidade heme coordena-se também a um átomo de nitrogênio de imidazol da globina e a uma molécula do gás oxigênio. $O$ oxigênio é facilmente liberado, provavelmente por troca com uma molécula de água. 

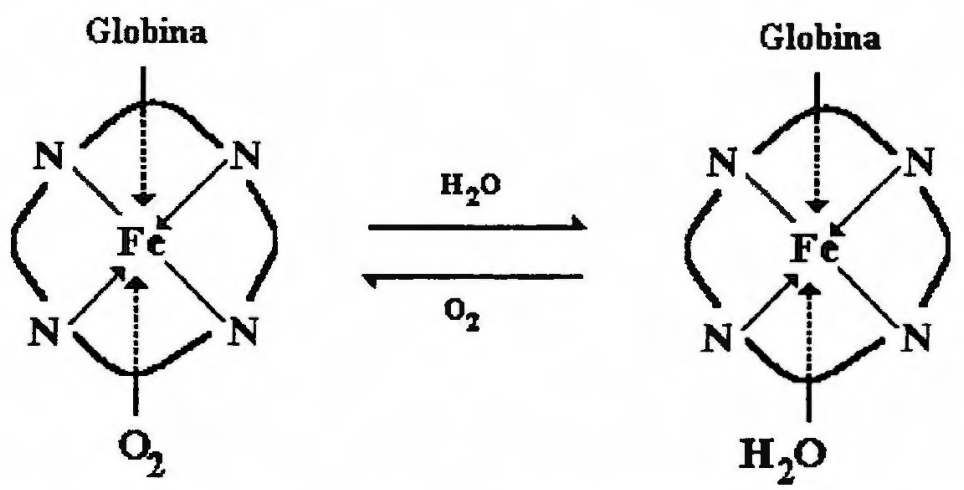

Figura 9 - Esquema do processo de transporte de oxigênio pela hemoglobina [46].

Já a forma oxidada da heme é a hemina $\left[(\mathrm{RN})_{4} \mathrm{Fe}^{+}\right]$que é derivada do íon férrico. Este grupo prostético, que é a porção não-protéica de várias enzimas importantes como, por exemplo, a catalase que é uma proteína capaz de decompor peróxido de hidrogênio a oxigênio e água com grande eficiência.

Outra porfirina de grande importância é a clorofila que é uma mistura de compostos muito semelhantes os quais são responsáveis pelo pigmento verde das plantas e desempenham papel muito importante no processo da fotossíntese, dentre os quais a clorofila $a$ é o principal pigmento.

Vários aspectos interessantes da estrutura devem ser observados. O pigmento é o complexo de magnésio de uma di-hidro-porfirina, que contém ainda uma cadeia de ácido propiônico modificada na forma de um $\beta$-ceto-éster cíclico. A estrutura contém uma cadeia de ácido propiônico em ligação éster com o álcool diterpênico fitol, o que faz com que o pigmento seja solúvel em gorduras. $\mathrm{O}$ aspecto mais marcante da molécula da clorofila é sua semelhança estrutural com a heme. Isto sugere que as porfirinas com esta estrutura geral têm importância nos processos vitais desde antes da separação dos reinos vegetal e animal no processo da evolução [48]. 


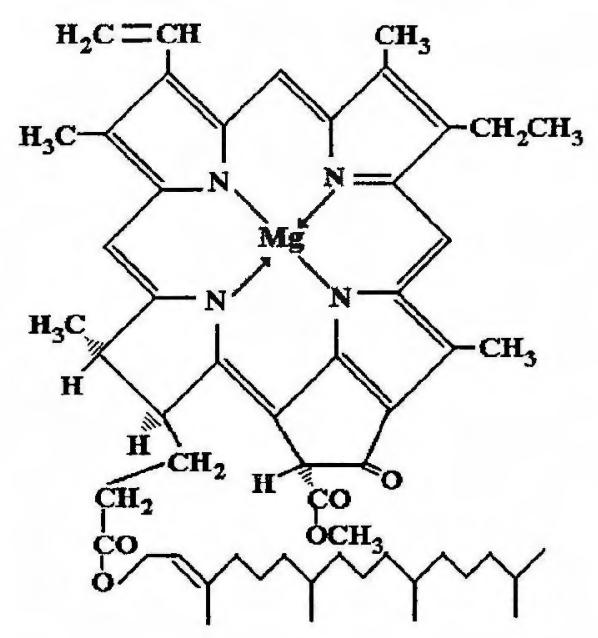

Figura 10 - Estrutura da clorofila a, o principal pigmento da clorofila [49].

A importância desta classe de moléculas pode ser resumida observando que elas são sítios ativos de numerosas proteínas cujas funções abrangem transporte e estocagem do gás oxigênio (hemoglobina), transporte de elétrons (citocromo c) e conversão de energia (clorofila). Além disso estas moléculas têm se destacado por serem eficientes sensibilizadores e catalisadores em numerosos sistemas químicos e fotoquímicos [50].

Por estas razões a síntese, caracterização e estudos sobre as propriedades destas macromoléculas são de grande interesse e neste Instituto de Química existem grupos que se dedicam a pesquisas desta classe de moléculas [51-52].

$\mathrm{O}$ enfoque de trabalho do grupo do Prof. Dr. Gianluca relaciona-se à síntese de porfirinas e metaloporfirinas aquo-solúveis e anfifilicas, além da caracterização das propriedades fotoquímicas e fotofísicas das mesmas. Isso é realizado por meio da fotossensibilização em sistemas de fotoconversão de energia e terapia fotodinâmica e pela interação de metaloporfirinas catiônicas sintéticas com moléculas de interesse biológico [53-54-55-56]. 
Já o grupo dos Profs. Drs. Toma e Araki realizam pesquisas voltadas principalmente para o estudo de porfirinas polinucleares, bem como o desenvolvimento de estratégias que permitam a preparação de eletrodos quimicamente modificados com estas supermoléculas os quais são utilizados como sensores amperométricos de vários substratos de interesse ambiental e biológico [57-58-59-60].

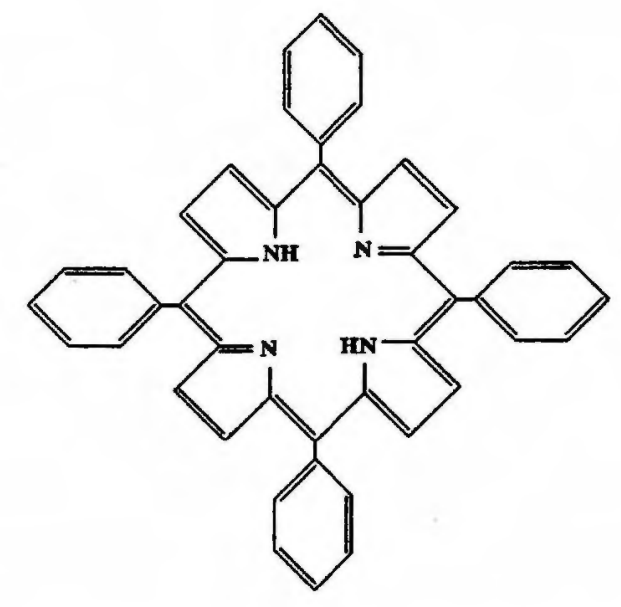

Figura 11 - Estrutura que de acordo com a nomenclatura de Fisher é a $\alpha$, $\beta, \gamma, \delta$-meso-tetrakis-fenilporfirina.

Neste trabalho é utilizada a porfirina cationica tetrarutenada (Co-TRP) sintetizada pelo grupo de pesquisa dos Profs. Drs. H. E. Toma e K. Araki cuja denominação é $\mu$-meso(tetrapiridyl) porfirinato de cobalto(III) tetrakis[bis(bipiridina)(cloro) rutênio (II). A outra porfirina utilizada é a aniônica cujo elemento metálico central é o zinco (Zn-TPPS), sendo esta obtida comercialmente e denominada meso-tetra(4-sulfonatofenil) porfirinato de zinco (II). Em ambas as porfirinas percebe-se que o núcleo central é a $\alpha, \beta, \gamma, \delta$-mesotetrakis-fenilporfirina, e este núcleo central é apresentado na figura 11. Já as estruturas das duas porfirinas utilizadas estão representadas na figura 12. 


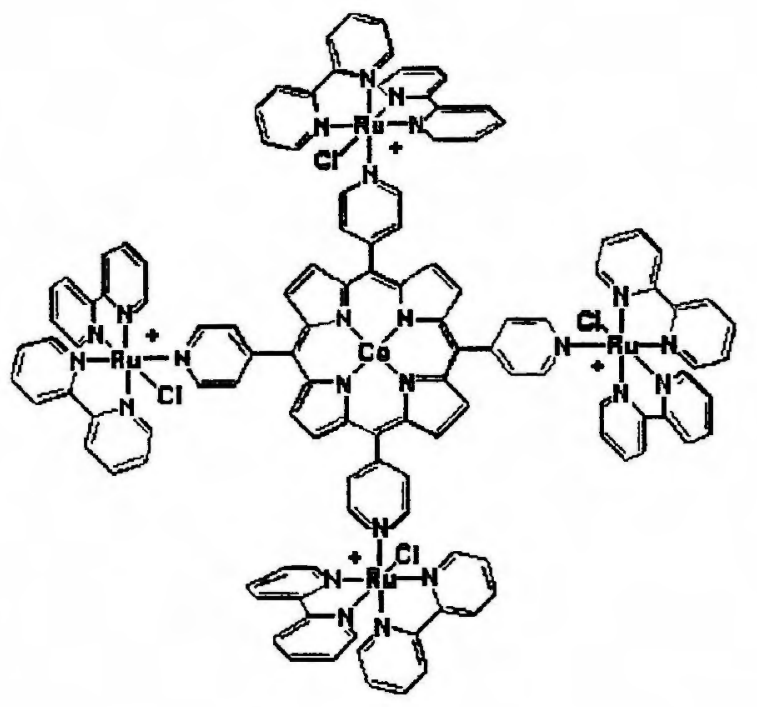

A

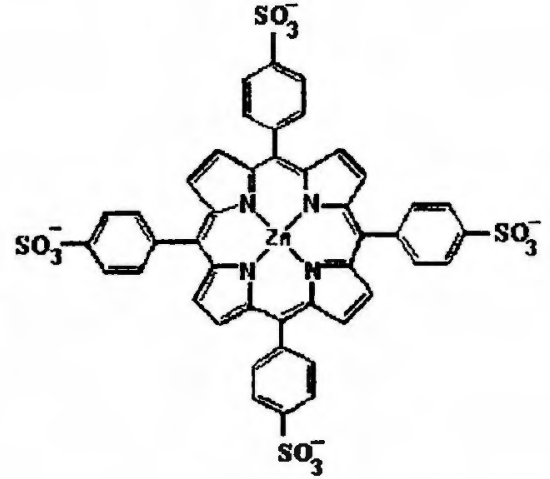

B

Figura 12 - Estrutura da porfirina catiônica (A) Co-TRP - $\mu$-meso(tetrapiridyl) porfirinato de cobalto(III) tetrakis[bis(bipiridina)(cloro) rutênio (II) e da porfirina aniônica Zn-TPPS - meso-tetra(4-sulfonatofenil) porfirinato de zinco (II).

\subsection{Redução do Nitrato a Nitrito}

Para que nitrato seja quantificado, como por exemplo em águas naturais, é necessária uma etapa inicial de redução a nitrito ou a amônia para posterior quantificação destas substâncias [61]. Tal necessidade deriva do fato do nitrato não ser eletroativo nas faixas de potencial usualmente empregadas.

A redução pode efetivar-se por vários métodos sejam eles químicos, fotoquímicos ou ainda térmicos [62]. Entre os métodos químicos podem ser citados aqueles que utilizam como agente redutor: cobre, hidrazina, alumínio/níquel, zinco, zinco/manganês [63], cádmio [64], amálgama de zinco/cádmio, cobre/cádmio [65].

Quando utiliza-se algum metal como agente redutor a reação de oxiredução pode ser resumida segundo a equação abaixo [66]:

$$
\mathrm{NO}_{3}^{-}+\mathrm{Me}_{(\mathrm{s})}+2 \mathrm{H}^{+} \rightarrow \mathrm{NO}_{2}^{-}+\mathrm{Me}^{++}+\mathrm{H}_{2} \mathrm{O}
$$


Neste trabalho optou-se em utilizar a coluna redutora de cádmio/cobre devido à experiência anterior com esta coluna redutora realizada por pesquisadores do grupo do Prof. Dr. Mauro Bertotti [67]. 


\section{PARTE EXPERIMENTAL}

3 - PARTE EXPERIMENTAL - 20

\subsection{Reagentes}

- Perclorato de potássio monohidratado $-\mathrm{NaClO}_{4} \cdot \mathrm{H}_{2} \mathrm{O}$ - Merck.

- Cloreto de potássio- $\mathrm{KCl}-$ Merck.

- Ácido acético - $\mathrm{H}_{3} \mathrm{CCOOH}-$ Merck.

- Acetato de sódio $-\mathrm{H}_{3} \mathrm{CCOONa}$ - Merck.

- Hidróxido de amônio $-\mathrm{NH}_{4} \mathrm{OH}$ - Merck.

- Cloreto de amônio - $\mathrm{NH}_{4} \mathrm{Cl}$ - Merck,

- $\mu$-meso(tetrapiridyl) porfirinato de cobalto(III) tetrakis[bis(bipiridina)(cloro) rutênio (II)] (Co-TRP) [68].

- meso-tetra(4-sulfonatofenil) porfirinato de zinco (II) (Zn-TPPS) [68].

- Nitrato de sódio - $\mathrm{NaNO}_{3}-$ Merck.

- Nitrito de sódio - $\mathrm{NaNO}_{2}-$ Merck.

- Ferrocianeto de sódio - $\mathrm{Na}_{4}\left[\mathrm{Fe}(\mathrm{CN})_{6}\right]$ - Merck.

- Ferricianeto de potássio $-\mathrm{K}_{3}\left[\mathrm{Fe}(\mathrm{CN})_{6}\right]$ - Merck.

- Sulfato de cobre II pentahidratado - $\mathrm{CuSO}_{4} \cdot 5 \mathrm{H}_{2} \mathrm{O}$ - Merck.

- Ácido clorídrico - $\mathrm{HCl}$ - Merck.

- Cádmio granulado (20 - 40 meshs) - Sigma Chemical.

- Metanol - $\mathrm{H}_{3} \mathrm{COH}$ - Merck.

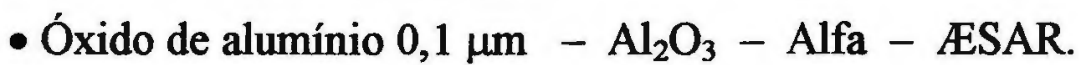

- Acetonitrila $-\mathrm{CH}_{3} \mathrm{CN}-$ Merck.

- $\mathrm{ZnTBzPyP}\left(\mathrm{ClO}_{4}\right)_{4}[69]$.

- $\mathrm{ZnTMeOBzPyP}\left(\mathrm{ClO}_{4}\right)_{4}[69]$.

- Tetraborato de sódio decahidratado $-\mathrm{Na}_{2} \mathrm{~B}_{4} \mathrm{O}_{7} \cdot 10 \mathrm{H}_{2} \mathrm{O}$ - Merck.

- Acetato de zinco dihidratado $-\mathrm{Zn}\left(\mathrm{CH}_{3} \mathrm{COO}\right)_{2} \cdot 2 \mathrm{H}_{2} \mathrm{O}-\mathrm{MercK}$.

- Sulfanilamida - Sigma Chemical.

- Dicloridrato de N-(1-naftil) etilenodiamina - Sigma-Aldrich. 


\subsection{Soluções}

As soluções das porfirinas catiônicas foram feitas dissolvendo-as em metanol ou acetonitrila. Todas as outras soluções foram preparadas a partir de reagente da dissolução dos respectivos reagentes de grau analítico em água previamente destilada e desionizada $(18 \mathrm{M} \Omega)$ utilizando equipamento da Nanopure Infinity - Barnstead/Thermolyne.

- Solução da porfirina catiônica Co-TRP preparada pela dissolução de $1 \mathrm{mg}$ da referida porfirina $\mathrm{em} 5 \mathrm{~cm}^{3}$ de metanol.

- Solução da porfirina aniônica Zn-TPPS preparada pela dissolução de $1 \mathrm{mg}$ da referida porfirina $\mathrm{em} 5 \mathrm{~cm}^{3}$ de água desionizada.

- Solução da porfirina catiônica $\mathrm{ZnTBzPyP}\left(\mathrm{ClO}_{4}\right)_{4} \quad 1,3 \mu \mathrm{mol} / \mathrm{L}$ em acetonitrila.

- Solução da porfirina catiônica $\mathrm{ZnTMeOBzPyP}\left(\mathrm{ClO}_{4}\right)_{4} 2,7 \mu \mathrm{mol} / \mathrm{L}$ em acetonitrila.

- Solução de sulfanilamida $5 \mathrm{~g} / \mathrm{L}$ foi preparada completando-se o volume com solução de $\mathrm{HCl} 20 \%$ v/v.

- Solução de dicloridrato de $\mathrm{N}$-(1-naftil) etilenodiamina $3 \mathrm{~g} / \mathrm{L}$ foi preparada completando-se o volume com solução de $\mathrm{HCl} 1 \%$ v/v.

- Solução de ferrocianeto de potássio $106 \mathrm{~g} / \mathrm{L}$, preparada para utilização na desproteinização de carnes curadas.

- Solução de tetraborato de sódio decahidratado $50 \mathrm{~g} / \mathrm{L}$, preparada para utilização na desproteinização de carnes curadas.

- Solução de acetato de zinco dihidratado $220 \mathrm{~g} / \mathrm{L}$ que foi preparada utilizando, além do sal, $30 \mathrm{~mL}$ de ácido acético e completando-se o volume com água desionizada para posterior utilização na desproteinização de carnes curadas.

\subsection{Aparelhagem}

- Potenciostato PAR 273A EG \& G.

Potenciostato utilizado para aplicar e controlar o potencial desejado no eletrodo de trabalho. 
- Eletrodo de trabalho de carbono vítreo $(\mathrm{d}=2 \mathrm{~mm})$.

Eletrodo de carbono vítreo preparado no laboratório com tubo de Teflon® que foi perfurado adequadamente com furadeira. Em uma das extremidades deste orifício foi introduzido bastão de carbono vítreo $(5 \mathrm{~mm}$ de comprimento e $2 \mathrm{~mm}$ de diâmetro) e na outra extremidade foi introduzido fio de latão para o contato elétrico. Entre os dois materiais foi colocado grafite em pó para melhorar o contato elétrico.

- Eletrodo auxiliar de platina.

Eletrodo preparado no laboratório vedando por aquecimento em um tubo de vidro de $3 \mathrm{~mm}$ de diâmetro interno uma chapa de $1,5 \mathrm{~mm}$ x $5 \mathrm{~mm}$ de platina. Em seguida foi introduzido grafite em pó para melhorar o contato elétrico entre a placa de platina e o fio de níquel/crômio. A outra extremidade do tubo de vidro foi vedada com cola Araldite ${ }^{\circ}$.

- Eletrodo de referência $\mathrm{Ag} / \mathrm{AgCl}$ (Sat. $\mathrm{NaCl}$ ).

Eletrodo de referência preparado em laboratório utilizando metodologia adaptada de Silva et al [70].

- Eletrodo auxiliar de aço inoxidável.

Eletrodo preparado com parte de uma de agulha hipodérmica de aço inoxidável que tem $1,5 \mathrm{~mm}$ de diâmetro interno e $25 \mathrm{~mm}$ de comprimento.

- Eletrodo de trabalho de carbono vítreo $(\mathrm{d}=3 \mathrm{~mm})$ - modelo TL-5 Bioanalytical Systems.

Esquema do eletrodo adquirido comercialmente e do esquema da célula eletroquímica para ensaios em fluxo são representados na figura 13.

- Injetor de amostra para sistema FIA (Adquirido no CENA, Piracicaba).

Injetor adquirido comercialmente para ensaios no sistema FIA.

- Eletrodo rotativo de platina - PAR modelo RDE $616(\mathrm{~d}=4 \mathrm{~mm})-$ EG\&G.

Eletrodo utilizado em ensaios voltamétricos referentes à determinação da constante cinética do processo eletrocatalítico envolvendo a oxidação do nitrito. 


\section{BIBLIOTECA}

INSTITUTO DE QUIMICA 3 - PARTE EXPERIMENTAL - 23

1 Universidado do São Panlo

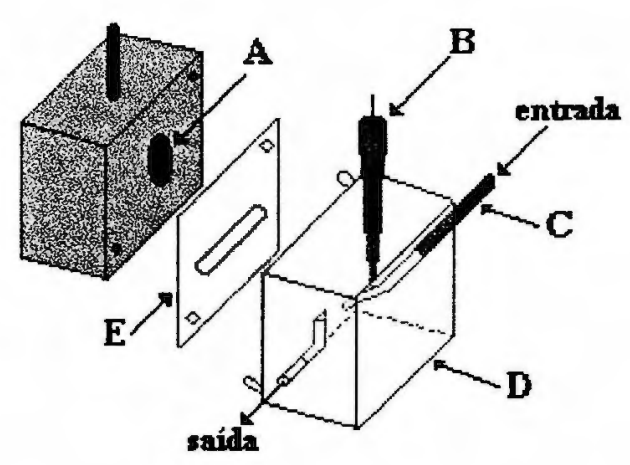

Figura 13 - Célula eletroquímica para os trabalhos em sistema FIA. (A) Eletrodo de carbono vítreo - modelo TL-5 - Bioanalytical Systems , (B) Eletrodo de referência $\mathrm{Ag} / \mathrm{AgCl}_{\text {sat, }}$, (C) Eletrodo auxiliar de aço inoxidável, (D) Bloco de resina acrílica e (E) espaçador de Teflon.

- Resistência $100 \Omega$ Leeds \& Northup Co.

- Resistência $10.000 \Omega$ Leeds \& Northup Co.

- Espectrofotômetro DU-70 Beckman.

Equipamento utilizado na determinação espectrofotométrica de nitrato e nitrito pelo método oficial.

- Impressora LX-300 Epson.

Equipamento utilizado para registrar os resultados obtidos durante determinação espectrofotométrica de nitrato e de nitrito.

- Bomba Peristáltica Ismatec Modelo 78016-30 - Cole-Palmer Instrument Company.

Equipamento utilizado para impulsionar a solução carregadora usada no método amperométrico e no espectrofotométrico.

\subsection{Esquemas das Aparelhagens}

\subsubsection{Ensaios em sistema estacionário}

O primeiro esquema de aparelhagem que está representado na figura 14 é aquele que foi utilizado em sistemas estacionários. 


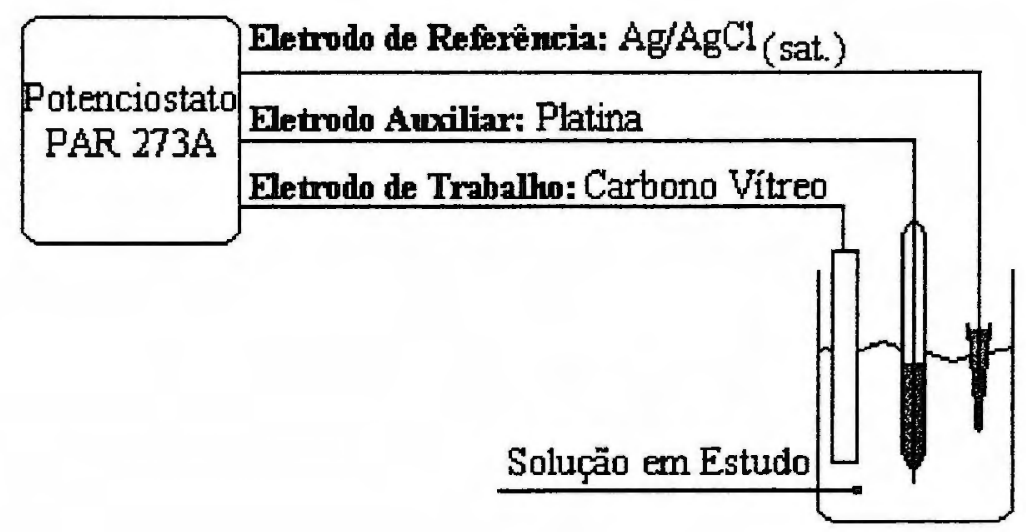

Figura 14 - Esquema para estudos de propriedades e características de eletrodos modificado com depósitos alternados de Co-TRP/Zn-TPPS, utilizando sistema de 3 eletrodos conectados a potenciostato EG\&G PAR modelo 273A.

\subsubsection{Ensaios em sistema Fia para determinação de nitrito}

A figura 15 mostra o esquema utilizado para quantificar nitrito, usando como solução carregadora tampão acetato de sódio/ácido acético $0,1 \mathrm{~mol} / \mathrm{L}(\mathrm{pH}$ $4,7)$ contendo perclorato de sódio $0,2 \mathrm{~mol} / \mathrm{L}$. A célula eletroquímica utilizada foi aquela representada na figura 13.

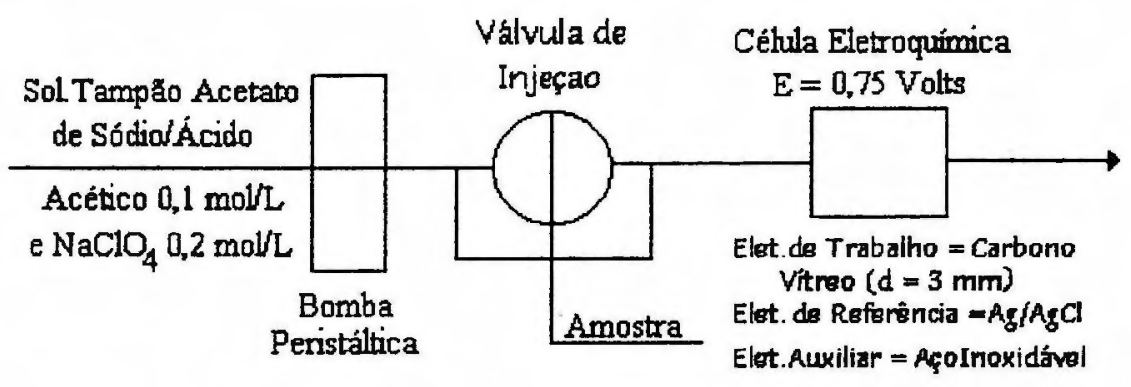

Figura 15 - Esquema para determinação de nitrito, utilizando sistema de 3 eletrodos conectados a potenciostato EG\&G PAR modelo 273A. Solução carregadora tampão acetato de sódio /ácido acético $(\mathrm{pH}=4,7)$ $0,1 \mathrm{~mol} / \mathrm{L}$ contendo $\mathrm{NaClO}_{4} 0,2 \mathrm{~mol} / \mathrm{L} . \mathrm{E}=0,75 \mathrm{~V}$. Volume da amostra $=$ $130 \mu \mathrm{L}$. 


\subsubsection{Ensaios em sistema Fia para determinação de nitrato em $\mathrm{pH}$ 9,1}

A figura 16 mostra o esquema utilizado para determinação amperométrica de nitrato, usando como solução carregadora tampão cloreto de amônio/hidróxido de amônio $0,05 \mathrm{~mol} / \mathrm{L}(\mathrm{pH} 9,1)$ contendo perclorato de sódio $0,5 \mathrm{~mol} / \mathrm{L}$. A célula eletroquímica utilizada está representada na figura 13.

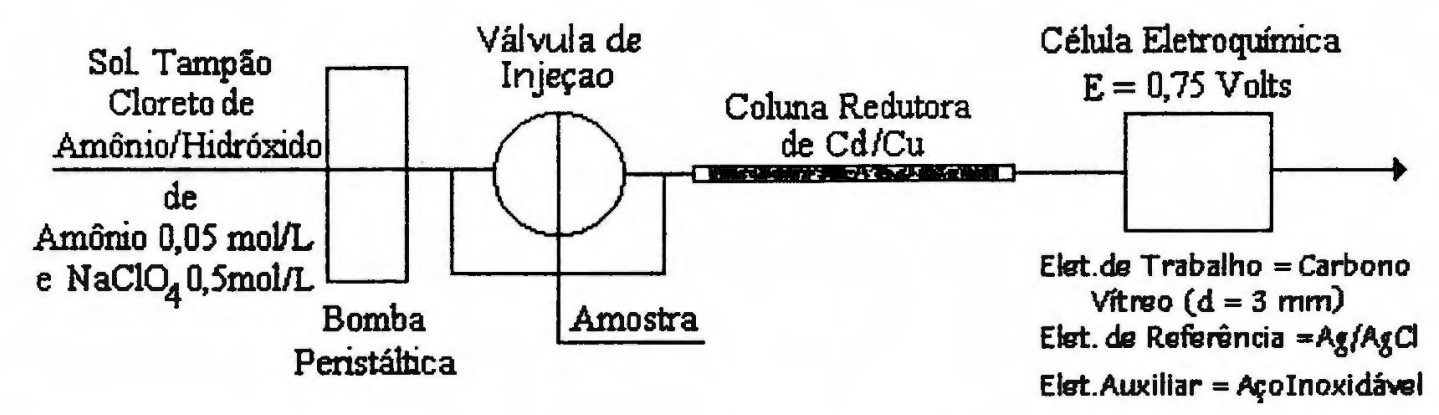

Figura 16 - Esquema do sistema utilizado nas determinações preliminares de nitrato, utilizando técnica de 3 eletrodos conectados a potenciostato da EG\&G PAR modelo 273A. Solução carregadora tampão cloreto de amônio/hidróxido de amônio $(\mathrm{pH}=9,1) 0,05 \mathrm{~mol} / \mathrm{L}$ contendo $0,5 \mathrm{~mol} / \mathrm{L}$ de $\mathrm{NaClO}_{4}$. $\mathrm{E}=0,75 \mathrm{~V}$. Volume da amostra $=130 \mu \mathrm{L}$.

3.4.4. Ensaios em sistema Fia para determinação de nitrato com acerto de $\mathrm{pH} \approx 4,5$

A figura 17 mostra o esquema utilizado para a determinação amperométrica de nitrato, usando como solução carregadora acetato de sódio $0,05 \mathrm{~mol} / \mathrm{L}(\mathrm{pH} 8,0$ ) contendo perclorato de sódio $0,2 \mathrm{~mol} / \mathrm{L}$, visto que na coluna redutora de cádmio/cobre o meio deve estar neutro ou levemente alcalino. Após esta coluna redutora existe confluência para tamponamento do meio $(\mathrm{pH} \approx 4,5)$ com a adição de solução de ácido acético $1 \mathrm{~mol} / \mathrm{L}$. A célula eletroquímica utilizada pode ser observada na figura 13 . 


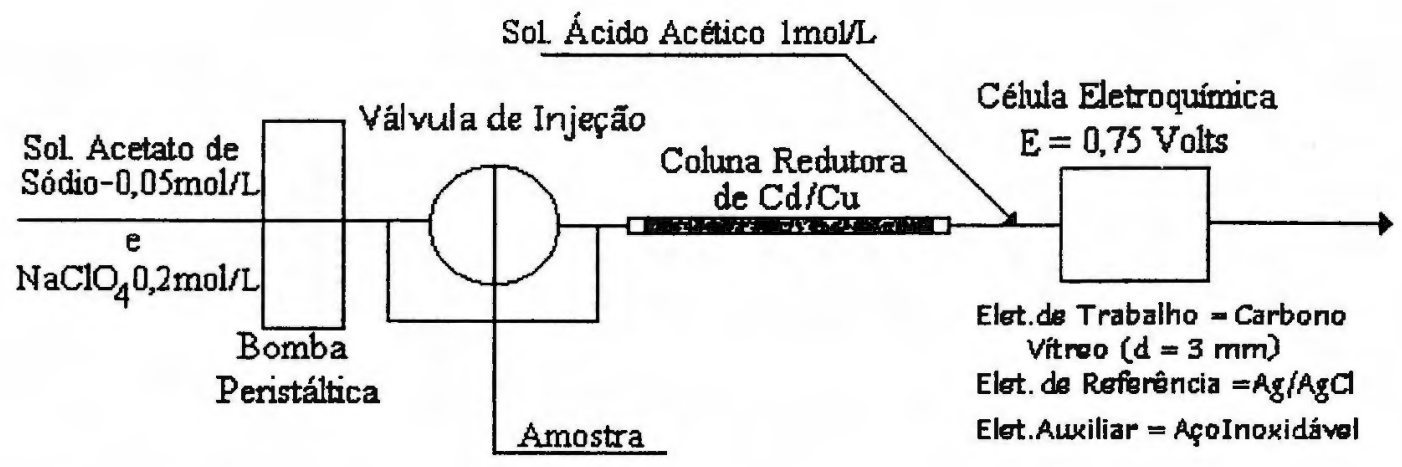

Figura 17 - Esquema do sistema utilizado para determinação de nitrato, utilizando conjunto de 3 eletrodos conectados a potenciostato da EG\&G PAR modelo 273A. Solução carregadora acetato de sódio $(\mathrm{pH}=8,0) 0,05$ $\mathrm{mol} / \mathrm{L}$ contendo $0,2 \mathrm{~mol} / \mathrm{L}$ de $\mathrm{NaClO}_{4}$. Após a coluna redutora de $\mathrm{Cd} / \mathrm{Cu}$, confluência de sol. de ácido acético $1 \mathrm{~mol} / \mathrm{L}$, para acerto de $\mathrm{pH} \approx 4,5 \mathrm{E}=$ $0,75 \mathrm{~V}$. Volume da amostra $=130 \mu \mathrm{L}$.

\subsubsection{Ensaios em sistema Fia para determinação de nitrato em} pH 8

A figura 18 mostra o esquema utilizado para a determinação amperométrica otimizada de nitrato, usando como solução carregadora acetato de sódio $0,05 \mathrm{~mol} / \mathrm{L}(\mathrm{pH} 8,0)$ contendo perclorato de sódio $0,2 \mathrm{~mol} / \mathrm{L}$. A célula eletroquímica utilizada é aquela representada na figura 13.

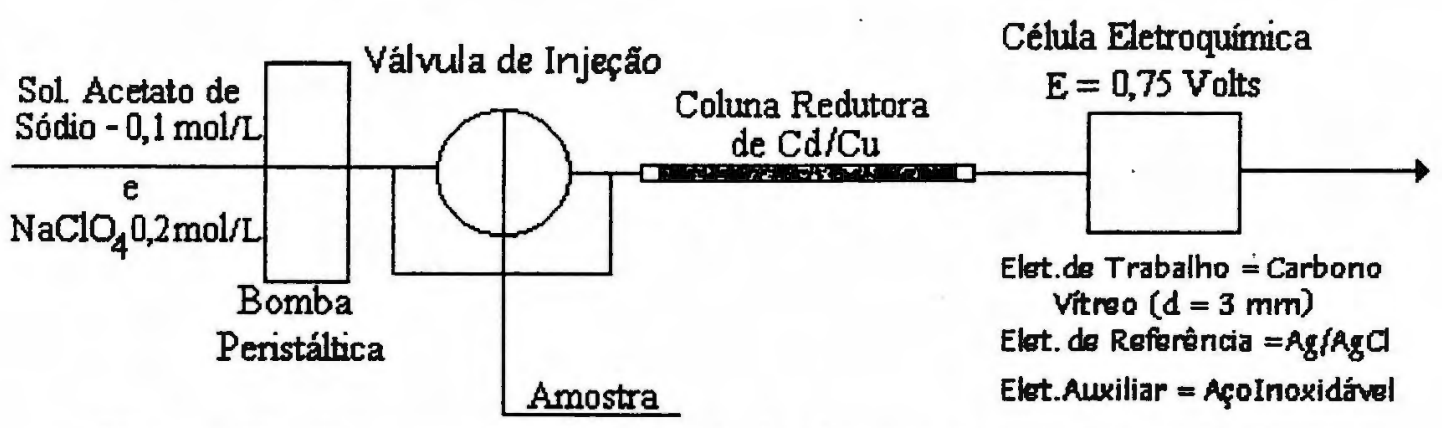

Figura 18 - Esquema do sistema otimizado para determinação de nitrato, utilizando conjunto de 3 eletrodos conectados a potenciostato da EG\&G PAR modelo 273A. Solução carregadora acetato de sódio $0,1 \mathrm{~mol} / \mathrm{L}$ $(\mathrm{pH}=8,0)$ contendo $0,2 \mathrm{~mol} / \mathrm{L}$ de $\mathrm{NaClO}_{4} . \mathrm{E}=0,75 \mathrm{~V}$. Volume da amostra $=130 \mu \mathrm{L}$. 


\subsection{Coluna Redutora de Cádmio/Cobre}

\section{3-PARTE EXPERIMENTAL - 27}

\subsubsection{Preparo da Coluna}

Para preparar a coluna redutora de cádmio/cobre seguiu-se o seguinte procedimento:

Aproximadamente $5 \mathrm{~g}$ de cádmio foram lavados com $50 \mathrm{~mL}$ solução de ácido clorídrico $0,1 \mathrm{~mol} / \mathrm{L}$ para que desta forma todo óxido de cádmio presente sobre a superfície dos grânulos do metal fossem removidos.

Em seguida, estes grânulos foram lavados com água desionizada. Mediuse o $\mathrm{pH}$ da água de limpeza usando o papel indicador universal Merck até verificar que o valor do mesmo correspondia a um meio neutro.

A estes grânulos de cádmio limpos foram adicionados $125 \mathrm{~mL}$ de solução de sulfato de cobre penta-hidratado ( $\mathrm{CuSO}_{4} \cdot 5 \quad \mathrm{H}_{2} \mathrm{O}$ ) $20 \mathrm{~g} / \mathrm{L}$ e, após o desaparecimento da coloração azul proveniente dos íons de $\mathrm{Cu}^{2+}$, foram adicionadas pequenas porções de água desionizada para que fossem retirados excessos de íons de $\mathrm{Cu}^{2+}$ que poderiam estar presentes.

Após a limpeza os grânulos foram acondicionados em um tubo de vidro de $10 \mathrm{~cm}$ de comprimento e de $0,2 \mathrm{~cm}$ de diâmetro interno. Em uma das extremidades do tubo de vidro foi colocado um tubo látex de $5 \mathrm{~cm}$ de comprimento e $0,1 \mathrm{~cm}$ de diâmetro interno para facilitar a coneç̧ão do tubo de vidro com o restante do sistema. Também foi colocada pequena quantidade de algodão para impedir a saída dos grânulos de cádmio/cobre. A introdução dos grânulos no tubo de vidro foi realizada utilizando água desionizada para prevenir a formação de bolhas de ar. Após completar todo o espaço da coluna de cádmio/cobre foi introduzida outra pequena quantidade de algodão para que os grânulos de cádmio/cobre não saíssem por esta extremidade da coluna. Nesta extremidade foi conectado tubo de látex de $5 \mathrm{~cm}$ de comprimento e $0,1 \mathrm{~cm}$ de diâmetro interno. Para verificar a efíciência da coluna foram realizados ensaios de rendimento da redução de nitrato a nitrito. 


\subsubsection{Rendimento da Coluna}

Para testar a eficiência da coluna de $\mathrm{Cd} / \mathrm{Cu}$ foram realizadas injeções sucessivas de solução tampão cloreto de amônio/hidróxido de amônio $0,05 \mathrm{~mol} / \mathrm{L}$ (pH 9,1) contendo perclorato de sódio $0,5 \mathrm{~mol} / \mathrm{L}$ e $1000 \mu \mathrm{mol} / \mathrm{L}$ de $\mathrm{NO}_{2}{ }^{-}$no fluxo carregador e posteriormente foram realizadas injeções sucessivas de solução tampão cloreto de amônio/hidróxido de amônio $0,05 \mathrm{~mol} / \mathrm{L}$ ( $\mathrm{pH} 9,1)$ contendo perclorato de sódio $0,5 \mathrm{~mol} / \mathrm{L}$ e $1000 \mu \mathrm{mol} / \mathrm{L}$ de $\mathrm{NO}_{2}{ }^{-}+1000 \mu \mathrm{mol} / \mathrm{L} \mathrm{NO}_{3}{ }^{-}$no fluxo carregador. Observou-se pelos resultados obtidos, que o rendimento da redução de nitrato a nitrito era da ordem de $53 \%$.

Para soluções mais diluídas em nitrato $(100 \mu \mathrm{mol} / \mathrm{L})$ obteve-se maior eficiência no processo de redução, atingindo-se valores em torno de $83 \%$. Redução mais eficiente foi conseguida trabalhando-se com nitrato $10 \mu \mathrm{mol} / \mathrm{L}$ e, neste caso, a redução foi quase total $(\approx 96 \%)$. Os fiagramas desta recuperação estão registrados na figura 19.

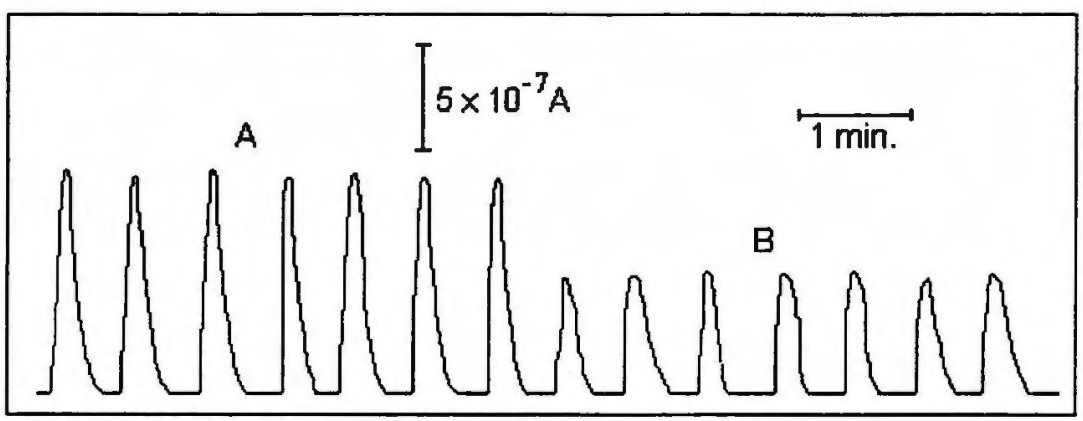

Figura 19 - Fiagrama para determinar a eficiência da redução de nitrato a nitrito utilizando coluna de $\mathrm{Cd} / \mathrm{Cu}$. (A) $10 \mu \mathrm{mol} / \mathrm{L}$ de $\mathrm{NO}_{3}{ }^{-}+10 \mu \mathrm{mol} / \mathrm{L}$ de $\mathrm{NO}_{2}^{-}$e (B) $10 \mu \mathrm{mol} / \mathrm{L}$ de $\mathrm{NO}_{2}^{-}$, no $\mathrm{E}=0,75 \mathrm{~V}$ vs. $\mathrm{Ag} / \mathrm{AgCl} \mathrm{com}$ eletrodo de carbono vítreo modificado com 3 pares de depósitos alternados de Co-TRP/Zn-TPPS, em solução tampão de cloreto de amônio/hidróxido de amônio $0,05 \mathrm{~mol} / \mathrm{L}$ e perclorato de sódio $0,5 \mathrm{~mol} / \mathrm{L}$. Vazão do fluxo carregador igual a $2,4 \mathrm{~cm}^{3} / \mathrm{min}$ e volume da amostra $=$ $130 \mu \mathrm{L}$.

\subsection{Procedimento de Desproteinização [71]}

Pesou-se aproximadamente $10 \mathrm{~g}$ da amostra de carne curada em um béquer de $150 \mathrm{~mL}$. Adicionou-se $5 \mathrm{~mL}$ da solução de tetraborato de sódio decahidratado $50 \mathrm{~g} / \mathrm{L}$ e cerca de $40 \mathrm{~mL}$ de água desionizada, com temperatura 
acima de $70^{\circ} \mathrm{C}$. Aqueceu-se esta solução em banho-maria por 15 minutos, homogeneizando constantemente com uma bagueta de vidro.

Em seguida, após esfriar a temperatura ambiente, adicionou-se $2 \mathrm{~mL}$ de solução de ferrocianeto de potássio $106 \mathrm{~g} / \mathrm{L} \mathrm{e} 2 \mathrm{~mL}$ de solição de acetato de zinco dihidratado $220 \mathrm{~g} / \mathrm{L}$. Agitou-se após a adição de cada solução.

Transferiu-se a solução formada para um balão volumétrico de $100 \mathrm{~mL}$ completando o volume com água desionizada. Com o auxílio de um agitador magnético agitou-se a solução por 30 minutos à temperatura ambiente. Após a homogeneização, filtrou-se a solução.

Posteriormente, foram realizadas as diluições necessárias para a determinação de nitrato e de nitrito.

\subsection{Procedimento de Extração [72]}

Este procedimento é uma adaptação do método de desproteinização, onde pesou-se aproximadamente $10 \mathrm{~g}$ da amostra de carne curada em um béquer de $150 \mathrm{~mL}$.

Transferiu-se a amostra para um balão volumétrico de $100 \mathrm{~mL}$ e completou-se o volume com solução acetato de sódio $0,1 \mathrm{~mol} / \mathrm{L}$. Agitou-se a mistura, com o auxílio de um agitador magnético, por 30 minutos a temperatura ambiente. Após 30 minutos em repouso filtrou-se a mistura.

Posteriormente, foram realizadas as diluições necessárias para a determinação de nitrato e de nitrito. 


\section{RESULTADOS E DISCUSSÃO}

\subsection{Procedimento de Imobilização de Depósitos alternados de Co- TRP/Zn-TPPS na Superfície do Eletrodo}

O eletrodo de carbono vítreo foi modificado depositando em sua superfície $1 \mu \mathrm{L}$ da solução de porfirina catiônica Co-TRP e $1 \mu \mathrm{L}$ da solução de porfirina aniônica $\mathrm{Zn}$-TPPS. Sabe-se, pelo trabalho de Azevedo et al, que a porfirina catiônica é a responsável pelo processo de transferência de elétrons na superfície do eletrodo, porém a necessidade da deposição da porfirina aniônica está associada à diminuição da solubilização da porfirina catiônica na solução aquosa [68]. A figura 20 apresenta o esquema detalhado do procedimento de imobilização.

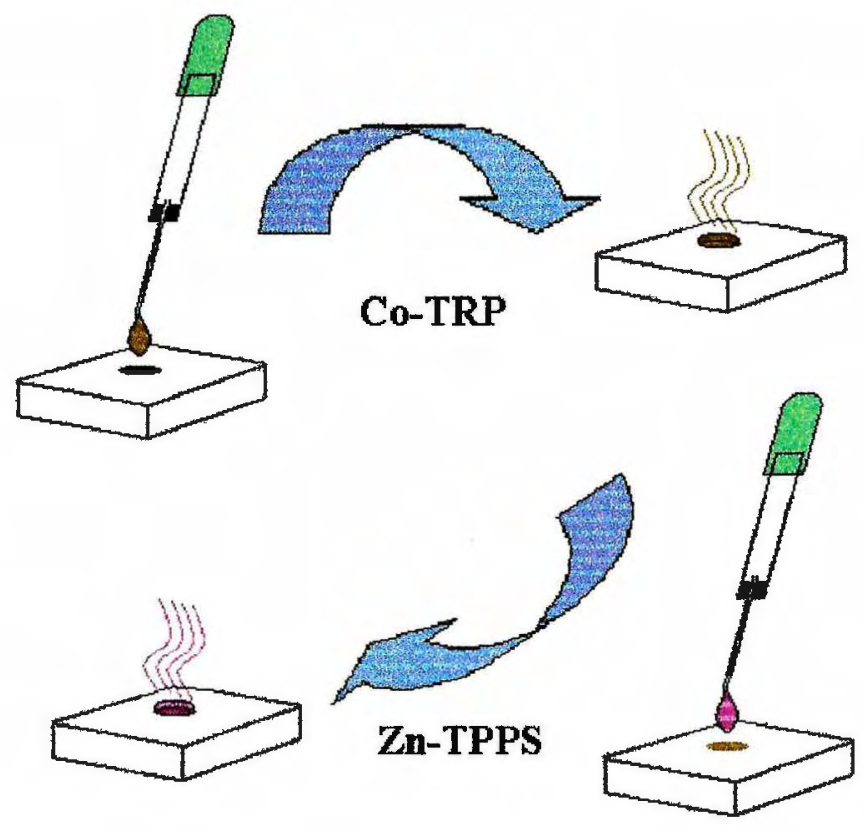

Figura 20 - Esquema do processo de recobrimento da superfície do eletrodo. Na parte superior, à esquerda, representa-se o depósito da solução de porfirina catiônica Co-TRP e a evaporação do solvente metanol. Em seguida, na parte inferior à direita, representa-se o depósito da solução de porfirina aniônica Zn-TPPS sobre a primeira porfirina e a evaporação do solvente (água). Após o processo de depósito lava-se o excesso de porfirina com água desionizada. Este processo repete-se tantas vezes quantas forem necessárias para a modificação do eletrodo. 


\subsection{Estudos Preliminares}

Foram realizados experimentos para a familiarização com a instrumentação analítica utilizada, para tanto empregou-se eletrodo de carbono vítreo e o par $\left[\mathrm{Fe}(\mathrm{CN})_{6}\right]^{4-} /\left[\mathrm{Fe}(\mathrm{CN})_{6}\right]^{3-}$.

\subsubsection{Variação na Velocidade de Varredura}

O funcionamento do conjunto potenciostato + célula eletroquímica foi avaliado com solução de Ferricianeto de Potássio $1 \mathrm{mmol} / \mathrm{L}$ em $\mathrm{KCl} 0,1 \mathrm{mmol} / \mathrm{L}$, uma vez que o processo de redução eletroquímica desta espécie é reversível e bem conhecido. De acordo com a equação de Randles-Sevcik [15], voltamogramas cíclicos para espécies eletroativas cujo processo global é controlado por difusão têm correntes de pico proporcionais à raiz quadrada da velocidade de varredura. $\mathrm{Na}$ figura 21 são apresentados os voltamogramas para $\left[\mathrm{Fe}(\mathrm{CN})_{6}\right]^{3-}$ com diferentes velocidades de varredura, observando-se voltamogramas cíclicos bastante típicos para esta espécie eletroativa. Verifica-se que quanto maior a velocidade de varredura maior é o valor da intensidade de corrente, e tal fato é explicado que, para janelas de tempo menores, não ocorre o esgotamento da espécie eletroativa localizada próximo à superfície do eletrodo.

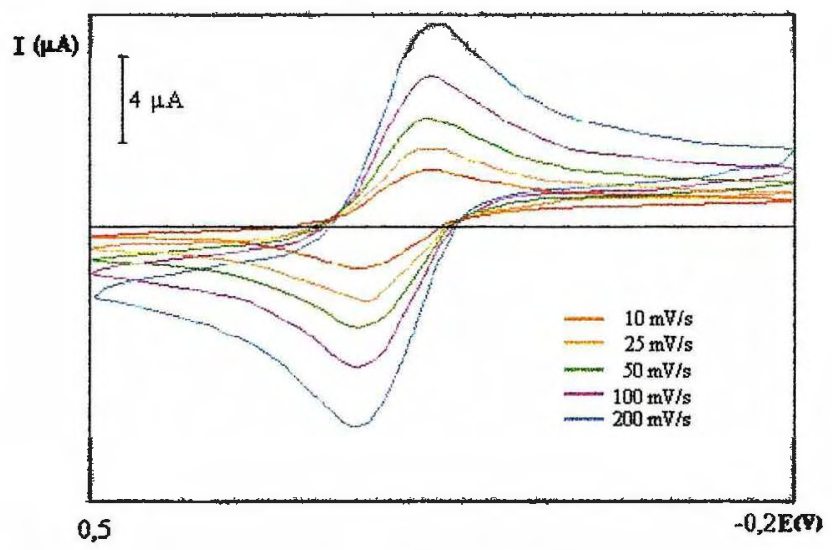

Figura 21 - Voltamogramas cíclicos obtidos com o potenciostato PAR 273A EG\&G, utilizando-se uma célula eletroquímica tradicional com os seguintes eletrodos: carbono vítreo $(\mathrm{d}=2 \mathrm{~mm}), \mathrm{Ag} / \mathrm{AgCl}$ e platina. Solução de Ferricianeto de Potássio $1 \mathrm{mmol} / \mathrm{L}$ em KCl 0,1 mol/L. 
Registrando os valores da intensidade da corrente de pico catódica em função dos valores da raiz quadrada da velocidade de varredura (figura 21), observa-se que o resultado é uma reta, confirmando-se assim as expectativas teóricas referentes à redução eletroquímica do $\left[\mathrm{Fe}(\mathrm{CN})_{6}\right]^{3-}$. O registro do voltamograma cíclico desta espécie eletroativa foi realizado rotineiramente para checar o bom funcionamento da aparelhagem, bem como dos eletrodos de referência e de trabalho.

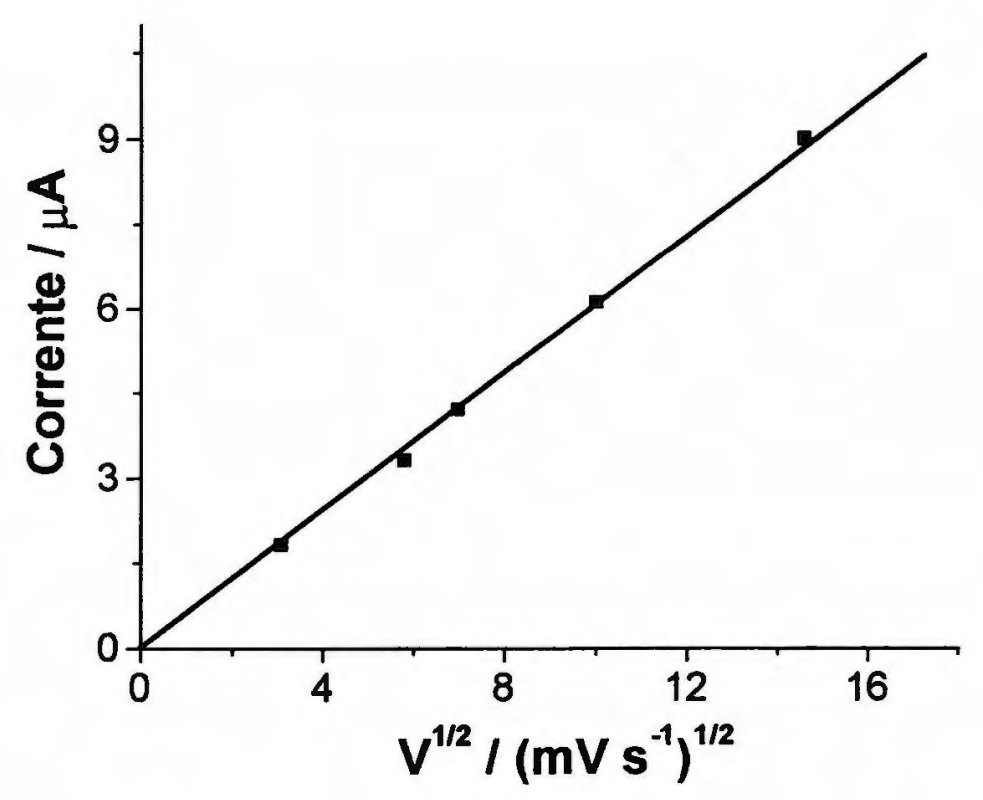

Figura 22 - Dependência da corrente de pico catódica em função da velocidade de varredura (dados da figura 21).

\subsubsection{Equação de Cottrell}

A equação de Cottrell relaciona a intensidade de corrente instantânea que flui na célula eletroquímica em um dado instante de tempo $t$ depois de se ter aplicado um pulso de potencial. De acordo com esta equação, a intensidade de corrente deverá diminuir continuamente com a raiz quadrada do tempo, para um valor constante do potencial aplicado, aproximando-se de zero para tempos infinitos. Cabe ressaltar que 
a equação de Cotrell abaixo descrita é válida para processos de eletrodos governados por difusão:

$$
I_{t}=n F C A(D / \pi t)^{1 / 2}
$$

Onde: $\mathbf{I}_{\mathbf{t}}=$ intensidade de corrente no instante $\mathrm{t}$;

$\mathbf{n}=$ número de elétrons envolvidos no processo eletroquímico;

$\mathbf{F}=$ constante de Faraday;

C = concentração da substância eletroativa;

$\mathbf{A}=$ área da superfície do eletrodo;

$\mathbf{D}=$ coeficiente de difusão;

$\mathbf{t}=$ tempo.

A representação gráfica da equação de Cottrell foi observada utilizando-se a cronoamperometria, técnica onde aplica-se, no eletrodo de trabalho, um dado valor de potencial, suficiente para provocar uma reação no eletrodo, e mede-se a corrente resultante em função do tempo [73].

Para tanto foi utilizada uma solução de $\mathrm{K}_{3}\left[\mathrm{Fe}(\mathrm{CN})_{6}\right] 1 \mathrm{mmol} / \mathrm{L}$ em $\mathrm{KCl} 0,1$ $\mathrm{mol} / \mathrm{L}$. A presença do eletrólito suporte minimiza efeitos de migração e trabalha-se em solução estacionária para evitar problemas associados à conveç̧ão. Desta forma, garante-se que o transporte do material para a superfície do eletrodo seja exclusivamente devido ao fenômeno de difusão.

Durante os primeiros milisegundos aplicou-se ao eletrodo de trabalho um potencial de $500 \mathrm{mV}$, valor no qual o $\left[\mathrm{Fe}(\mathrm{CN})_{6}\right]^{3-}$ não é eletroativo. Em seguida aplicou-se um pulso a um potencial de $100 \mathrm{mV}$ por 1 segundo, obtendo-se o cronoamperograma apresentado na figura 22. O decaimento da intensidade de corrente é explicado pela diminuição da concentração da espécie eletroativa na camada de difusional em função do processo de redução eletroquímica. 


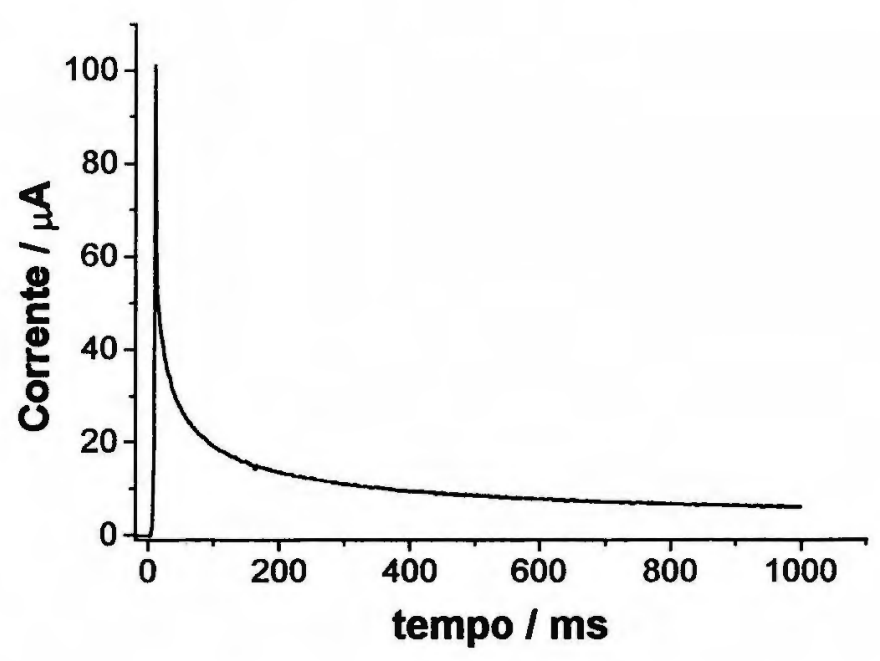

Figura 23 - Cronoamperograma obtido com solução de $\mathrm{K}_{3}\left[\mathrm{Fe}(\mathrm{CN})_{6}\right]$ $1 \mathrm{mmol} / \mathrm{L}$ em $\mathrm{KCl} 0,1 \mathrm{~mol} / \mathrm{L}$. Pulso de potencial de $500 \mathrm{mV}$ para $100 \mathrm{mV}$.

A análise dos dados obtidos da figura 23, da intensidade de corrente (I) em função do inverso da raiz quadrada do tempo $\left(\mathrm{t}^{-1 / 2}\right)$, representada pela reta da figura 24 demonstra que o processo de eletrodo é governado pela difusão.

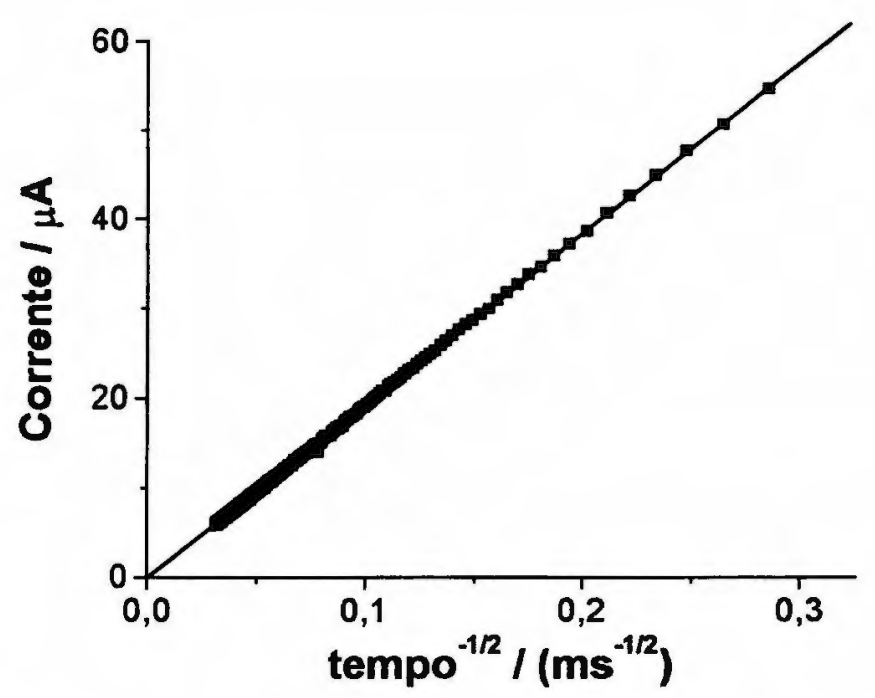

Figura 24 - Aplicação da equação de Cottrell, utilizando a análise de dados da figura 23 . 


\subsubsection{Ensaios preliminares utilizando o par Co-TRP/Zn-TPPS}

A primeira parte dos ensaios foi realizada utilizando o eletrodo de carbono vítreo modificado com 3 pares de depósitos alternados de Co-TRP/Zn-TPPS como eletrodo de trabalho, de acordo com o que está apresentado na figura 20. Como eletrodo de referência foi usado o de $\mathrm{Ag} / \mathrm{AgCl}$ e como auxiliar o eletrodo de platina.

Registrando-se os voltamogramas cíclicos, em solução tampão acetato de sódio/ácido acético $0,1 \mathrm{~mol} / \mathrm{L}(\mathrm{pH}=4,7)$, verificou-se (figura 25) que durante a ciclagem ocorre perda gradativa de porfirina devido à sua solubilização.

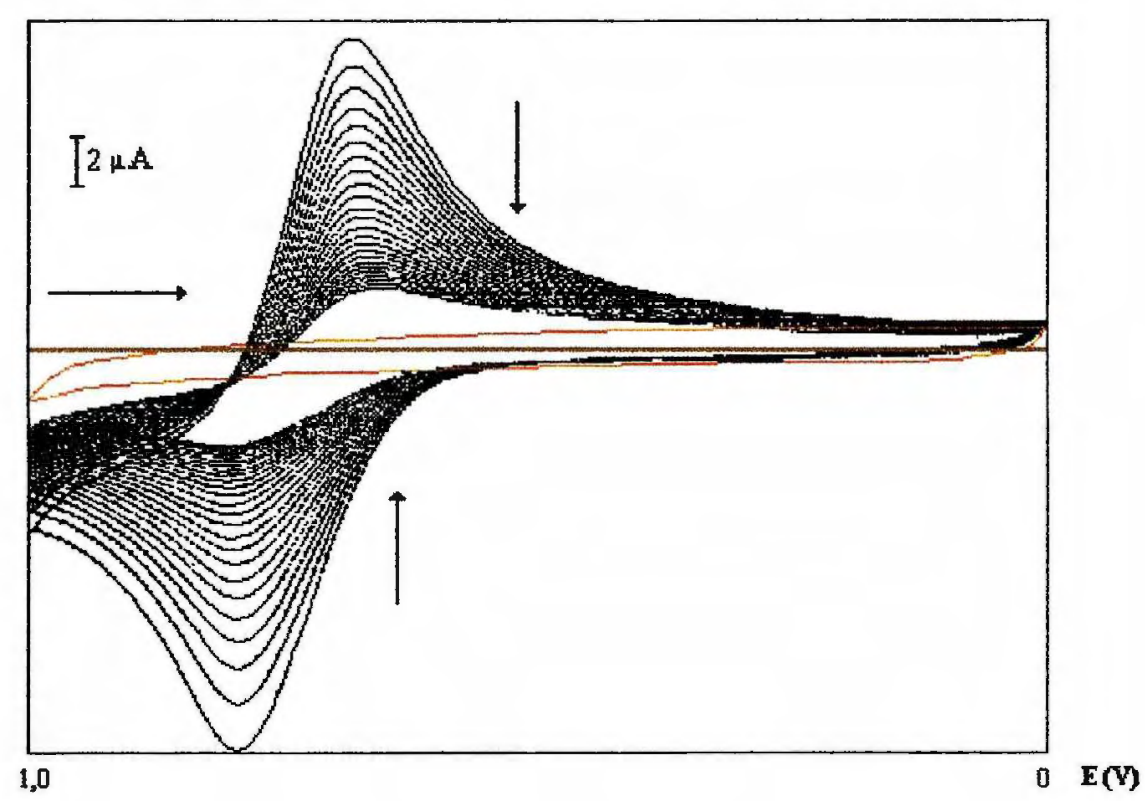

Figura 25 - Voltamogramas cíclicos com eletrodo modificado de carbono vítreo $(\mathrm{d}=2 \mathrm{~mm})$ recoberto com Co-TRP/Zn-TPPS, em solução tampão acetato de sódio/ácido acético $0,1 \mathrm{~mol} / \mathrm{L}$.

Segundo a literatura [68], para minimizar a solubilização do material depositado na superficie do eletrodo é necessária a adição de perclorato de sódio ou outro sal que apresente um ânion volumoso. Desta forma este ânion funciona como o contra-íon reduzindo-se perdas devido ao processo de solubilização. 
Para avaliar a influência da concentração do contra íon na diminuição do sinal de corrente, ensaios foram realizados com soluções de $\mathrm{NaClO}_{4}$ em várias concentrações $(0,05 ; 0,1 ; 0,15 ; 0,2$ e $0,25 \mathrm{~mol} / \mathrm{L})$. Notou-se que a partir da concentração $0,2 \mathrm{~mol} / \mathrm{L}$ de $\mathrm{NaClO}_{4}$ não ocorria mais perda de material depositado sobre a superfície do eletrodo para a solução; tal fato foi constatado pela obtenção de voltamogramas sobrepostos $(n=10)$ durante varredura consecutiva de potencial (figura 26).

Os picos anódico $\left(\mathrm{Ep}_{\mathrm{a}}=+0,71 \mathrm{~V}\right)$ e catódico $\left(\mathrm{Ep}_{\mathrm{c}}=+0,64 \mathrm{~V}\right)$ dos voltamogramas da figura 26 devem-se respectivamente à oxidação do complexo de rutênio (II) ao complexo de rutênio (III) e à redução do complexo de rutênio (III) ao complexo de rutênio(II) [27].

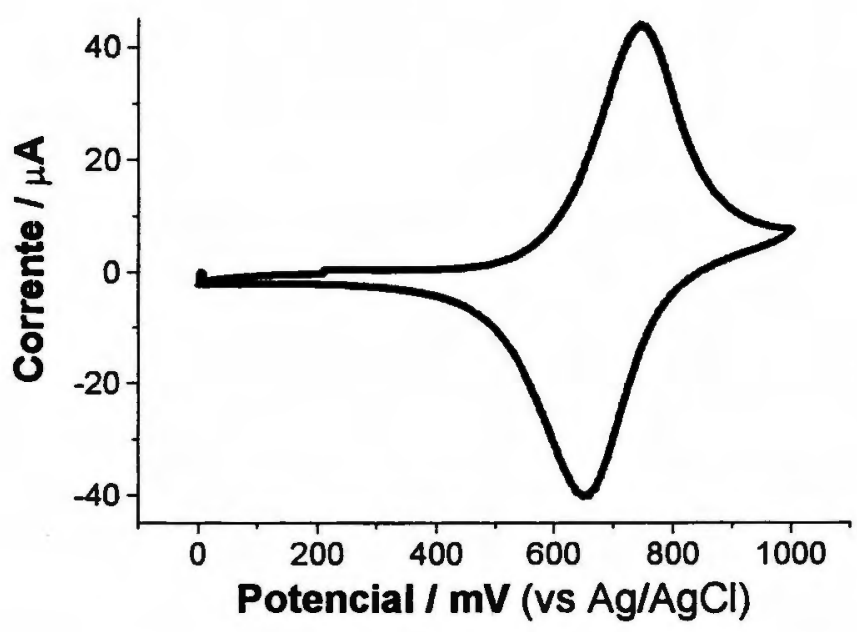

Figura 26 - Voltamogramas cíclicos $(\mathrm{n}=10)$ registrados com eletrodo modificado de carbono vítreo $(\mathrm{d}=2 \mathrm{~mm})$ com Co-TRP/Zn-TPPS, em solução tampão acetato de sódio/ácido acético $0,1 \mathrm{~mol} / \mathrm{L}$ contendo perclorato de sódio $0,2 \mathrm{~mol} / \mathrm{L}$. 


\subsubsection{Eletrodo Modificado com outras Porfirinas}

Testes referentes à oxidação eletroquímica do $\mathrm{NO}_{2}^{-}$em superfícies modificadas com outras 2 porfirinas foram realizados. Estas apresentam como ín metálico central o zinco e como ânion o $\mathrm{ClO}_{4}^{-}$, sendo que este ânion foi utilizado justamente para minimizar o problema de solubilidade da porfirina em sistemas aquosos [69].

\subsubsection{1. $\mathrm{ZnTBzPyP}\left(\mathrm{ClO}_{4}\right)_{4}$}

Para verificarmos as propriedades eletroquímicas da porfirina catiônica $\mathrm{ZnTBzPyP}\left(\mathrm{ClO}_{4}\right)_{4}[69]$ foi preparada solução em acetonitrila com concentração de $1,3 \mu \mathrm{mol} / \mathrm{L}$. Desta solução colocou-se $1 \mu \mathrm{L}$ na superfície previamente limpa e polida do eletrodo de carbono vítreo para que ocorresse a imobilização da mesma . Após a evaporação do solvente lavou-se o excesso de porfirina com água desionizada. Este processo de imobilização e limpeza foi realizado em triplicata para obtermos um "sanduíche" com 3 depósitos desta porfirina.

Montou-se o sistema para solução estacionária (pág. 24) e varreu-se o potencial de $0 \mathrm{~V}$ a $1 \mathrm{~V}$ utilizando solução tampão acetato de sódio/ácido acético 0,1 $\mathrm{mol} / \mathrm{L}(\mathrm{pH}=4,7)$ contendo perclorato de sódio $0,2 \mathrm{~mol} / \mathrm{L}$. Foi possível visualizar a solubilização da porfirina imobilizada no eletrodo, pois ao redor do eletrodo verificou-se uma coloração verde similar àquela observada na solução da porfirina em acetonitrila.

Esta mesma porfirina foi imobilizada intercalando com a porfirina aniônica $\mathrm{Zn}$-TPPS [68], ou seja $1 \mu \mathrm{L}$ da solução da porfirina catiônica $\mathrm{ZnTBzPyP}\left(\mathrm{ClO}_{4}\right)_{4}$ [69] foi depositada na superfície limpa e polida do eletrodo de carbono vítreo $(\mathrm{d}=$ $2 \mathrm{~mm})$ e, após a evaporação do solvente, foi depositado $1 \mu \mathrm{L}$ da solução da porfirina aniônica $\mathrm{Zn}$-TPPS [68]. Depois da evaporação do solvente o eletrodo foi lavado com jatos de água desionizada para que se retirasse o excesso da porfirina aniônica, que não se ligou à porfirina catiônica. Este processo de deposição e limpeza foi realizado 
em triplicata para obter-se um "sanduíche" com 3 pares de depósitos alternados destas porfirinas.

Novamente montou-se o sistema para solução estacionária (pág. 25) e varreuse o potencial de 0V a 1V utilizando solução tampão acetato de sódio/ácido acético $0,1 \mathrm{~mol} / \mathrm{L}(\mathrm{pH}=4,7)$ contendo perclorato de sódio $0,2 \mathrm{~mol} / \mathrm{L}$. Mesmo com estes cuidados na deposição das duas porfirinas, uma catiônica e outra aniônica e da utilização de perclorato como contra-íon para minimizar o problema de solubilização da porfirina verificou-se que a mesma é solubilizada. Da mesma forma que no primeiro ensaio com esta porfirina foi possível visualizar a solubilização ao redor do eletrodo; verificou-se uma coloração verde similar àquela observada na solução de porfirina em acetonitrila. Com estes resultados percebeu-se que não existem atrativos analíticos em modificar eletrodos com esta porfirina.

\subsubsection{2. $\mathrm{ZnTMeOBzPyP}\left(\mathrm{ClO}_{4}\right)_{4}$}

Para verificar as propriedades eletroquímicas da porfirina catiônica $\mathrm{ZnTMeOBzPyP}\left(\mathrm{ClO}_{4}\right)_{4}$ [69] foi preparada solução em acetonitrila na concentração de $2,7 \mu \mathrm{mol} / \mathrm{L}$. Desta solução colocou-se $1 \mu \mathrm{L}$ na superfície previamente limpa e polida do eletrodo de carbono vítreo e, após a evaporação do solvente, foi depositado $1 \mu \mathrm{L}$ da solução da porfirina aniônica Zn-TPPS [68]. Utilizou-se procedimento similar ao anterior para obter-se um "sanduíche" com 3 depósitos alternados destas porfirinas e, desta forma, a imobilização das mesmas.

Utilizando-se do sistema para solução estacionária (pág. 24) varreu-se o potencial de $0 \mathrm{~V}$ a $1 \mathrm{~V}$, em solução tampão acetato de sódio/ácido acético $0,1 \mathrm{~mol} / \mathrm{L}$ $(\mathrm{pH}=4,7)$ contendo perclorato de sódio $0,2 \mathrm{~mol} / \mathrm{L}$ e não obteve-se sinal de corrente. Resultados semelhantes foram observados após a adição de $1 \mathrm{mmol} / \mathrm{L}$ de $\mathrm{NO}_{2}{ }^{-}$. Concluiu-se desta maneira que a presença do filme contendo estas porfirinas dificultam o processo eletroquímico referente à oxidação eletroquímica do nitrito. 
Observou-se ainda que ao imobilizar-se somente esta porfirina cationica $\mathrm{ZnTMeOBzPyP}\left(\mathrm{ClO}_{4}\right)_{4}$ [69], ou intercalada com a porfirina $\mathrm{Zn}$-TPPS[68] aparece, no voltamograma cíclico, o componente anódico onde $\mathrm{Ep}_{\mathrm{a}}=+1,2 \mathrm{~V}$ trabalhando-se com solução tampão de acetato de sódio/ácido acético $0,1 \mathrm{~mol} / \mathrm{L}$ contendo perclorato de sódio $0,2 \mathrm{~mol} / \mathrm{L}$ e $\mathrm{NO}_{2}^{-} 1 \mathrm{mmol} / \mathrm{L}$. Analisando os dois voltamogramas cíclicos percebe-se que a intensidade de corrente, quando modifica-se o eletrodo somente com a porfirina catiônica, é maior do que utilizando esta mesma porfirina intercalada com a porfirina $\mathrm{Zn}$-TPPS. Isto se deve ao fato de que a interação entre a porfirina catiônica e a aniônica minimiza o processo catalítico, visto que não existe um íon metálico central que facilita este processo.

\subsection{Caracterização do Eletrodo Modificado}

\subsubsection{Ensaios com Pares de Depósitos Alternados de Co-TRP/Zn- TPPS}

Foram realizados ensaios para verificar se realmente os sinais de corrente registrados quando da oxidação do nitrito a nitrato, em eletrodo de carbono vítreo modificado com Co-TRP/Zn-TPPS, intensificava-se em relação aos sinais de corrente obtidos utilizando o mesmo eletrodo de carbono vítreo sem modificação. Para tanto os experimentos foram realizados em uma solução tampão acetato de sódio/ácido acético $0,1 \mathrm{~mol} / \mathrm{L}(\mathrm{pH} 4,7)$ contendo perclorato de sódio $0,2 \mathrm{~mol} / \mathrm{L}$ e 1 $\mathrm{mmol} / \mathrm{L}$ de $\mathrm{NO}_{2}^{-}$. Os resultados podem ser observados na figura 27. 


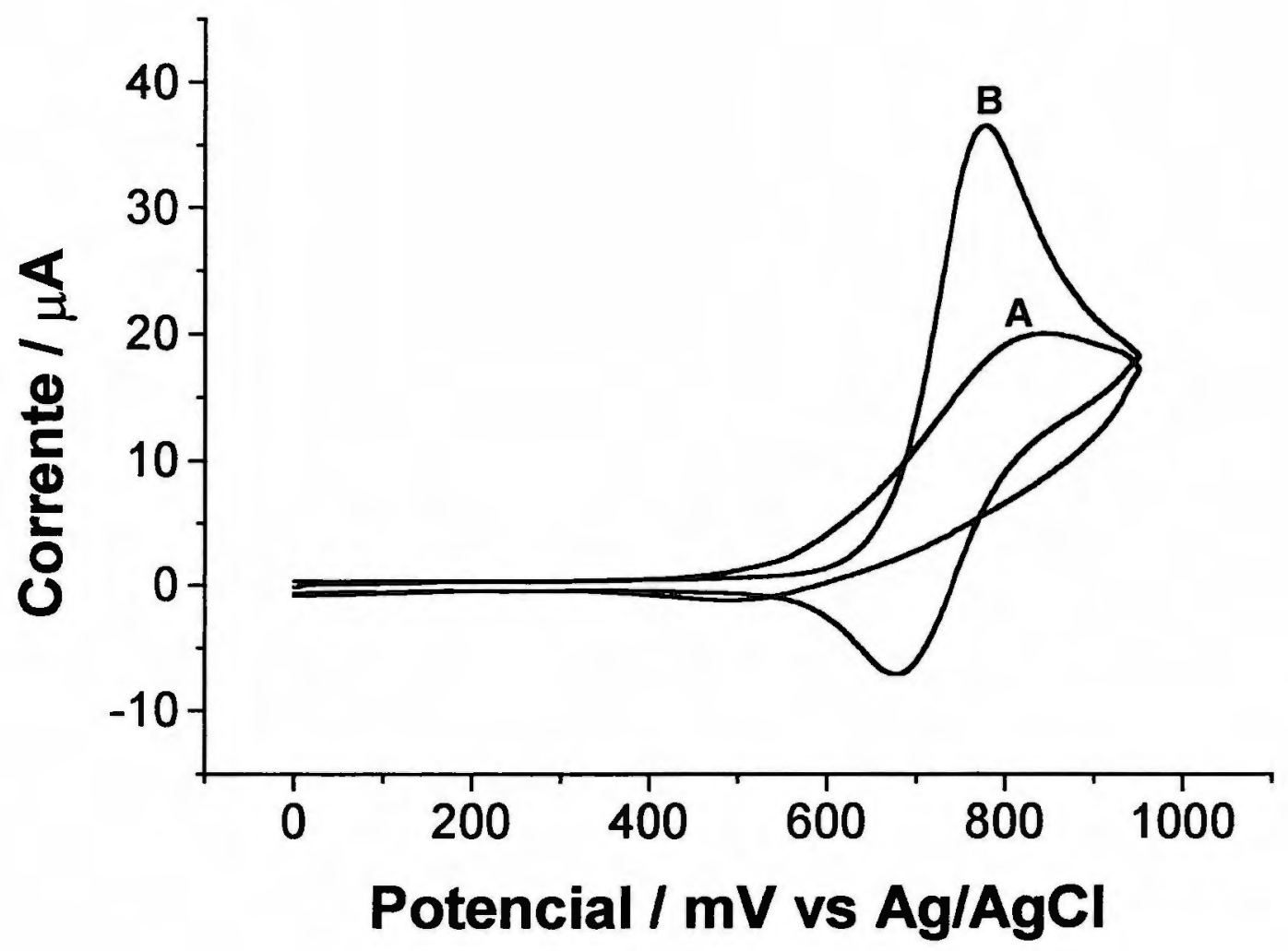

Figura 27 - Voltamogramas cíclicos obtidos em solução tampão acetato de sódio/ácido acético $0,1 \mathrm{~mol} / \mathrm{L}(\mathrm{pH} \mathrm{4,7)}$ contendo perclorato de sódio 0,2 $\mathrm{mol} / \mathrm{L}$ e $1 \mathrm{mmol} / \mathrm{L}$ de $\mathrm{NO}_{2}^{-}$. (A) Eletrodo de carbono vítreo polido e (B) eletrodo de carbono vítreo modificado com 1 depósito alternado de CoTRP/Zn-TPPS.

Nos voltamogramas cíclicos apresentados na figura 27 percebe-se a intensificação do sinal de corrente para a oxidação de nitrito. Nota-se também a antecipação do potencial de pico anódico para nitrito, quando modifica-se a superficie do eletrodo com pares de depósitos alternados de Co-TRP/Zn-TPPS .

O provável esquema de mediação é apresentado na figura 28 , onde verifica-se que o nitrito é oxidado a nitrato e isto ocorre pela redução do $\mathrm{Ru}^{3+} a \mathbf{R u}^{2+}$. 


$$
\begin{gathered}
\mathrm{Ru}^{2+} \rightleftharpoons \mathrm{Ru}^{3+}+e^{-} \\
\mathrm{NO}_{2}^{-}+\mathrm{Ru}^{3+}+e^{-} \longrightarrow \mathrm{NO}_{3}^{-}(?)+R u^{2+}
\end{gathered}
$$

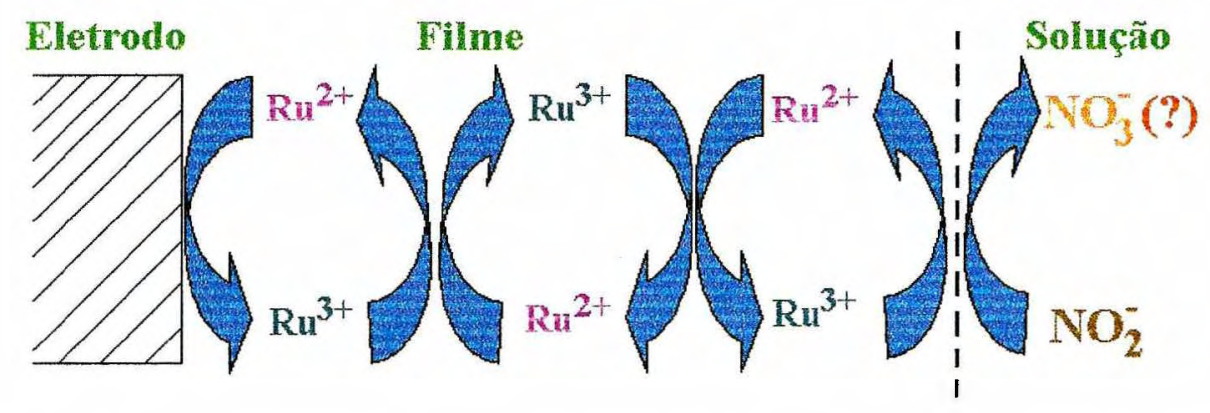

Figura 28 - Provável esquema de mediação para a intensificação do sinal de corrente quando da oxidação de nitrito em eletrodo modificado com Co-TRP/Zn-TPPS.

\subsubsection{Número de Depósitos Alternados de Co-TRP/Zn-TPPS}

Para cada quantidade de pares de depósitos alternados registrou-se voltamograma cíclico em solução tampão acetato de sódio/ácido acético $0,1 \mathrm{~mol} / \mathrm{L}$ $(\mathrm{pH}=4,7)$ contendo $\mathrm{NaClO}_{4}$ 0,2 mol/L e logo após voltamograma cíclico na mesma solução contendo $\mathrm{NO}_{2}^{-} 1 \mathrm{mmol} / \mathrm{L}$. O comportamento pode ser observado na figura 29, onde são apresentados os resultados obtidos com 1, 3, 5, 7, 10 e 15 pares de depósitos alternados de Co-TRP/Zn-TPPS. Percebe-se o aumento na intensidade de corrente para filmes mais espessos devido ao aumento da quantidade de material modificador (porfirinas). Porém, ocorre diminuição no $\Delta \mathrm{I}$, que é diferença de intensidade de corrente anódica entre os valores obtidos utilizando somente a solução tampão acetato de sódio/ácido acético $0,1 \mathrm{~mol} / \mathrm{L}(\mathrm{pH} 4,7)$ contendo perclorato de sódio e a solução tampão acetato de sódio/ácido acético $0,1 \mathrm{~mol} / \mathrm{L}$ $(\mathrm{pH} 4,7)$ contendo perclorato de sódio $0,2 \mathrm{~mol} / \mathrm{L}$ e $1 \mathrm{mmol} / \mathrm{L}$ de $\mathrm{NO}_{2}^{-}$. 

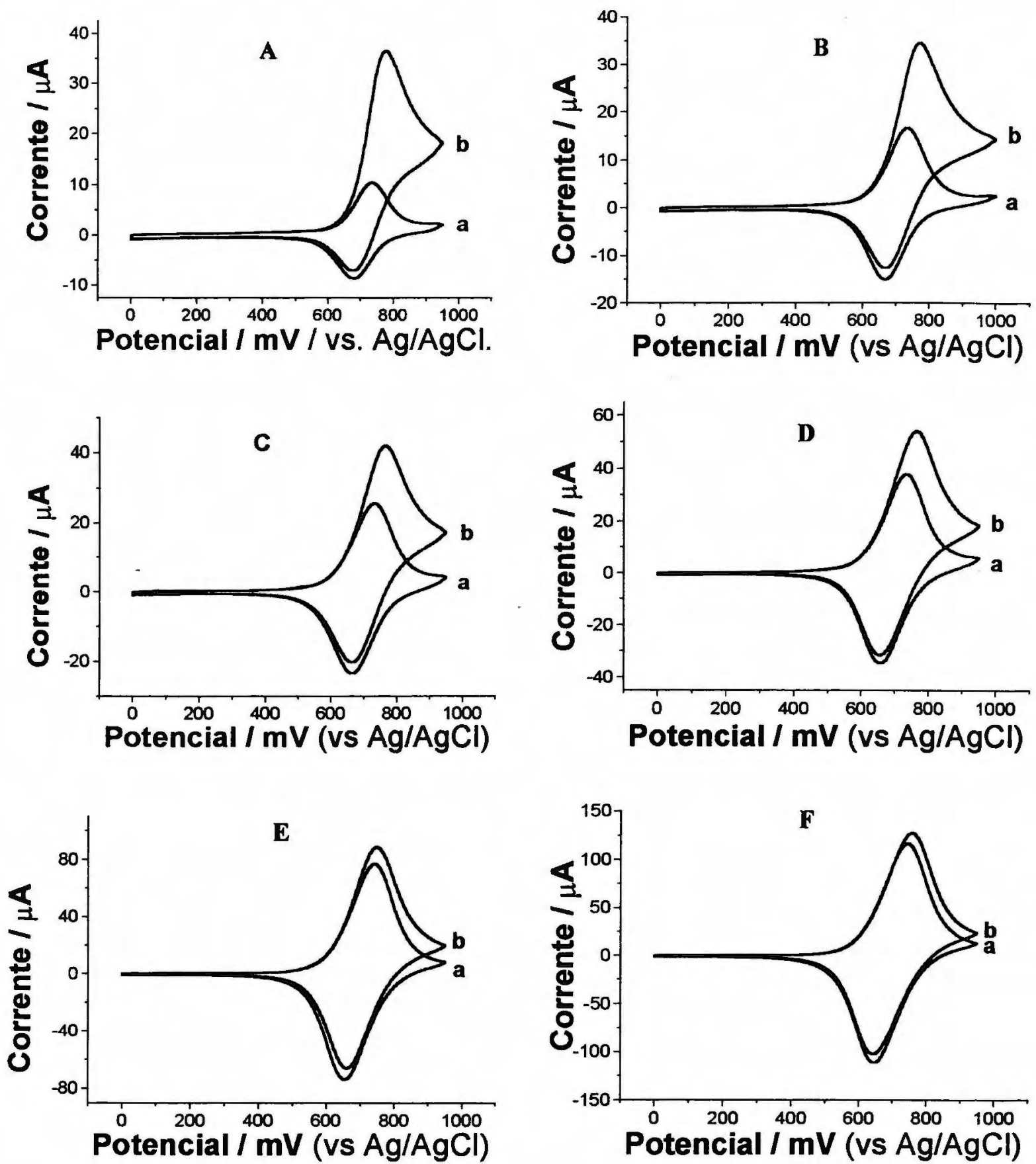

Figura 29 - Voltamogramas cíclicos registrados utilizando 1 (A), 3 (B), 5 (C), 7 (D), 10 (E) e 15 (F) pares de depósitos alternados de Co-TRP/Zn-TPPS em eletrodo de carbono vítreo. Em (a) solução tampão acetato de sódio/ácido acético $0,1 \mathrm{~mol} / \mathrm{L}(\mathrm{pH} \mathrm{4,7)}$ contendo perclorato de sódio $0,2 \mathrm{~mol} / \mathrm{L}$ e em (b) solução tampão acetato de sódio/ácido acético $0,1 \mathrm{~mol} / \mathrm{L}(\mathrm{pH} 4,7)$ contendo perclorato de sódio $0,2 \mathrm{~mol} / \mathrm{L}$ e $1 \mathrm{mmol} / \mathrm{L}$ de $\mathrm{NO}_{2}^{-}$. 
Os dados extraídos dos voltamogramas cíclicos da figura 29 foram registrados na tabela 1 , onde $I_{k}$ equivale à intensidade de corrente quando a varredura foi realizada na solução tampão $\mathrm{pH} \mathrm{4,7}$ contendo nitrito, $I_{d}$ equivale à intensidade de corrente quando a varredura foi realizada na solução tampão $\mathrm{pH} 4,7$ sem nitrito e $\Delta \mathrm{I}$ equivale à diferença entre $I_{k}$ e $I_{d}$.

Tabela 1 - Dados extraídos dos voltamogramas cíclicos da figura 29, onde $\mathrm{I}_{\mathrm{k}}=$ intensidade de corrente obtida em solução tampão $\mathrm{pH} 4,7$ contendo nitrito, $I_{d}=$ intensidade de corrente obtida em solução tampão sem nitrito e $\Delta \mathrm{I}=\mathrm{I}_{\mathrm{k}}-\mathrm{I}_{\mathrm{d}}$.

$\mathbf{N}^{0}$ de Pares

\begin{tabular}{cccc}
$\begin{array}{c}\text { Depósitos } \\
\text { Alternados }\end{array}$ & $\mathbf{I}_{\mathbf{k}}(\boldsymbol{\mu A})$ & $\mathbf{I}_{\mathbf{d}}(\boldsymbol{\mu A})$ & $\Delta \mathbf{I}(\mu \mathbf{A})$ \\
\hline 1 & 36,6 & 10,4 & 26,2 \\
\hline 3 & 34,7 & 16,7 & 18,0 \\
\hline 5 & 42,1 & 25,7 & 16,4 \\
\hline 7 & 53,9 & 37,9 & 16,0 \\
\hline 10 & $\mathbf{8 8 , 9}$ & 77,1 & 11,8 \\
\hline 15 & 127,2 & 116,7 & 10,5
\end{tabular}

A partir destes resultados foi possível registrar o gráfico corrente de pico versus número de depósitos alternados (figura 30 ), onde observou-se que quanto maior o número de pares de depósitos alternados de Co-TRP/Zn-TPPS depositados menor é o $\Delta \mathrm{I}$ (diferença entre a intensidade de corrente anódica para nitrito no eletrodo modificado com as diferentes quantidades de depósitos alternados e a intensidade de corrente anódica para o eletrólito suporte verificada no mesmo eletrodo). 


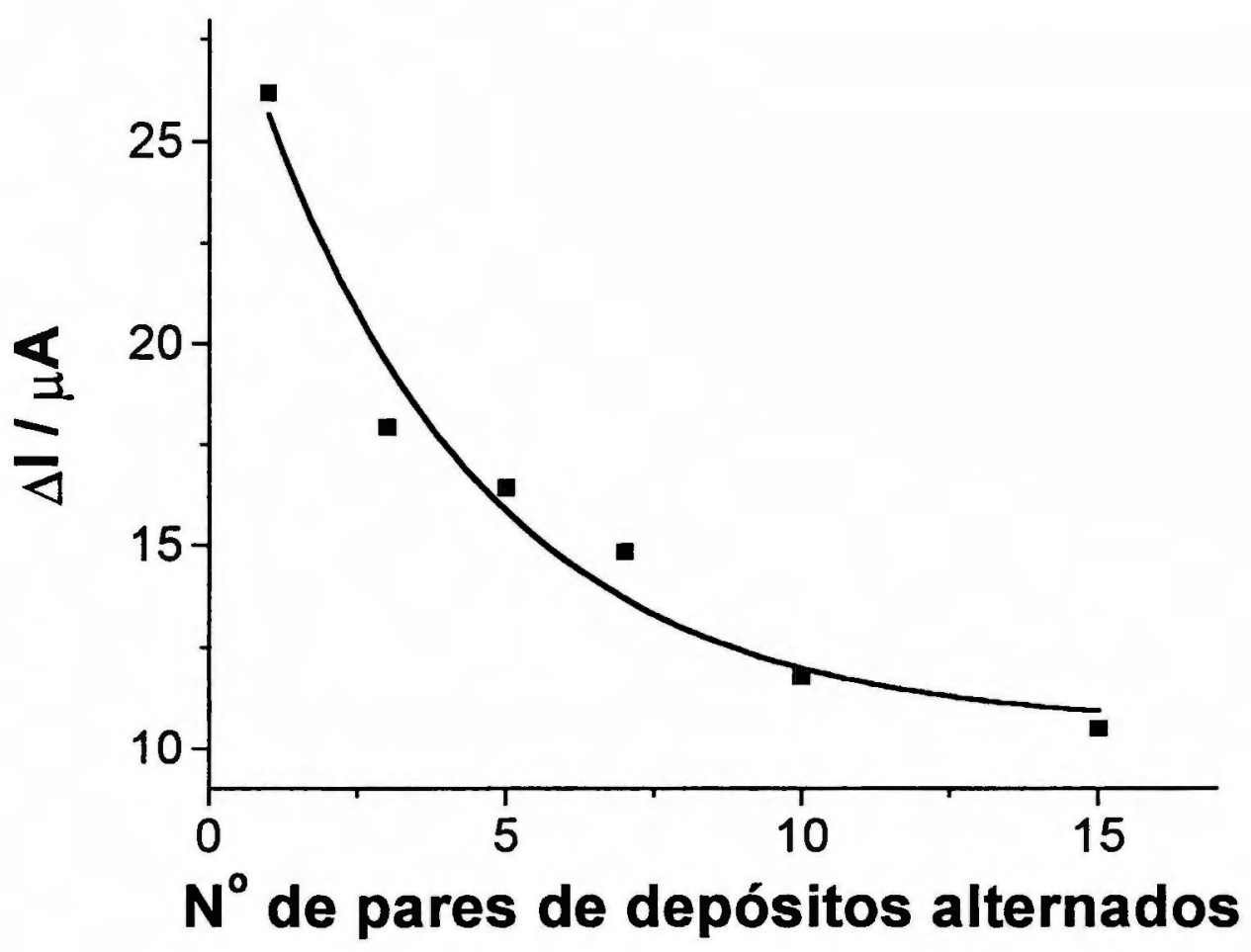

Figura 30 - Dependência de $\Delta \mathrm{I}$ (corrente de pico na presença de $\mathrm{NO}_{2}{ }^{-}$corrente de pico na ausência de $\mathrm{NO}_{2}{ }^{-}$) em função do número de pares de depósitos alternados, conforme dados extraídos da tabela 1.

Os resultados dos ensaios amperométricos confirmaram aqueles obtidos com os ensaios voltamétricos, ou seja quanto mais espesso for o filme modificador menor será a diferença da resposta de intensidade de corrente. Foram realizadas injeções de solução tampão acetato de sódio/ácido acético $0,1 \mathrm{~mol} / \mathrm{L}(\mathrm{pH} 4,7)$ contendo perclorato de sódio $0,2 \mathrm{~mol} / \mathrm{L}$ e $1 \mathrm{mmol} / \mathrm{L}$ de $\mathrm{NO}_{2}^{-}$ao fluxo carregador, alterando-se o potencial aplicado ao eletrodo de trabalho e com diferentes quantidades de pares de depósitos alternados de Co-TRP/Zn-TPPS. Os dados apresentados na tabela 2 representam a média aritmética de 3 injeções sucessivas em cada um dos potenciais aplicados e em cada quantidade de pares de depósitos alternados. 
Tabela 2 - Médias aritméticas das intensidades de corrente obtidas de 3 injeções sucessivas de solução tampão acetato de sódio/ácido acético 0,1

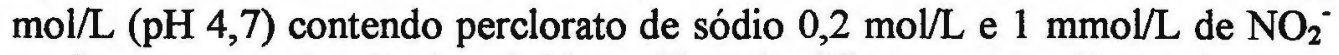
no fluxo carregador. Dados obtidos utilizando diferentes quantidades de pares de depósitos alternados de Co-TRP/Zn-TPPS e aplicando diferentes potenciais ao eletrodo de trabalho.

\begin{tabular}{c|cccccc}
$\begin{array}{c}\text { Quantidade de } \\
\text { pares de Depósitos } \\
\text { Alternados } \\
\rightarrow\end{array}$ & $\mathbf{1}$ & $\mathbf{3}$ & $\mathbf{5}$ & $\mathbf{7}$ & $\mathbf{1 0}$ & $\mathbf{1 5}$ \\
\hline Potencial (mV) $\downarrow$ & $\mu \mathrm{A}$ & $\mu \mathrm{A}$ & $\mu \mathrm{A}$ & $\mu \mathrm{A}$ & $\mu \mathrm{A}$ & $\mu \mathrm{A}$ \\
\hline 700 & 2,7 & 2,3 & 2,2 & 2,2 & 2,0 & 1,8 \\
\hline 750 & 11,1 & 10,5 & 10,1 & 9,3 & 9,4 & 8,3 \\
\hline 800 & 22,0 & 20,5 & 20,4 & 19,2 & 17,9 & 17,0 \\
\hline 850 & 28,9 & 28,7 & 28,2 & 27,2 & 25,9 & 23,7 \\
\hline 900 & 32,5 & 32,1 & 31,4 & 30,7 & 29,5 & 29,0 \\
\hline 950 & 33,9 & 32,5 & 32,5 & 31,9 & 31,6 & 29,9
\end{tabular}

Observando os dados da tabela 2 verifica-se que quanto maior a quantidade de pares de depósitos alternados de material modificador menor a intensificação do sinal de corrente. Isto ocorre devido à falta de permeabilidade quando se aumenta a espessura do filme modificador [37]. Este fato pode ser melhor visualizado na figura 31, que é a representação gráfica destes dados, ou seja intensidade de corrente versus a quantidade de depósitos alternados. 


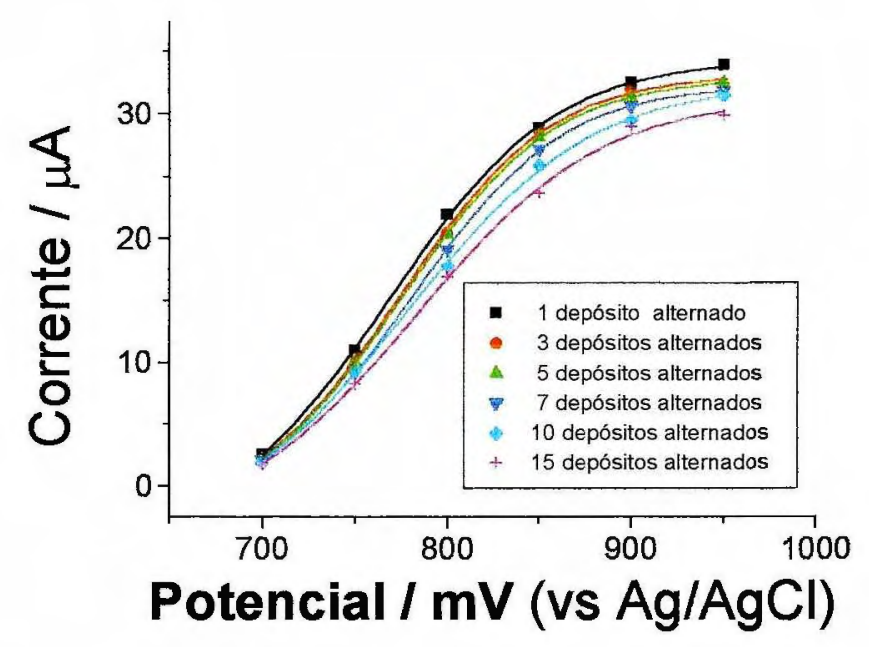

Figura 31 - Gráfico que apresenta as curvas de intensidade de corrente em função da quantidade de pares de depósitos alternados de Co-TRP/Zn-TPPS em eletrodo de carbono vítreo conforme dados obtidos da tabela 2.

Observando os resultados obtidos até o momento e sabendo que o objetivo principal deste trabalho é quantificar nitrato e nitrito com detector amperométrico em fluxo, resolveu-se escolher o potencial de $750 \mathrm{mV}$ nos demais experimentos em fluxo. Embora perceba-se pela figura 30 que a intensidade de corrente limite $\left(\mathrm{I}_{\mathrm{L}}\right)$ apresenta-se em $950 \mathrm{mV}$, ao trabalhar em $750 \mathrm{mV}$ o $\Delta \mathrm{I}$, entre o eletrodo polido e o eletrodo modificado com pares de depósitos alternados de Co-TRP/Zn-TPPS é maior.

Ensaios foram realizados em eletrodo de carbono vítreo polido e em eletrodo de carbono vítreo modificado com 1 par de depósito alternado de Co-TRP/Zn-TPPS em fluxo, injetando sucessivamente solução tampão acetato de sódio/ácido acético $0,1 \mathrm{~mol} / \mathrm{L}$ contendo perclorato de sódio $0,2 \mathrm{~mol} / \mathrm{L}$ e $1 \mathrm{mmol} / \mathrm{L}$ de $\mathrm{NO}_{2}^{-}$. Os resultados podem ser observados na figura 32, onde percebe-se que em fluxo o sinal de corrente intensifica-se sensivelmente quando comparam-se os resultados obtidos utilizando eletrodo modificado com aqueles obtidos utilizando eletrodo polido.

O sinal de corrente obtido, quando injeta-se solução tampão contendo nitrito em eletrodo modificado com 1 par de depósito alternado de Co-TRP/Zn-TPPS, é 
aproximadamente 13,5 vezes maior do que aquele observado nas mesmas condições utilizando eletrodo polido.

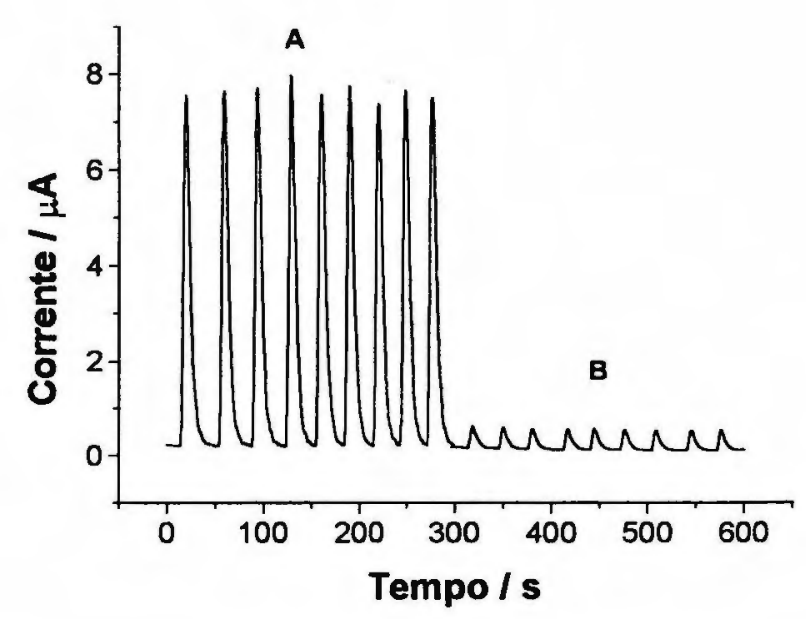

Figura 32 - Injeções sucessivas de solução tampão $\mathrm{pH} 4,7$ contendo 1 $\mathrm{mmol} / \mathrm{L}$ de $\mathrm{NO}_{2}^{-}$, utilizando como solução carregadora tampão acetato/ácido acético $0,1 \mathrm{~mol} / \mathrm{L}(\mathrm{pH}=4,7)$ contendo $0,2 \mathrm{~mol} / \mathrm{L}$ de $\mathrm{NaClO}_{4}$, e aplicando 750 $\mathrm{mV}$ no (A) eletrodo de carbono vitreo modificado com 1 par de depósito alternado de Co-TRP/Zn-TPPS e no (B) eletrodo polido.

\subsubsection{Homogeneidade e Permeabilidade do filme Co-TRP/Zn-TPPS}

Para verificar a permeabilidade e homogeneidade do filme foram realizados ensaios com outras espécies redox reversíveis, como por exemplo $\left[\mathrm{Ru}\left(\mathrm{NH}_{3}\right)_{6}\right]^{3+}$. No eletrodo de carbono vítreo polido, a onda redox reversível pode ser observada em - 0,2 V, contudo quando o eletrodo de carbono vítreo foi modificado com um depósito alternado de Co-TRP/Zn-TPPS, a resposta voltamétrica aproxima-se da linha de base. Para eletrodos de carbono vítreo modificado com filmes mais espessos, não foi possível observar a deteç̧ão de sinal associado com o complexo de rutênio. Estes resultados estão em concordância com os resultados previstos no 
trabalho de eletrodos modificados com Ni-TRP, onde o arranjo compacto das moléculas pode ser evocado para explicar a falta de permeabilidade [56].

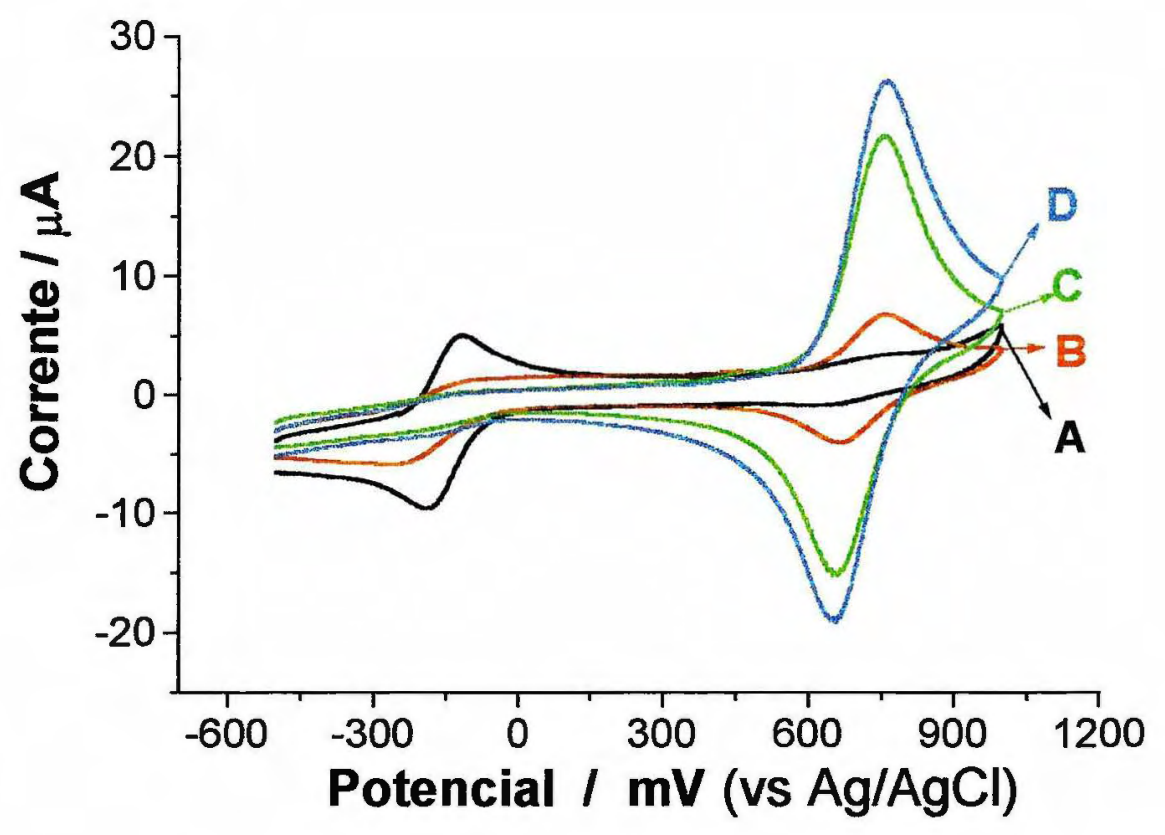

Figura 33 - Estudo da permeabilidade do filme utilizando-se eletrodo modificado com 1(B), 3(C) e 5(D) pares de depósitos alternados de CoTRP/Zn-TPPS. Voltamogramas registrados em solução tampão acetato de sódio/ácido acético $(\mathrm{pH} \mathrm{4,7)} 0,1 \mathrm{~mol} / \mathrm{L}$ contendo perclorato de sódio 0,2 $\mathrm{mol} / \mathrm{L}$ e $\mathrm{Ru}\left(\mathrm{NH}_{3}\right)_{6} \mathrm{Cl}_{3} 20 \mathrm{mmol} / \mathrm{L}$. Em (A) apresenta-se o voltamograma obtido com eletrodo polido.

Com o aumento do número de pares de depósitos alternados de Co-TRP/ZnTPPS sobre a superfície do eletrodo de carbono vítreo foi possível avaliar a influência da espessura do filme no processo anódico relativo à oxidação do nitrito. 
Realizaram-se ensaios voltamétricos alterando a velocidade de varredura e em três diferentes concentrações do substrato; os voltamogramas cíclicos resultantes podem ser observados na figura 34 .
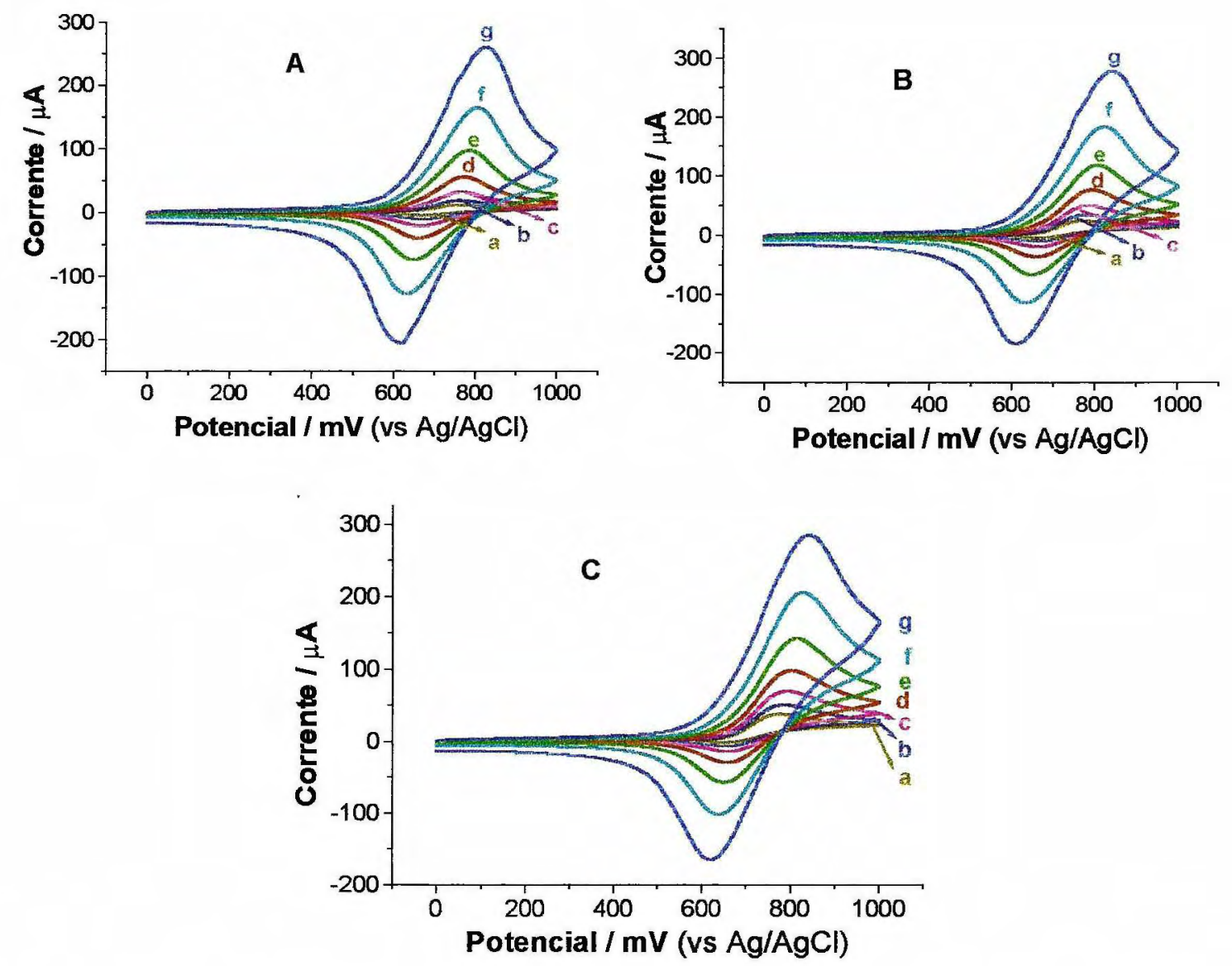

Figura 34 - Voltamogramas cíclicos alterando a velocidade de varredura (a) 12,5; (b) 25; (c) 50; (d) 100; (e) 200; (f) 400 e (g) $800 \mathrm{mV} / \mathrm{s}$ em solução tampão acetato de sódio/ácido acético $0,1 \mathrm{~mol} / \mathrm{L}$ contendo perclorato de sódio $0,2 \mathrm{~mol} / \mathrm{L}$ e $1 \mathrm{mmol} / \mathrm{L}$ de nitrito. Eletrodo de carbono vítreo modificado com (A) 1, (B) 3 e (C) 5 pares de depósitos alternados de CoTRP/Zn-TPPS.

Com os dados da figura 34 foi possível apresentar a tabela 3 e os valores de $\mathrm{E}_{\mathrm{pa}}-\mathrm{E}_{\mathrm{pc}}$ observados nesta tabela demonstram um aumento sistemático tanto quando 
aumenta-se a velocidade de varredura como quando aumenta-se a espessura do filme. Estes resultados sugerem que filmes mais espessos são menos permeáveis.

Tabela 3 - Potencial de pico da onda anódica $\left(\mathrm{E}_{\mathrm{pa}}\right)$ e Potencial de pico da onda catódica $\left(\mathrm{E}_{\mathrm{pc}}\right)$ obtidos da figura 34, bem como o $\Delta \mathrm{E}_{\mathrm{p}}$ ( diferença entre o $\mathrm{E}_{\mathrm{pa}}$ e o $\mathrm{E}_{\mathrm{pc}}$ ).

Espessura do Velocidade de

Filme ( $\mathbf{N}^{\mathbf{0}}$ de $\quad$ Varredura/ $\quad \mathbf{E}_{\mathbf{p a}} / \mathbf{m V} \quad \mathbf{E}_{\mathbf{p c}} / \mathbf{m V} \quad \Delta \mathbf{E}_{\mathbf{p}} / \mathbf{m V}$

Depósitos $\mathrm{mV} / \mathrm{s}$

Alternados)

\begin{tabular}{ccccc}
\hline 1 & 12.5 & 736 & 668 & 68 \\
25.0 & 744 & 664 & 80 \\
50.0 & 750 & 662 & 88 \\
100.0 & 758 & 660 & 98 \\
200.0 & 762 & 658 & 104 \\
& 400.0 & 774 & 656 & 118 \\
& 800.0 & 782 & 654 & 128 \\
\hline 3 & 12.5 & 742 & 668 & 74 \\
& 25.0 & 748 & 662 & 86 \\
& 50.0 & 754 & 658 & 96 \\
& 100.0 & 762 & 652 & 110 \\
& 200.0 & 766 & 646 & 120 \\
& 400.0 & 776 & 642 & 134 \\
& 800.0 & 786 & 640 & 146 \\
\hline 5 & 12.5 & 746 & 666 & 80 \\
& 25.0 & 752 & 656 & 96 \\
& 50.0 & 760 & 650 & 110 \\
& 100.0 & 766 & 646 & 118 \\
& 200.0 & 772 & 644 & 128 \\
& 400.0 & 778 & 642 & 136 \\
& 800.0 & 794 & 638 & 156 \\
\hline
\end{tabular}

\subsubsection{Envenenamento da Superficie do Eletrodo de Carbono Vitreo}

Uma das principais desvantagens em utilizar-se eletrodo de carbono vítreo nos ensaios de quantificação de nitrito, além de se trabalhar em potencial positivo relativamente alto( $1 \mathrm{~V})$, é o envenenamento da superfície. Tal fato pode ser 
constatado observando-se os voltamogramas consecutivos apresentados na figura 35. Isto se deve possivelmente à adsorção de algum produto da oxidação do nitrito com conseqüente bloqueio da superfície eletródica [27-35].

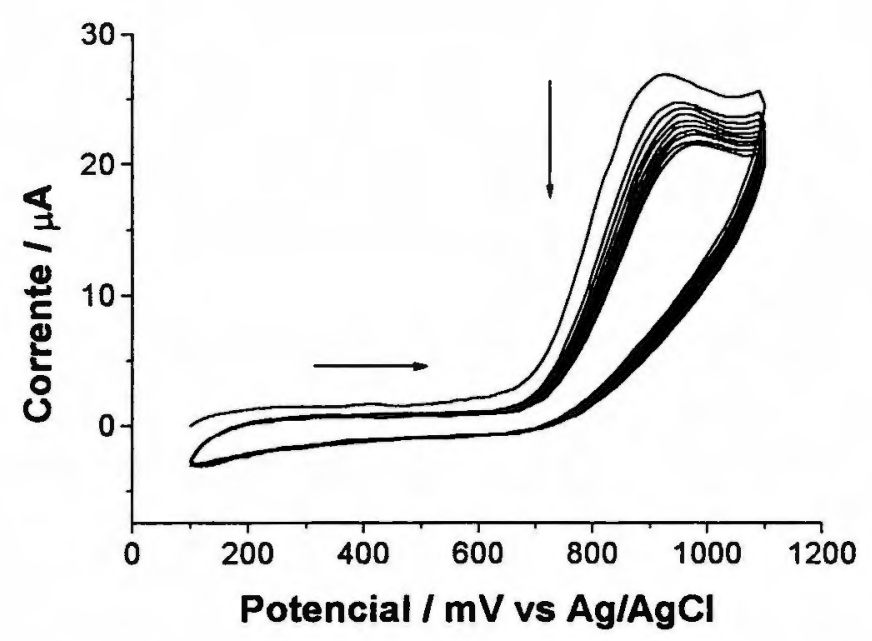

Figura 35 - Voltamogramas cíclicos sucessivos obtidos com eletrodo de carbono vítreo imerso em solução $1 \mathrm{mmol} / \mathrm{L}$ de nitrito em tampão acetato de sódio/ácido acético $0,1 \mathrm{~mol} / \mathrm{L}(\mathrm{pH}=4,7)$ contendo $0,2 \mathrm{~mol} / \mathrm{L}$ de $\mathrm{NaClO}_{4}$. Velocidade de varredura $=50 \mathrm{mV} / \mathrm{s}$.

Os resultados obtidos amperometricamente com eletrodo de carbono vítreo polido (figura 36) também corroboram as conclusões acima, pois percebe-se um decréscimo constante do sinal obtido. Este fato não ocorre quando se analisa os resultados obtidos com o eletrodo de carbono vítreo modificado com 1 par de depósito alternado de Co-TRP/Zn-TPPS(figura 32A), não havendo tendência de perda de sinal. 


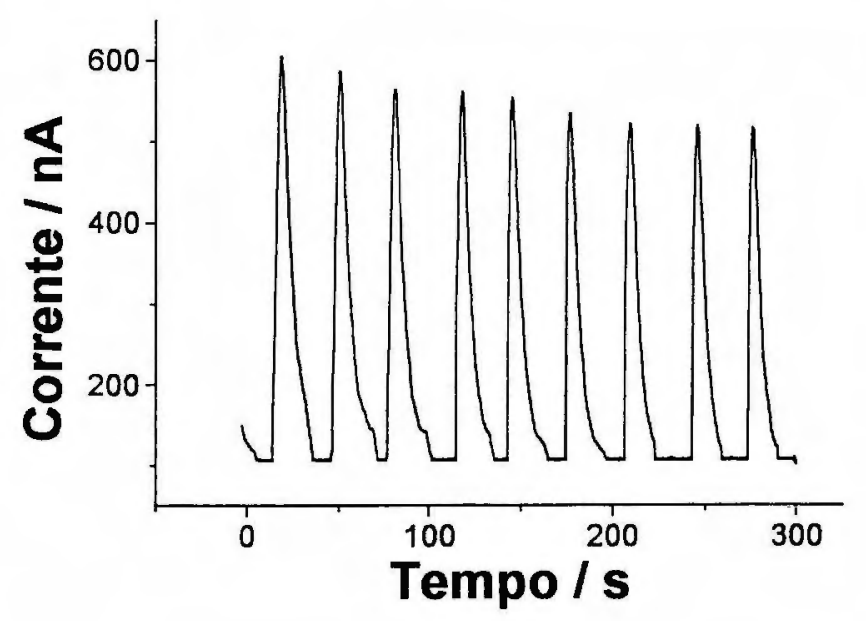

Figura 36 - Injeções sucessivas de solução $1 \mathrm{mmol} / \mathrm{L}$ de nitrito em tampão acetato de sódio/ácido acético $0,1 \mathrm{~mol} / \mathrm{L}(\mathrm{pH}=4,7)$ contendo $0,2 \mathrm{~mol} / \mathrm{L}$ de perclorato de sódio, aplicando potencial de $750 \mathrm{mV}$ (eletrodo de carbono vítreo polido).

\subsubsection{Quantidade de Agente Modificador}

O excesso superficial $(\Gamma)$ é dado por:

$$
\Gamma=\mathrm{Q} / \mathrm{nFA}
$$

onde: $\mathrm{Q}$ é a carga envolvida no processo anódico, $\mathrm{n}$ é o número de elétrons envolvido no processo, $\mathrm{F}$ é a constante de Faraday e A é a área superficial do eletrodo [74].

O valor de $Q$ foi obtido pela integração da onda anódica registrada do filme conforme pode ser observado na figura 37. 


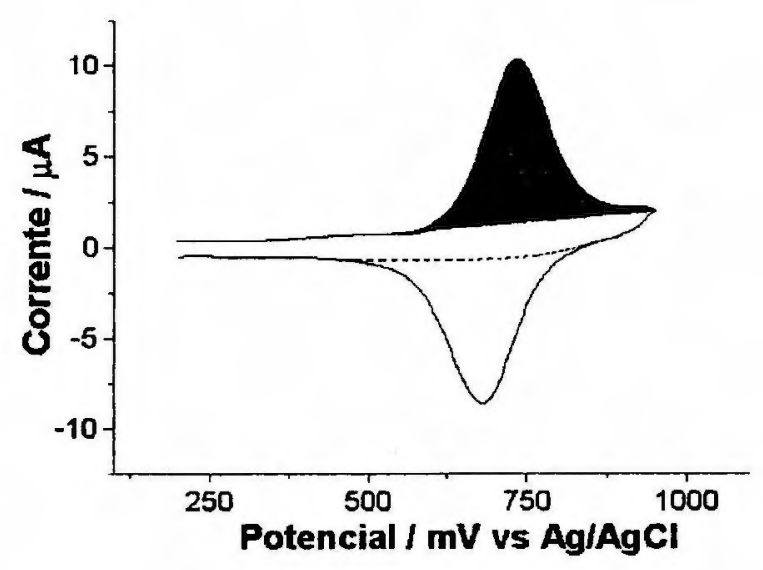

Figura 37 - Voltamograma cíclico com eletrodo modificado com 1 par de depósito alternado de Co-TRP/Zn-TPPS, em solução tampão acetato de sódio/ácido acético $0,1 \mathrm{~mol} / \mathrm{L}(\mathrm{pH} 4,7)$ contendo $\mathrm{NaClO}_{4} \quad 0,2 \mathrm{~mol} / \mathrm{L}$. Componente anódico, enegrecido é a área integrada para cálculo da carga (Q).

A quantidade de agente modificador que recobre a superficie do eletrodo modificado foi avaliada medindo-se a carga referente ao componente anódico em voltamograma registrado em eletrólito suporte. Considerando o número de elétrons envolvidos no processo catalítico $(\mathrm{n}=4)$, visto que existem 4 grupos $\left[\mathrm{Ru}^{\mathrm{III} / \mathrm{II}}(\mathrm{bipy})_{2} \mathrm{Cl}\right]$ na estrutura da Co-TRP [27], conforme pode ser observado na figura 12, e resultado estimado (para um par de depósito alternado) foi $\Gamma=3,5 \times 10^{-9} \mathrm{~mol} / \mathrm{cm}^{2}$.

\subsubsection{Estabilidade do eletrodo modificado}

Para verificar a estabilidade do eletrodo modificado com Co-TRP/Zn-TPPS foram realizados voltamogramas cíclicos em diferentes dias - pelo período aproximado de 30 dias - utilizando o eletrodo para ensaios rotineiros, em solução tampão de acetato de sódio/ácido acético $0,1 \mathrm{~mol} / \mathrm{L}(\mathrm{pH} 4,7)$ contendo $\mathrm{NaClO}_{4} \quad 0,2$ $\mathrm{mol} / \mathrm{L}$ (figura 38). Não houve acondicionamento especial para o eletrodo e este ficou exposto ao ar durante o período em que não foi utilizado. 


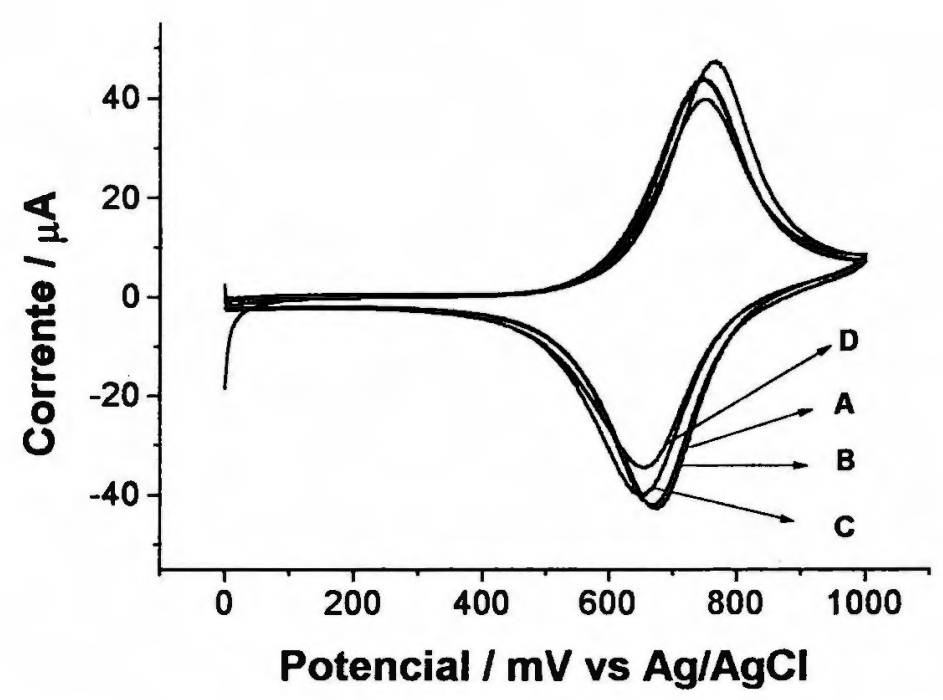

Figura 38 - Voltamogramas cíclicos obtidos em solução tampão acetato de sódio/ácido acético $0,1 \mathrm{~mol} / \mathrm{L}$ contendo perclorato de sódio $0,02 \mathrm{~mol} / \mathrm{L}$ nas seguintes datas : (A) 11/05/00, (B) $18 / 05 / 00$, (C) $20 / 05 / 00$ e (D) $06 / 06 / 00$. Durante este período que não foi utilizado o eletrodo ficou exposto ao ar.

A estabilidade para este tipo de eletrodo é excelente visto que após 10 dias, ou seja, aproximadamente 40 horas de uso em ensaios rotineiros, a perda de sinal de corrente foi de apenas $7 \%$. Após 30 dias, ou seja aproximadamente 90 horas, a perda de sinal de corrente não passou de $15,2 \%$.

\subsubsection{Estudo do processo de transferência de elétrons no eletrodo}

\section{modificado}

Para este estudo, foi realizado um ensaio cronoamperométrico utilizando eletrodo de carbono vítreo modificado com 1 par de depósito alternado de CoTRP/Zn-TPPS em solução tampão acetato de sódio/ácido acético $(\mathrm{pH}=4,7)$ contendo $0,2 \mathrm{~mol} / \mathrm{L}$ de $\mathrm{NaClO}_{4}$. O resultado obtido é apresentado na figura 39A. Segundo a equação de Cottrell, gráficos de I vs. $t^{1 / 2}$, devem consistir em uma reta [75] quando o processo de eletrodo é governado por difusão, ou seja todo o material que chega à superfície do eletrodo é prontamente oxidado ou reduzido em extensão 
determinada pelas premissas da equação de Nernst. Este comportamento é observado, para tempos relativamente curtos, de acordo com a figura 39B.
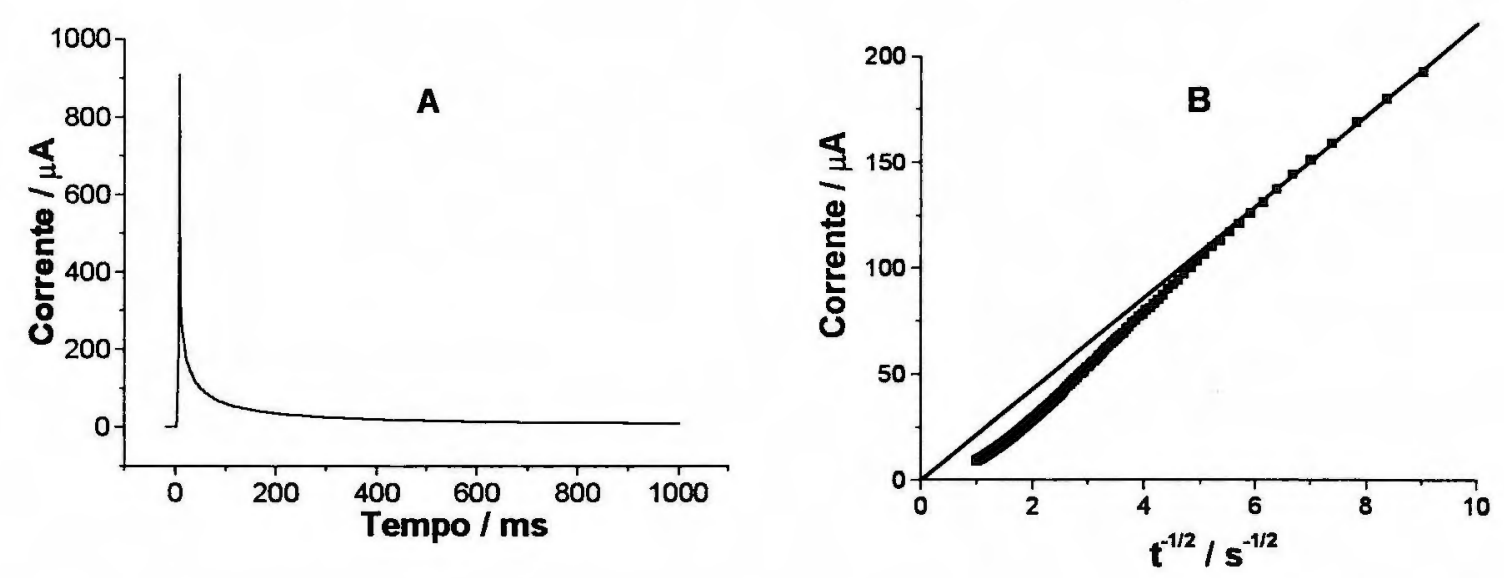

Figura 39 - (A) Cronoamperograma realizado em sol. tampão acetato de sódio/ácido acético $0,1 \mathrm{~mol} / \mathrm{L}$ contendo $0,2 \mathrm{~mol} / \mathrm{L}$ de $\mathrm{NaClO}_{4}$ com eletrodo de carbono vítreo modificado com 1 par de depósito alternado de CoTRP/Zn-TPPS. (B) Análise dos dados da figura 39A, I vs $\mathrm{t}^{-1 / 2}$.

Para corroborar com os dados anteriores e sendo o processo de redução eletroquímica do $\mathrm{Fe}(\mathrm{CN})_{6}^{+4}$ reversível - além de bem conhecido na literatura foram realizados ensaios em diferentes velocidades de rotação com o eletrodo rotativo de platina modificado com 1 par de depósito alternado de Co-TRP/ZnTPPS. Os ensaios foram realizados em solução tampão acetato de sódio/ácido acético ( $\mathrm{pH} 4,7)$ contendo $0,2 \mathrm{~mol} / \mathrm{L}$ de $\mathrm{NaClO}_{4}$ com 5 diferentes concentrações finais de ferrocianeto de sódio. Podem ser observados nos voltamogramas cíclicos da figura 40 os resultados obtidos para concentrações de ferricianeto de sódio $0,1(\mathrm{~A}) ; 0,5(\mathrm{~B}) ; 1(\mathrm{C}) ; 5(\mathrm{D})$ e $10(\mathrm{E}) \mathrm{mmol} / \mathrm{L}$. 

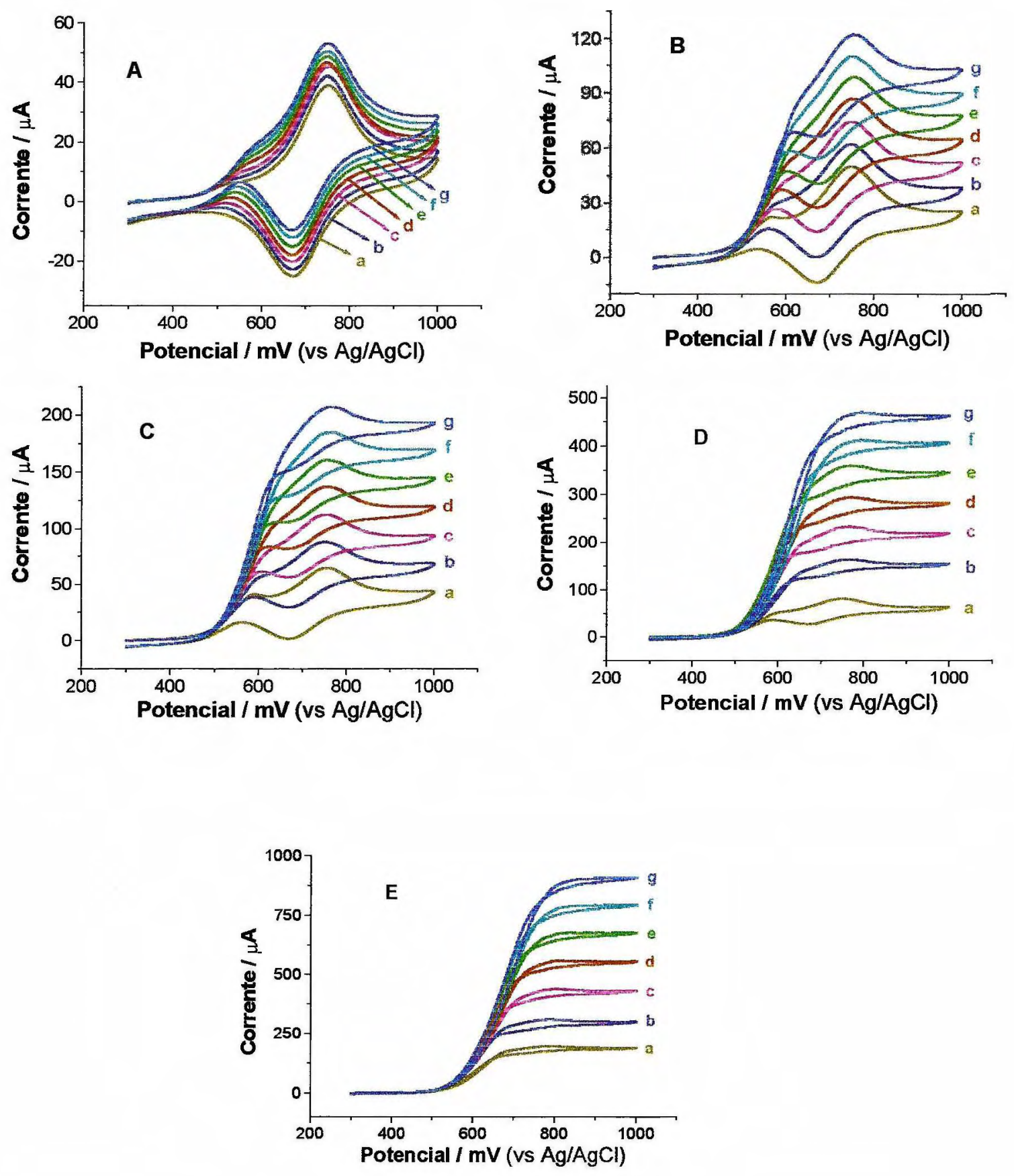

Figura 40 -Voltamogramas cíclicos obtidos com velocidades de rotação (a) 100, (b) 400, (c) 900, (d) 1600, (e) 2500, (f) 3600 e (g) $4900 \mathrm{rpm}$ em (A) sol. tampão acetato de sódio/ácido acético $(\mathrm{pH} 4,7)$ contendo $0,2 \mathrm{~mol} / \mathrm{L}$ de $\mathrm{NaClO}_{4}$ com concentração final de $\mathrm{Na}_{4}\left[\mathrm{Fe}(\mathrm{CN})_{6}\right]$ (A) 0,1 , (B) 0,5 , (C) 1 , (D) $5 \mathrm{e} \mathrm{(E)} 10 \mathrm{mmol} / \mathrm{L}$. V $=50 \mathrm{mV} / \mathrm{s}$. 
Representando os dados obtidos nos voltamogramas cíclicos da figura 40 no gráfico de I versus $\omega^{1 / 2}$ demonstrado na figura 41 para as diferentes concentrações de $\mathrm{Na}_{4}\left[\mathrm{Fe}(\mathrm{CN})_{6}\right]$, obtém-se retas que confirmam que, em uma faixa ampla de concentração (100 vezes), este íon continua apresentando cinética de reação rápida mesmo com o eletrodo de platina rotativo modificado com um par de depósito alternado de Co-TRP/Zn-TPPS.

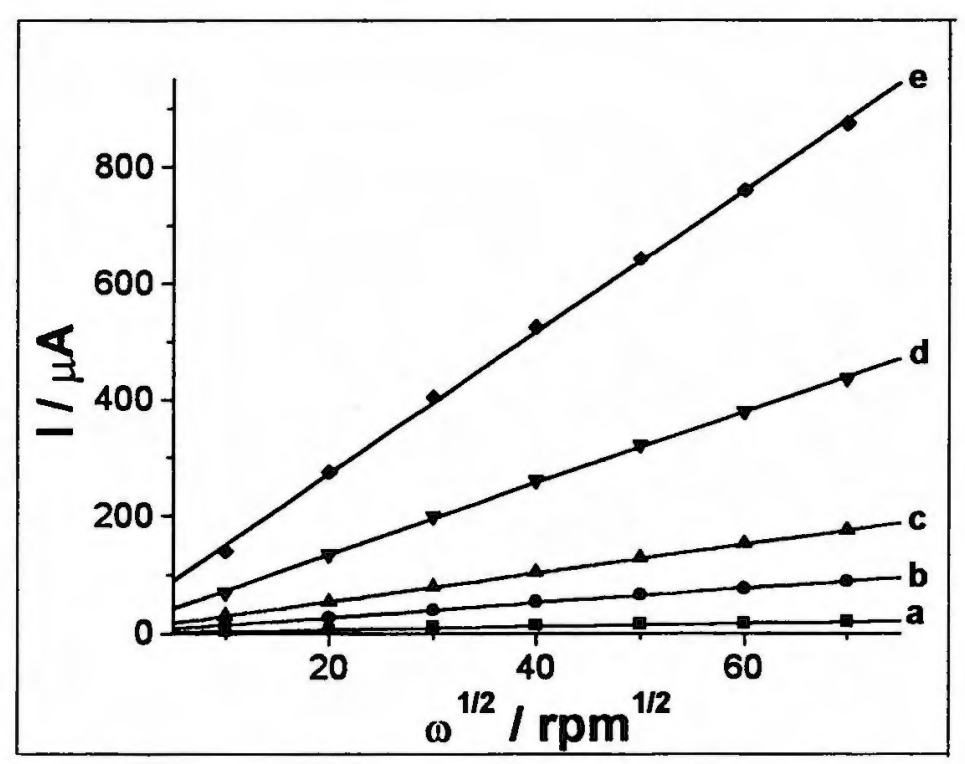

Figura 41 - Gráfico de I vs. $\omega^{1 / 2}$ obtido através de dados da figura 40 , sendo que as retas verificadas são referentes as diferentes concentrações de $\mathrm{Na}_{4}\left[\mathrm{Fe}(\mathrm{CN})_{6}\right]$, (a) 0,1 ; (b) 0,5 ; (c) 1 ; (d) 5 e (e) $10 \mathrm{mmol} / \mathrm{L}$.

Experimentos similares foram realizados empregando-se nitrito como substrato e os resultados podem ser observados na figura 42. 

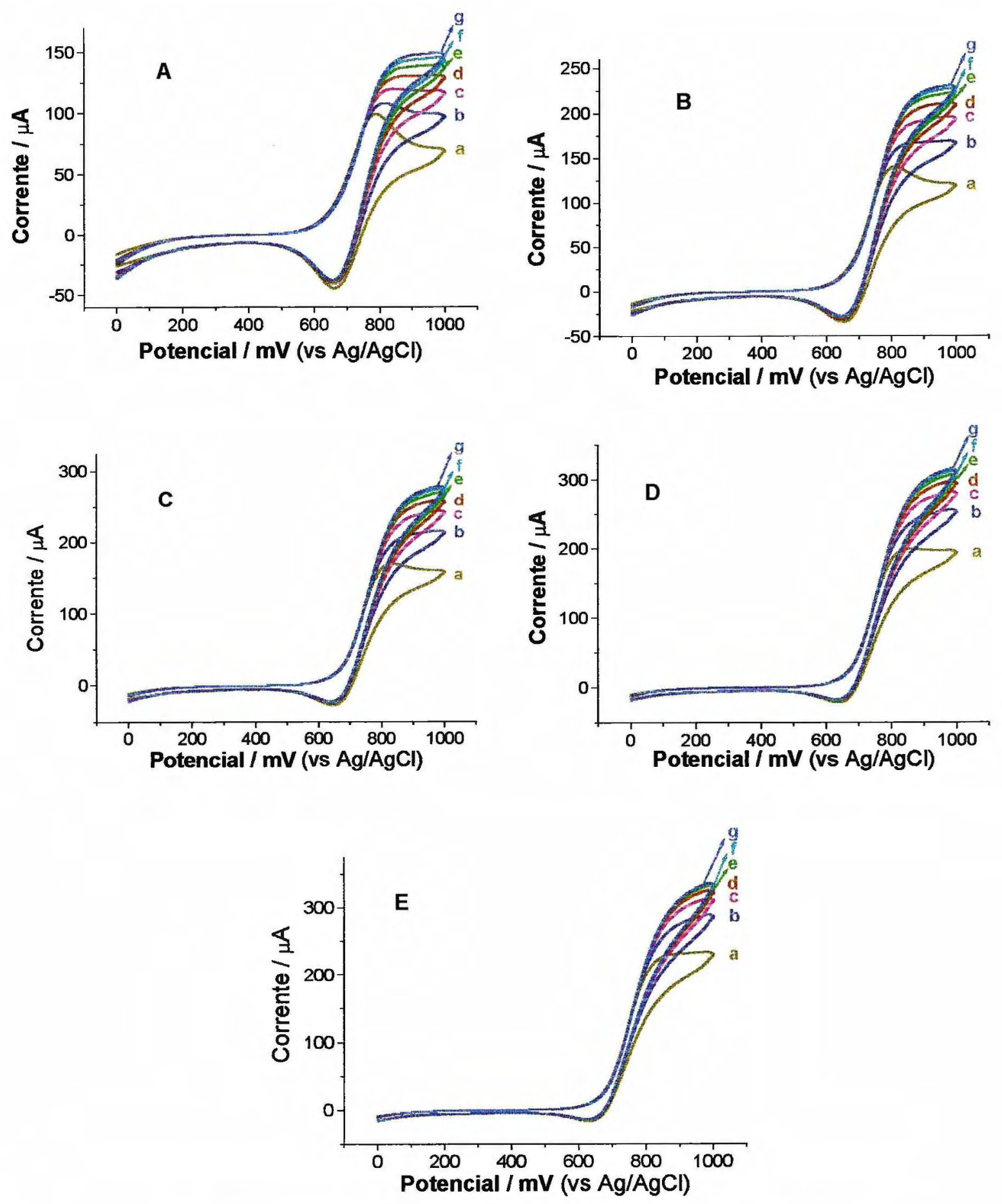

Figura 42 -Voltamogramas cíclicos obtidos com velocidades de rotação (a) 100, (b) 400, (c) 900, (d) 1600, (e) 2500, (f) 3600 e (g) 4900 rpm em (A) sol. tampão acetato de sódio/ácido acético $(\mathrm{pH} \mathrm{4,7)}$ contendo $0,2 \mathrm{~mol} / \mathrm{L}$ de $\mathrm{NaClO}_{4}$ com concentração final de $\mathrm{NaNO}_{2}$ (A) 1, (B) 2 , (C) 3 , (D) 4 e (E) 5 $\mathrm{mmol} / \mathrm{L} . \mathrm{V}=50 \mathrm{mV} / \mathrm{s}$. 


\section{4 - RESULTADOS E DISCUSSÃO - 59}

Para avaliar a cinética do processo de oxidação do nitrito no eletrodo modificado foram representados os gráficos de I vs. $\omega^{1 / 2}$ (Levich) e o gráfico $\mathrm{I}^{-1}$ versus $\omega^{-1 / 2}$ (Koutecky - Levich) [74] com dados obtidos a partir dos voltamogramas mostrados na figura 42 . Os resultados podem ser observados na figura 43 , onde percebe-se que o transporte de massa não é o fator que governa o processo global de eletrodo.
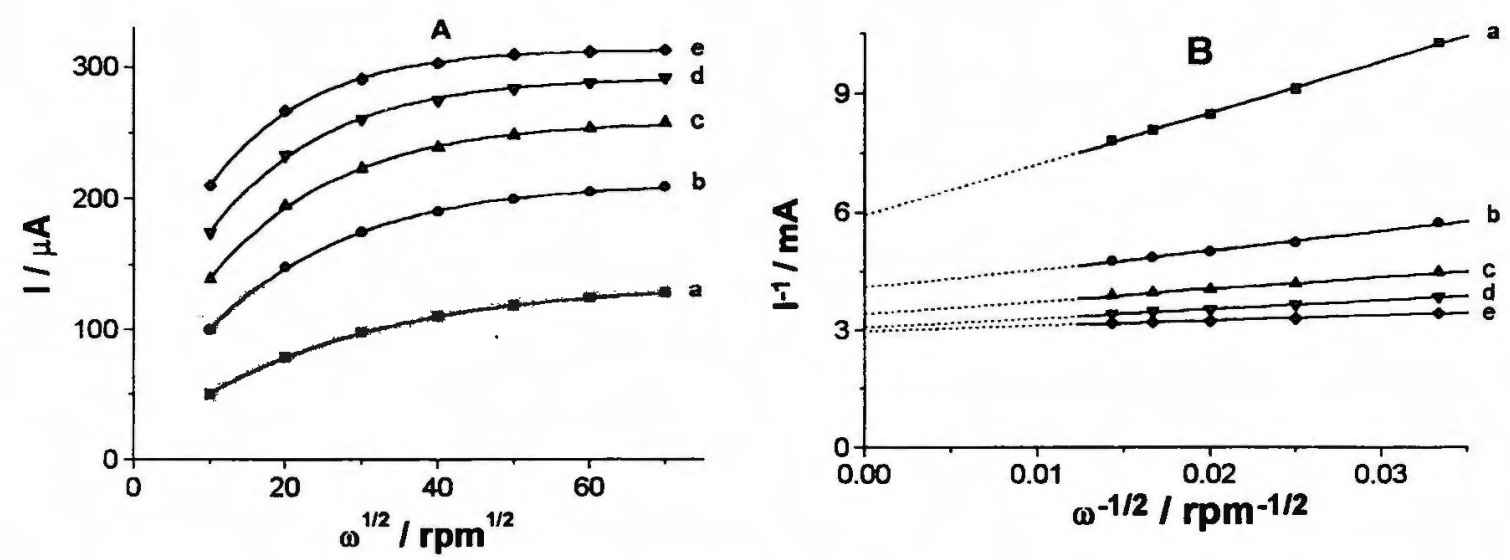

Figura 43 - Gráficos obtidos a partir de dados do voltamograma cíclico da figura 42. Tanto para (A) como para (B), as concentrações de $\mathrm{NaNO}_{2}$ são (a) 1 , (b) 2 , (c) 3 , (d) 4 e (e) $5 \mathrm{mmol} / \mathrm{L}$ em solução tampão acetato/ácido acético $0,1 \mathrm{~mol} / \mathrm{L}(\mathrm{pH} 4,7)$ contendo $\mathrm{NaClO}_{4} 0,2 \mathrm{~mol} / \mathrm{L}$.

Observa-se pelos resultados apresentados nos voltamogramas da figura 40 bem como no gráfico de I vs $\omega^{1 / 2}$ (Levich) que é apresentado na figura 41 que a oxidação do $\left[\mathrm{Fe}(\mathrm{CN})_{6}\right]^{4}$ é controlada predominantemente pela difusão do substrato em solução. Já no caso do $\mathrm{NO}_{2}^{-}$os resultados observados nos voltamogramas cíclicos da figura 42 bem como através do gráfico de I vs $\omega^{1 / 2}$ (Levich) da figura 43A e do gráfico de $\mathrm{I}^{-1}$ vs $\omega^{-1 / 2}$ (Koutecky - Levich) da figura 43B indicam a existência de um componente cinético que limita o processo global de eletrodo 
4 - RESULTADOS E DISCUSSÃO - 60

envolvendo a transferência de elétrons. Este componente cinético pode ser a transferência de carga dos elétrons entre os complexos de rutênio, ou pela difusão do íon através do filme, ou ainda pela transferência de elétrons do nitrito para o complexo de rutênio existente no filme.

4.4. Determinação da Constante de Velocidade Referente à Oxidação do $\mathrm{NO}_{2}^{-}$no Eletrodo Modificado

Com o auxílio da equação de Koutecky - Levich (equação 4) é possível determinar o valor da constante de velocidade à oxidação do $\mathrm{NO}_{2}^{-}$no eletrodo modificado.

$$
\left(\mathrm{I}_{\mathrm{L}}\right)^{-1}=(\mathrm{nFAk} \Gamma \mathrm{C})^{-1}+\left(0,62 \mathrm{nFAD} \mathrm{D}^{2 / 3} v^{-1 / 6} \mathrm{C}^{1 / 2}\right)^{-1}
$$

Verifica-se nesta equação que o coeficiente linear (a) é igual a (nFAkГC) ${ }^{-1}$. Conseqüentemente a constante de velocidade para a reação eletrocatalítica $(k)$ pode ser estimada através do coeficiente angular do gráfico de "a"(coeficientes lineares obtidos da figura 43B) vs. 1/C (figura 44).

$$
\mathrm{a}=(\mathrm{nFAk} \Gamma \mathrm{C})^{-1}
$$




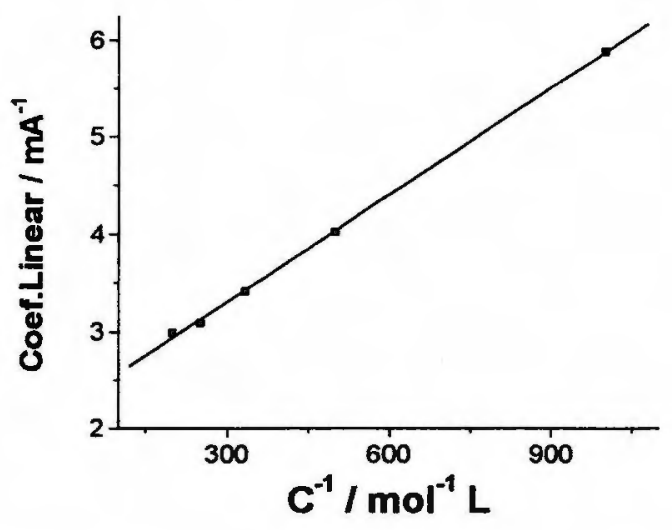

Figura 44 - Gráfico de coeficiente linear vs. $C^{-1}$, sendo que os coeficientes lineares foram obtidos através da regressão linear da figura 43B.

Com base nos valores do coeficiente linear da figura 43B e através da equação de Koutecky-Levich (Equação 4), foi possível determinar para $\mathrm{k} o$ valor de $3,4 \times 10^{3} \mathrm{~mol}^{-1} \mathrm{~s}^{-1} \mathrm{~L}$.

\subsection{Coeficiente de Difusão do $\mathrm{NO}_{2}^{-}$}

Com os coeficientes angulares (b) obtidos da figura 43B e da equação 4 , foi possível determinar $o$ valor do coeficiente de difusão (D) igual a $(1,1 \pm 0,5) \times 10^{-5} \mathrm{~cm}^{2} \mathrm{~s}^{-1}$, que apresenta a mesma ordem de grandeza observada na literatura que é igual a $1,33 \times 10^{-5} \mathrm{~cm}^{2} \mathrm{~s}^{-1}[76]$.

Com a equação de Koutecky - Levich (equação 4) sabe-se que:

$$
b=\left(0,62 n F A D^{2 / 3} v^{-1 / 6} \mathrm{C}^{1 / 2}\right)^{-1}
$$

Portanto:

$$
\mathrm{D}=\left(0,62 \text { n F A b C } v^{-1 / 6}\right)^{-3 / 2}
$$




\subsection{Ensaios Quantitativos}

\subsubsection{Determinação de Nitrito em Tampão pH 4,7}

Os primeiros ensaios quantitativos para determinação de nitrito foram realizados de acordo com o esquema apresentado na figura 15 deste trabalho, que é similar àquele apresentado por Azevedo et al [38].

Aplicou-se ao eletrodo de carbono vítreo modificado com 1 par de depósito alternado de Co-TRP/Zn-TPPS vs. eletrodo de $\mathrm{Ag} / \mathrm{AgCl}$ o potencial de $750 \mathrm{mV}$.

Ao fluxo carregador foram realizadas injeções sucessivas de solução tampão pH 4,7 contendo perclorato de sódio $0,2 \mathrm{~mol} / \mathrm{L}$ e $1,3,5,7$ e $9 \mu \mathrm{mol} / \mathrm{L}$ de $\mathrm{NO}_{2}{ }^{-}$e a resposta amperométrica pode ser observada na figura 45 .

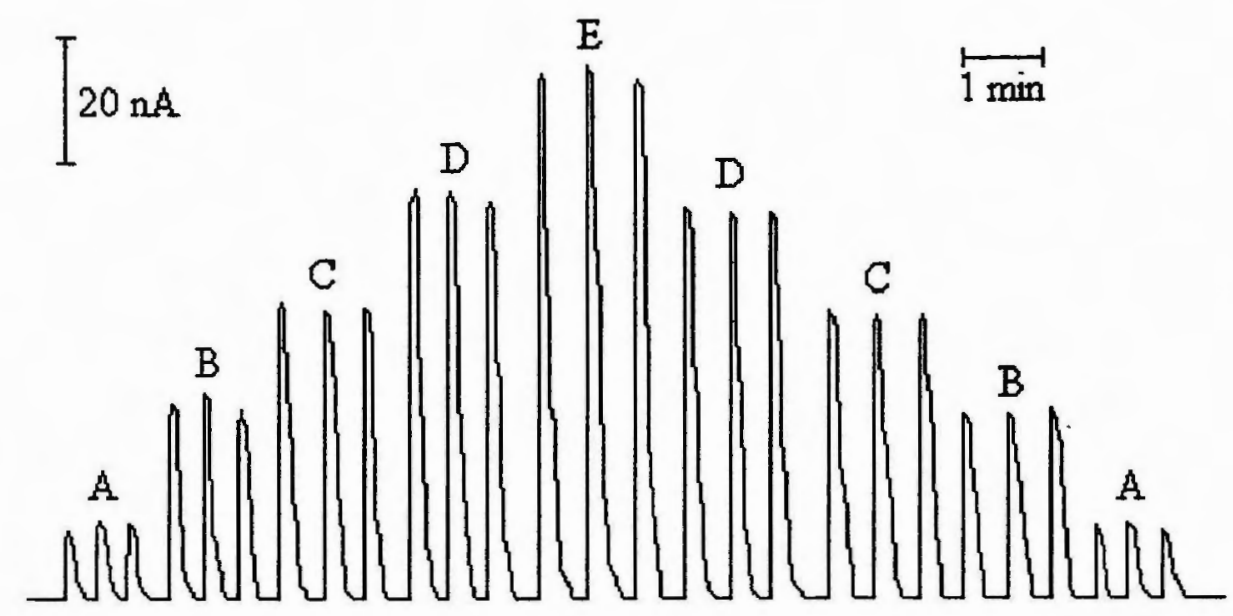

Figura 45 - Resposta amperométrica em fluxo. Utilizando eletrodo de carbono vítreo modificado com 1 par de depósito alternado de Co-TRP/ZnTPPS, no $\mathrm{E}=0,75 \mathrm{~V}$ vs. $\mathrm{Ag} / \mathrm{AgCl}$, com injeções consecutivas de (A) 1; (B) 3; (C) 5 ; (D) 7 e (E) $9 \mu \mathrm{mol} / \mathrm{L}$ de $\mathrm{NO}_{2}{ }^{-}$. Solução tampão acetato de sódio/ácido acético $0,1 \mathrm{~mol} / \mathrm{L}$ contendo $\mathrm{NaClO}_{4} 0,2 \mathrm{~mol} / \mathrm{L}$. Vazão do fluxo carregador $=2,4 \mathrm{~cm}^{-3} / \mathrm{min}$. Volume da amostra $=130 \mu \mathrm{L}$.

Dos resultados amperométricos obtidos foi possível traçar a curva analítica que está registrada na figura 46 , onde percebe-se que a linearidade da curva é muito boa. 


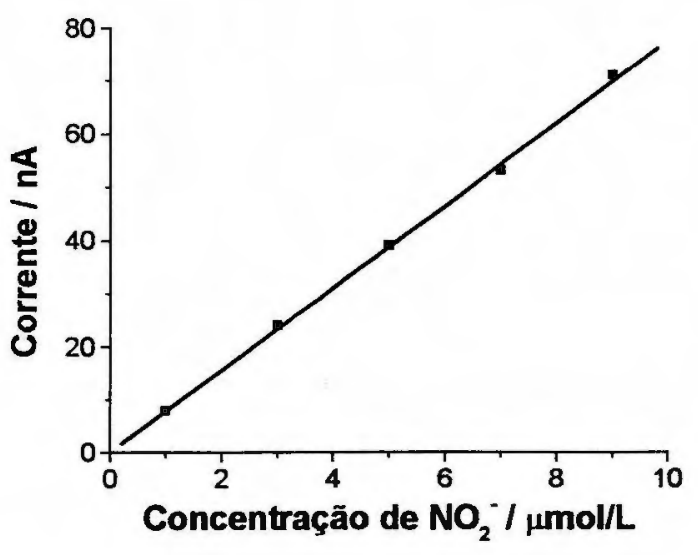

Figura 46 - Curva analítica para nitrito obtida com dados da figura 45.

Em sistema FIA foi possível determinar o limite de detecção de $1,4 \mu \mathrm{g} / \mathrm{L}$ de nitrito expressos em nitrogênio, ou seja $0,2 \mu \mathrm{mol} / \mathrm{L}$ de $\mathrm{NO}_{2}^{-}$. Verificou-se a repetibilidade do método (figura 47) utilizando a mesma solução carregadora à qual foram feitas injeções de solução $5 \mu \mathrm{mol} / \mathrm{L}$ de nitrito. Através destes resultados foi possível calcular o desvio padrão de $1,3 \%$.

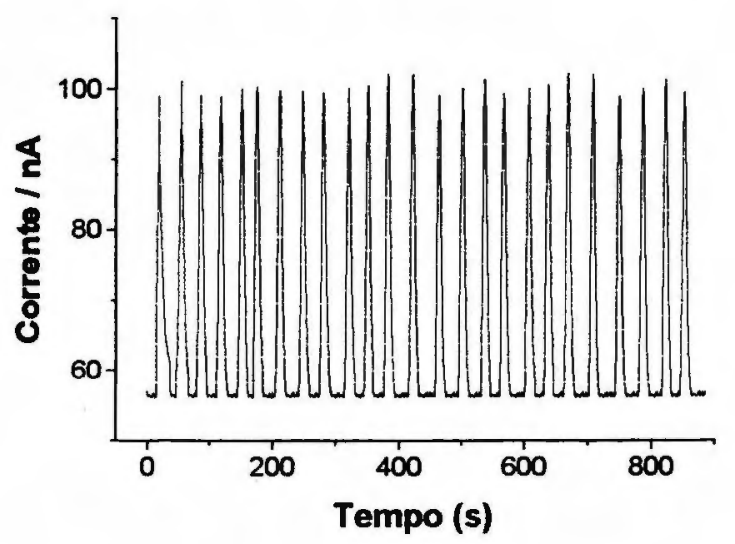

Figura 47 - Fiagramas obtidos para determinar a repetibilidade do método. Como eletrodo de trabalho foi usado carbono vítreo modificado com 1 par de depósito alternado de Co-TRP/Zn-TPPS, eletrodo auxiliar de aço inoxidável, eletrodo de referência $\mathrm{Ag} / \mathrm{AgCl}$ em solução tampão acetato de sódio/ácido acético $0,1 \mathrm{~mol} / \mathrm{L}\left(\mathrm{pH} \mathrm{4,7)}\right.$ contendo $\mathrm{NaClO}_{4} 0,2 \mathrm{~mol} / \mathrm{L}$ e $5 \mu \mathrm{mol} / \mathrm{L}$ de nitrito. $\mathrm{E}=0,75 \mathrm{~V}$. 


\subsubsection{Determinação de Nitrito e Nitrato em Tampão pH 9,1}

4 - RESULTADOS E DISCUSSÃo - 64

Existe limitação quando utiliza-se a coluna redutora de cádmio/cobre para a redução de nitrato a nitrito. Esta redução só é quantitativa se o meio for neutro ou ligeiramente básico para tanto pensou-se em utilizar como solução carregadora tampão cloreto de amônio/hidróxido de amônio $0,05 \mathrm{~mol} / \mathrm{L}(\mathrm{pH} 9,1)$ contendo perclorato de sódio $0,5 \mathrm{~mol} / \mathrm{L}$.

Foram realizados ensaios amperométricos em fluxo utilizando eletrodo de carbono vítreo modificado com 3 pares de depósitos alternados de Co-TRP/ZnTPPS polarizado em $+0,75 \mathrm{~V}$ vs. $\mathrm{Ag} / \mathrm{AgCl}$ e eletrodo de aço inoxidável. As injeções da solução tampão hidróxido de amônio/cloreto de amônio $0,05 \mathrm{~mol} / \mathrm{L}(\mathrm{pH} \mathrm{9,1)}$ contendo perclorato de sódio $0,5 \mathrm{~mol} / \mathrm{L}$ e $10,30,50,70$ e $90 \mu \mathrm{mol} / \mathrm{L}$ de $\mathrm{NO}_{2}{ }^{-}$, ao fluxo carregador apresentaram os fiagramas que são apresentados na figura 48. Já para nitrato foi utilizada a mesma solução tampão anterior contendo 10, 30, 50, 70 e $90 \mu \mathrm{mol} / \mathrm{L} \mathrm{de} \mathrm{NO}_{3}{ }^{-}$e os fiagramas podem ser observados na figura 48. Com os resultados obtidos das figuras 48 e 49 foi possível traçar a curva analítica para $\mathrm{NO}_{2}^{-}$ e a curva analítica para $\mathrm{NO}_{3}{ }^{-}$, os quais estão registradas nas figuras 50 e 51 .

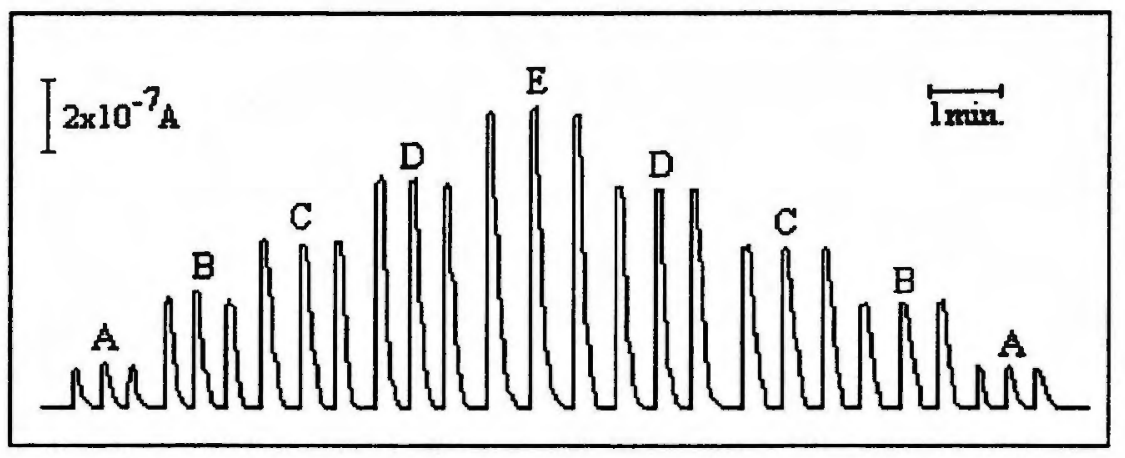

Figura 48 - Resposta amperométrica em fluxo utilizando coluna redutora de $\mathrm{Cd} / \mathrm{Cu}$ e eletrodo de carbono vítreo modificado com 3 pares de depósitos alternados de Co-TRP/Zn-TPPS, no $\mathrm{E}=0,75 \mathrm{~V}$ vs. $\mathrm{Ag} / \mathrm{AgCl}$, com injeções consecutivas de (A) 10 ; (B) 30 ; (C) 50 ; (D) 70 e (E) $90 \mu \mathrm{mol} / \mathrm{L}$ de $\mathrm{NO}_{2}^{-}$. Solução tampão $\mathrm{NH}_{4} \mathrm{Cl} / \mathrm{NH}_{4} \mathrm{OH} 0,05 \mathrm{~mol} / \mathrm{L}(\mathrm{pH} 9,1)$ contendo $\mathrm{NaClO}_{4} 0,5$ $\mathrm{mol} / \mathrm{L}$. Vazão do fluxo carregador $=2,4 \mathrm{~cm}^{3} / \mathrm{min}$. Vol. da amostra $=130 \mu \mathrm{L}$. 


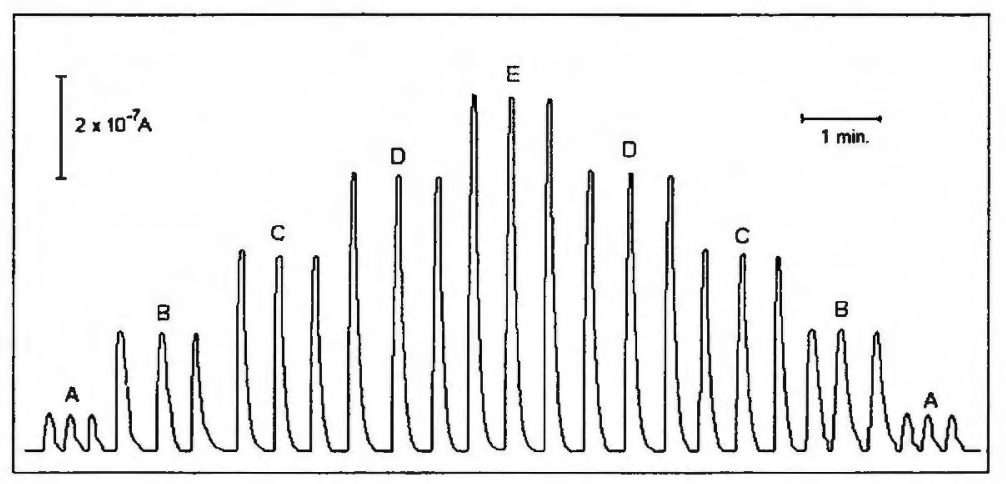

Figura 49 - Resposta amperométrica em fluxo utilizando coluna redutora $\mathrm{Cd} / \mathrm{Cu}$ e eletrodo de carbono vítreo modificado com 3 pares de depósitos alternados de Co-TRP/Zn-TPPS, no $\mathrm{E}=0,75 \mathrm{~V}$ vs. $\mathrm{Ag} / \mathrm{AgCl}$, com injeções consecutivas de (A) 10; (B) 30; (C) 50; (D) 70 e (E) $90 \mu \mathrm{mol} / \mathrm{L}$ de $\mathrm{NO}_{3}{ }^{-}$. Solução tampão $\mathrm{NH}_{4} \mathrm{Cl} / \mathrm{NH}_{4} \mathrm{OH} 0,05 \mathrm{~mol} / \mathrm{L}(\mathrm{pH} 9,1)$ contendo $\mathrm{NaClO}_{4} \quad 0,5$ $\mathrm{mol} / \mathrm{L}$. Vazão do fluxo carregador $=2,4 \mathrm{~cm}^{3} / \mathrm{min}$. Vol. da amostra $=130 \mu \mathrm{L}$.

As curvas analíticas para $\mathrm{NO}_{2}^{-}$(figura 50) e para $\mathrm{NO}_{3}^{-}$(figura 51) apresentaram excelentes linearidades nestas condições e foram obtidas com os dados retirados dos fiagramas ( figuras 48 e 49). Porém deve-se ressaltar que ao utilizar solução tampão cloreto de amônio/hidróxido de amônio $0,05 \mathrm{~mol} / \mathrm{L}$ contendo perclorato de sódio $0,5 \mathrm{~mol} / \mathrm{L}$ curvas analíticas só foram obtidas em concentrações mais elevadas possivelmente devido à menor sensibilidade do eletrodo modificado em meio alcalino.

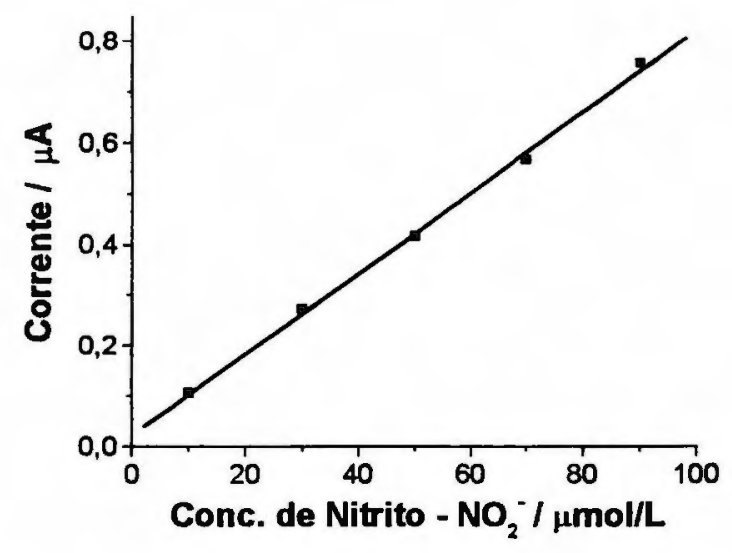

Figura 50 - Curva analítica para nitrito obtida com dados da figura 48. 


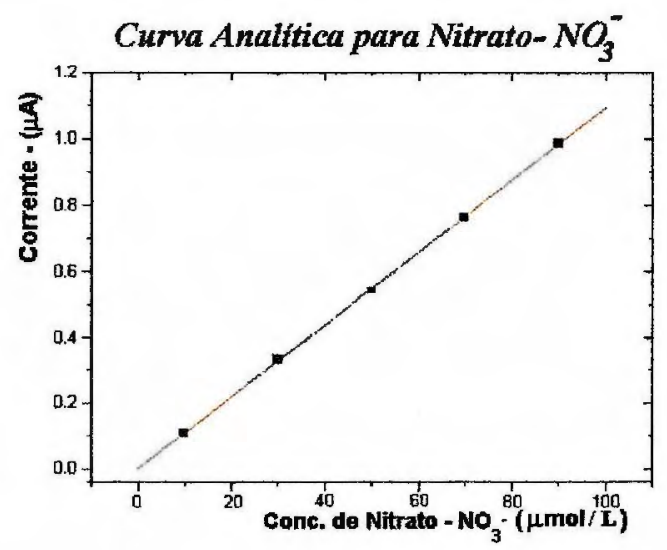

Figura 51 - Curva analítica para nitrato obtida com dados da figura 49.

Na tentativa de determinar a repetibilidade do método para as injeções de $\mathrm{NO}_{2}^{-}$(figura 52) nestas condições, foram realizadas 21 injeções sucessivas de solução tampão cloreto de amônio/hidróxido de amônio $0,05 \mathrm{~mol} / \mathrm{L}$ contendo perclorato de sódio $0,5 \mathrm{~mol} / \mathrm{L}$ e $70 \mu \mathrm{mol} / \mathrm{L}$ de nitrito ao fluxo carregador. Porém pelos resultados obtidos foi possível verificar que ocorre tendência sistemática de perda na intensidade do sinal analítico, ocasionado provavelmente pela complexação do rutênio — presente na porfirina catiônica Co-TRP; visto que a amônia é um excelente complexante.

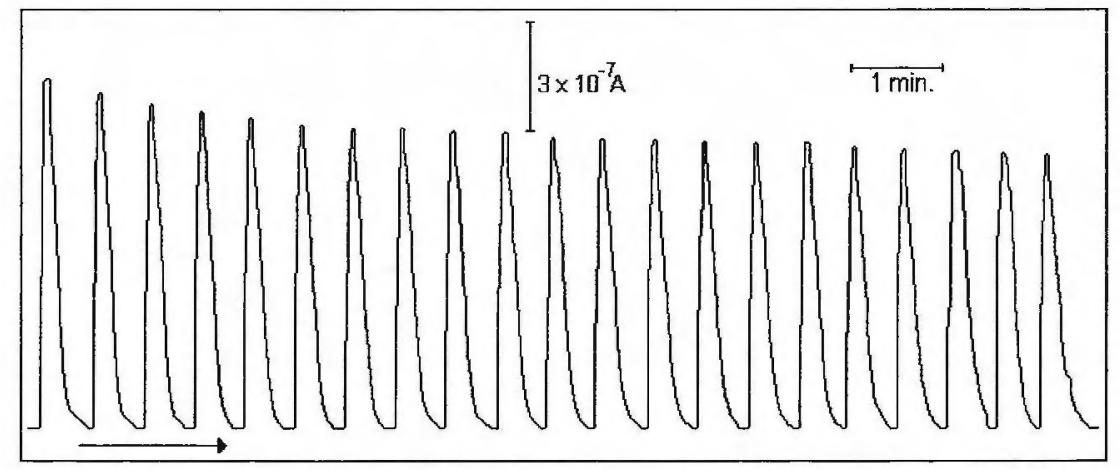

Figura 52 - Fiagramas obtidos após injeções sucessivas de nitrito (70 $\mu \mathrm{mol} / \mathrm{L}$ ) ao fluxo carregador (solução tampão $\mathrm{pH} \mathrm{9,1)} \mathrm{passando} \mathrm{pela}$ coluna redutora de $\mathrm{Cd} / \mathrm{Cu}$, com vazão do fluxo carregador igual a $2,4 \mathrm{~cm}^{3} / \mathrm{min}$ e volume da amostra $=130 \mu \mathrm{L}$. Foi utilizado eletrodo de carbono vítreo modificado com 3 pares de depósitos alternados de Co$\mathrm{TRP} / \mathrm{Zn}$-TPPS polarizado em $\mathrm{E}=0,75 \mathrm{~V}$ vs. $\mathrm{Ag} / \mathrm{AgCl}$. 
A mesma tentativa foi realizada para determinar a repetibilidade para as injeções de $\mathrm{NO}_{3}^{-}$(figura 53) nestas condições e para tanto foram feitas 23 injeções sucessivas de solução tampão ( $\mathrm{pH} 9,1) \mathrm{com} 70 \mu \mathrm{mol} / \mathrm{L}$ de nitrato ao fluxo carregador.

Da mesma forma que para nitrito, ocorreu tendência sistemática de perda na intensidade de corrente e os prováveis fatos que provocam esta diminuição estão discriminados nos comentários referente à figura 52.

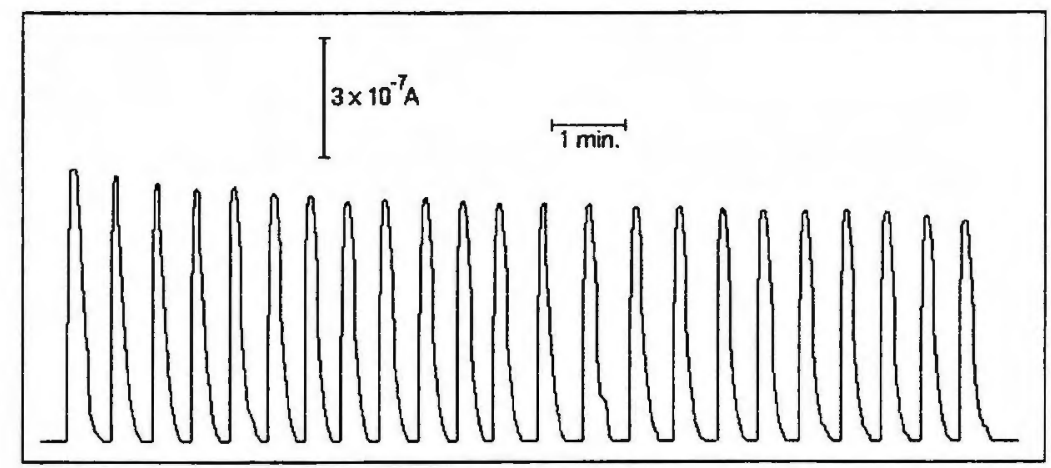

Figura 53 - Fiagramas obtidos após injeções sucessivas de nitrato $(70 \mu \mathrm{mol} / \mathrm{L}$ ) ao fluxo carregador (solução tampão $\mathrm{pH} 9,1)$ passando pela coluna redutora de $\mathrm{Cd} / \mathrm{Cu}$, com vazão do fluxo carregador igual a $2,4 \mathrm{~cm}^{3} / \mathrm{min}$ e volume da amostra $=130 \mu \mathrm{L}$. Foi utilizado eletrodo de carbono vítreo modificado com 3 pares de depósitos alternados de Co$\mathrm{TRP} / \mathrm{Zn}$-TPPS polarizado em $\mathrm{E}=0,75 \mathrm{~V}$ vs. $\mathrm{Ag} / \mathrm{AgCl}$.

\subsubsection{Determinação de Nitrato com Acerto de pH}

Devido aos problemas encontrados com a utilização da solução tampão cloreto de amônio/hidróxido de amônio ( $\mathrm{pH}$ 9,1) e da necessidade de empregar solução neutra ou levemente alcalina na coluna redutora $\mathrm{de} \mathrm{Cd} / \mathrm{Cu}$, pensou-se em usar solução acetato de sódio $0,1 \mathrm{~mol} / \mathrm{L}$ como solução carregadora, visto que esta solução apresenta pH 8 e o acetato de sódio é reagente necessário na preparação da solução tampão acetato de sódio/ácido acético (pH 4,7).

Os ensaios seguintes foram realizados utilizando o esquema de aparelhagem apresentado na figura 17. Neste esquema utiliza-se solução de acetato de sódio 
$0,05 \mathrm{~mol} / \mathrm{L}(\mathrm{pH}=8)$ como solução carregadora e, após a passagem desta pela coluna redutora de cádmio/cobre, é introduzida, por confluência, solução de ácido acético $1 \mathrm{~mol} / \mathrm{L}$ para acerto do valor do $\mathrm{pH}$ para aproximadamente 4,5. Este valor foi verificado antes e após a passagem da amostra pelo sensor amperométrico utilizando papel indicador universal Merck.

Para evitar maiores problemas com diluição da amostra o fluxo carregador apresentava vazão de $2,7 \mathrm{~mL} / \mathrm{min}$ e a vazão da solução de ácido acético era de $0,5 \mathrm{~mL} / \mathrm{min}$. A princípio pensou-se que devido a este fato, ruído significativo aparece na resposta amperométrica como pode ser observado na figura 54, inviabilizando a utilização deste procedimento. Porém após análise mais detalhada o ruído pode ter ocorrido devido ao fato da solução não estar devidamente homogeneizada e para isso deve-se acoplar ao sistema um loop, que faz com que o percurso analítico seja maior, possibilitando assim melhor homogenização do fluxo carregador.

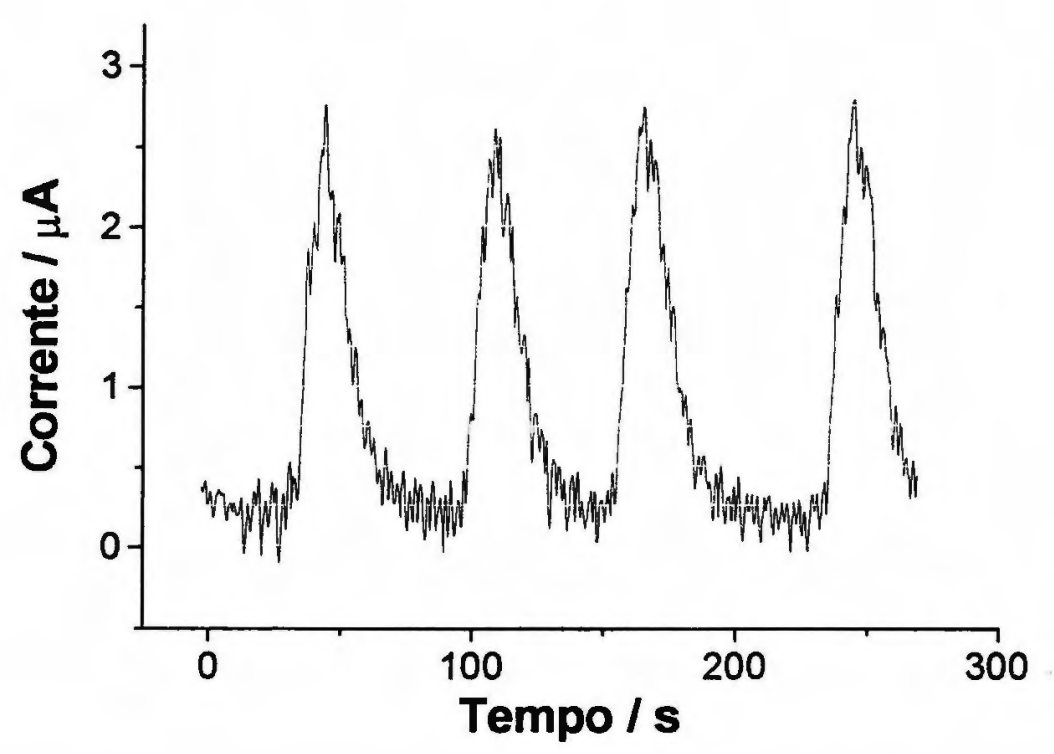

Figura 54 - Resposta amperométrica obtida utilizando sistema apresentado na figura 17, onde foram realizadas injeções sucessivas de solução acetato de sódio $0,05 \mathrm{~mol} / \mathrm{L}(\mathrm{pH} 8)$ contendo perclorato de sódio $0,2 \mathrm{~mol} / \mathrm{L}$ e $1 \mathrm{mmol} / \mathrm{L}$ de $\mathrm{NO}_{2}^{-}$ao fluxo carregador. Após a passagem pela coluna redutora de cádmio/cobre ocorreu o ajuste do $\mathrm{pH}$ para $\approx 4,5$ utilizando solução de ácido acético $1 \mathrm{~mol} / \mathrm{L}$. $\mathrm{E}=750 \mathrm{mV}$. 


\subsubsection{Solução Tampão pH 4,7 X Solução Acetato pH 8}

4 - RESULTADOS E DISCUSSÃO - 69

Como os resultados anteriores não foram promissores pensou-se, em seguida, em utilizar uma única solução como carregadora, sem a necessidade de acerto do $\mathrm{pH}$.

Para tanto, foram realizados ensaios amperométricos para comparar os resultados de intensidade de corrente quando injeta-se soluções contendo nitrito. Desta forma, foram realizadas injeções sucessivas de solução tampão acetato de sódio/ácido acético $0,1 \mathrm{~mol} / \mathrm{L}(\mathrm{pH} 4,7)$ contendo perclorato de sódio $0,2 \mathrm{~mol} / \mathrm{L}$ e 1 $\mathrm{mmol} / \mathrm{L}$ de nitrito ao fluxo carregador (figura $55 \mathrm{~A}$ ). Em seguida foram realizadas injeções sucessivas de solução acetato de sódio $0,1 \mathrm{~mol} / \mathrm{L}(\mathrm{pH})$ contendo perclorato de sódio $0,2 \mathrm{~mol} / \mathrm{L} \mathrm{e} 1 \mathrm{mmol} / \mathrm{L}$ de nitrito ao fluxo carregador (figura 55B).
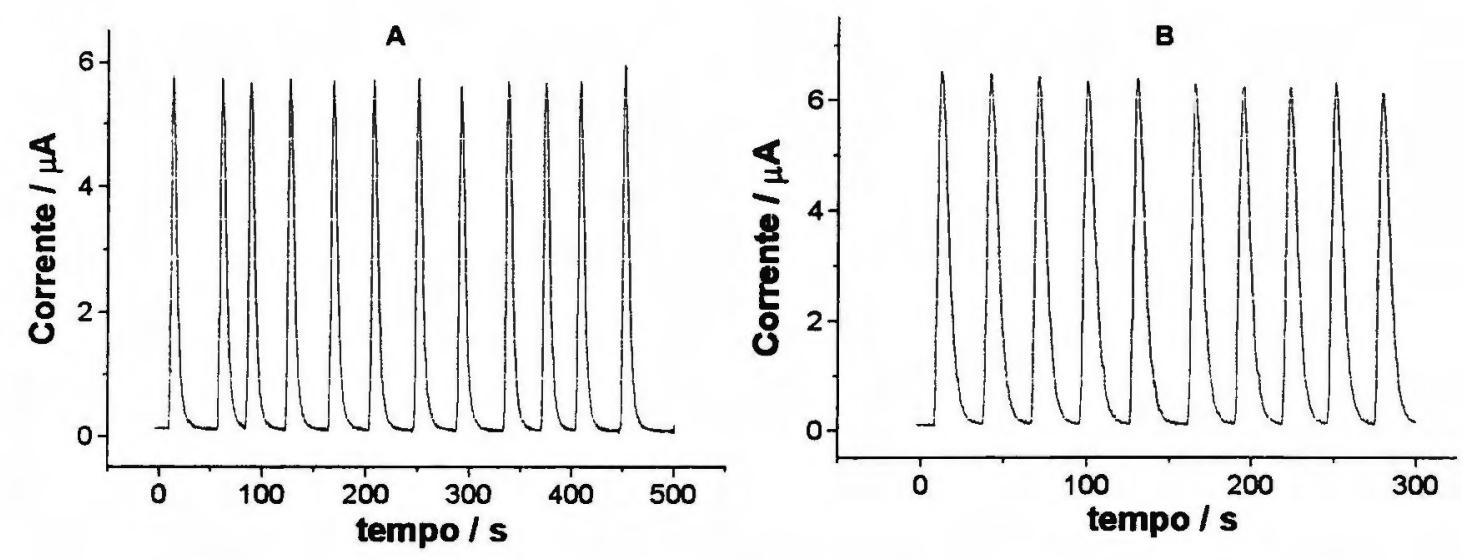

Figura 55 - Resposta amperométrica para comparar os resultados de intensidade de corrente injetando (A) solução tampão acetato de sódio/ácido acético $0,1 \mathrm{~mol} / \mathrm{L}(\mathrm{pH} 4,7)$ contendo perclorato de sódio $0,2 \mathrm{~mol} / \mathrm{L}$ e 1 $\mathrm{mmol} / \mathrm{L}$ de nitrito e (B) solução acetato de sódio $0,1 \mathrm{~mol} / \mathrm{L}(\mathrm{pH} 8)$ contendo perclorato de sódio $0,2 \mathrm{~mol} / \mathrm{L}$ e $1 \mathrm{mmol} / \mathrm{L}$ de nitrito ao fluxo carregador.

Pode-se verificar, nestas figuras, que os resultados de intensidade de corrente obtidos utilizando estas duas soluções são similares. Desta forma torna-se mais prático utilizar solução acetato de sódio $0,1 \mathrm{~mol} / \mathrm{L}(\mathrm{pH} 8)$ contendo perclorato de sódio $0,2 \mathrm{~mol} / \mathrm{L}$, visto que utilizando esta solução não há necessidade de acerto do valor do $\mathrm{pH}$ em fluxo, pela adição de solução alguma. 
Com isto a probabilidade de ocorrer algum problema como a diminuição da intensidade do sinal analítico ou o aparecimento indesejável de ruído é mínima.

\subsubsection{Resultados Obtidos Utilizando Solução Acetato (pH 8)}

\subsubsection{Determinação de Nitrato e Nitrito em $\mathrm{pH} 8$}

Os ensaios para quantificar nitrato foram realizados conforme o esquema da figura 18. Para obter dados suficientes na prepararação da curva analítica foram injetadas soluções de acetato de sódio $0,1 \mathrm{~mol} / \mathrm{L}(\mathrm{pH} 8$ ) contendo perclorato de sódio $0,2 \mathrm{~mol} / \mathrm{L}$ e $10,30,50,70$ e $90 \mu \mathrm{mol} / \mathrm{L}$ de $\mathrm{NO}_{3}{ }^{-}$, ao fluxo carregador. Os resultado destes ensaios, ou seja os fiagramas obtidos, podem ser observados na figura 56.

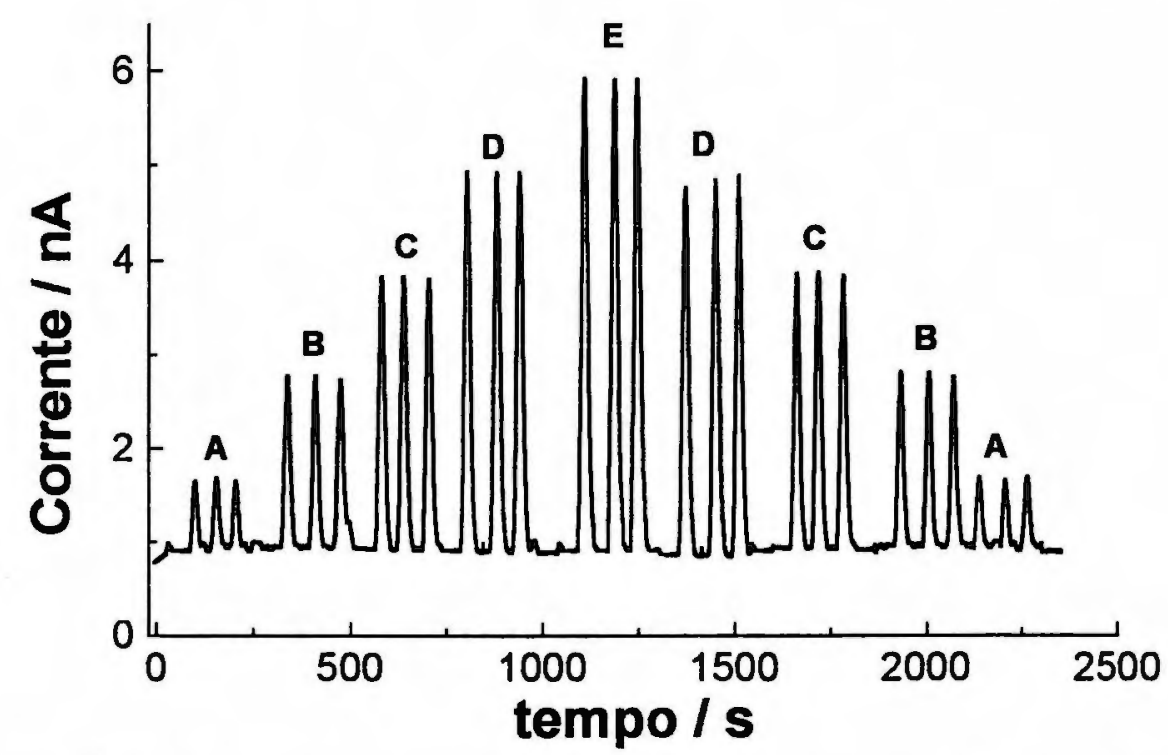

Figura 56 - Resposta amperométrica em fluxo utilizando coluna redutora de $\mathrm{Cd} / \mathrm{Cu}$ e eletrodo de carbono vítreo modificado com 1 par de depósitos alternados de Co-TRP/Zn-TPPS, no E $=0,75 \mathrm{~V}$ vs. $\mathrm{Ag} / \mathrm{AgCl}$, com injeções consecutivas de (A) 10; (B) 30; (C) 50; (D) 70 e (E) $90 \mu \mathrm{mol} / \mathrm{L}$ de $\mathrm{NO}_{3}$. Solução carregadora acetato de sódio $0,1 \mathrm{~mol} / \mathrm{L}(\mathrm{pH} 8)$ contendo perclorato de sódio $0,2 \mathrm{~mol} / \mathrm{L}$. Vazão do fluxo carregador $=2,4 \mathrm{~cm}^{3} / \mathrm{min}$. Volume da amostra $=130 \mu \mathrm{L}$. 
A curva analítica para nitrato (figura 57) obtida, apresentou equação $I(n A)=$ $0,25+0,053 \mathrm{C}$ e $\mathrm{r}^{2}=0,99983$, sendo a faixa de concentração de nitrato de 10 a $90 \mu \mathrm{mol} / \mathrm{L}$. Foi possível determinar o limite de detecção em $1 \mu \mathrm{mol} / \mathrm{L}$ e a repetibilidade de $1,5 \%$.

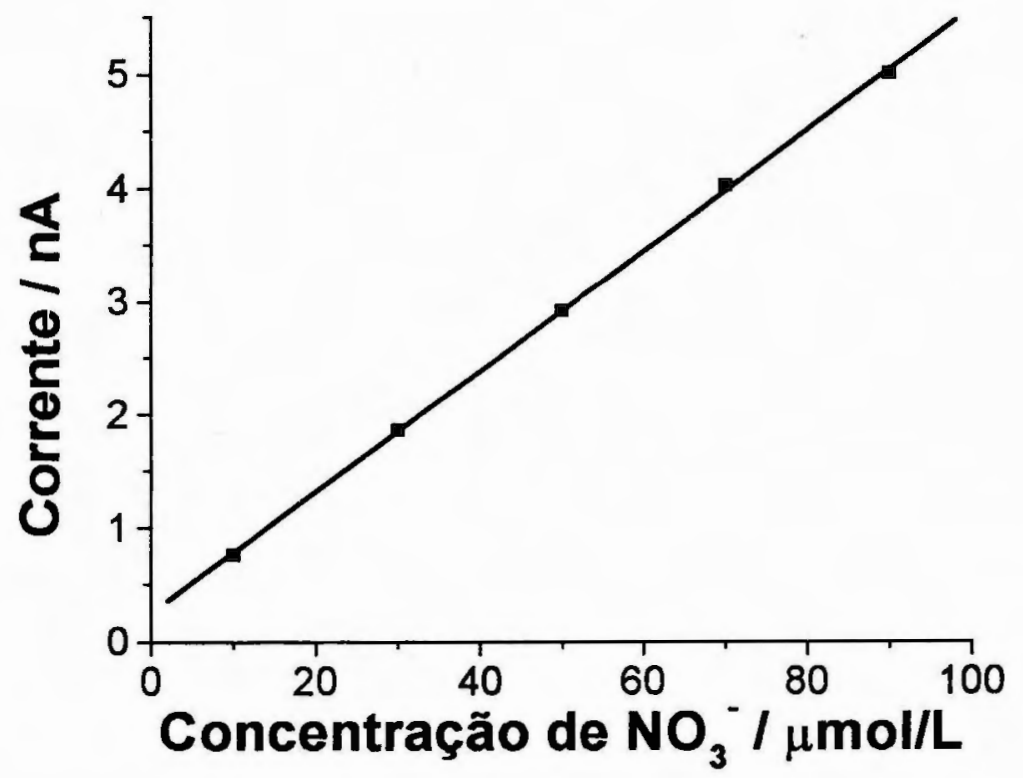

Figura 57 - Curva analítica para nitrato obtida com dados da figura 56.

Já para quantificar nitrito foi utilizado o mesmo esquema da figura 18, sem a presença da coluna redutora de $\mathrm{Cd} / \mathrm{Cu}$. Foram efetuadas injeções de solução de acetato de sódio $0,1 \mathrm{~mol} / \mathrm{L}(\mathrm{pH} 8$ ) contendo perclorato de sódio $0,2 \mathrm{~mol} / \mathrm{L} \mathrm{e} 1,3,5,7$ e $9 \mu \mathrm{mol} / \mathrm{L}$ de $\mathrm{NO}_{2}{ }^{-}$, a o fluxo carregador. Os resultados destes ensaios, ou seja os fiagramas obtidos, podem ser observados na figura 58. 


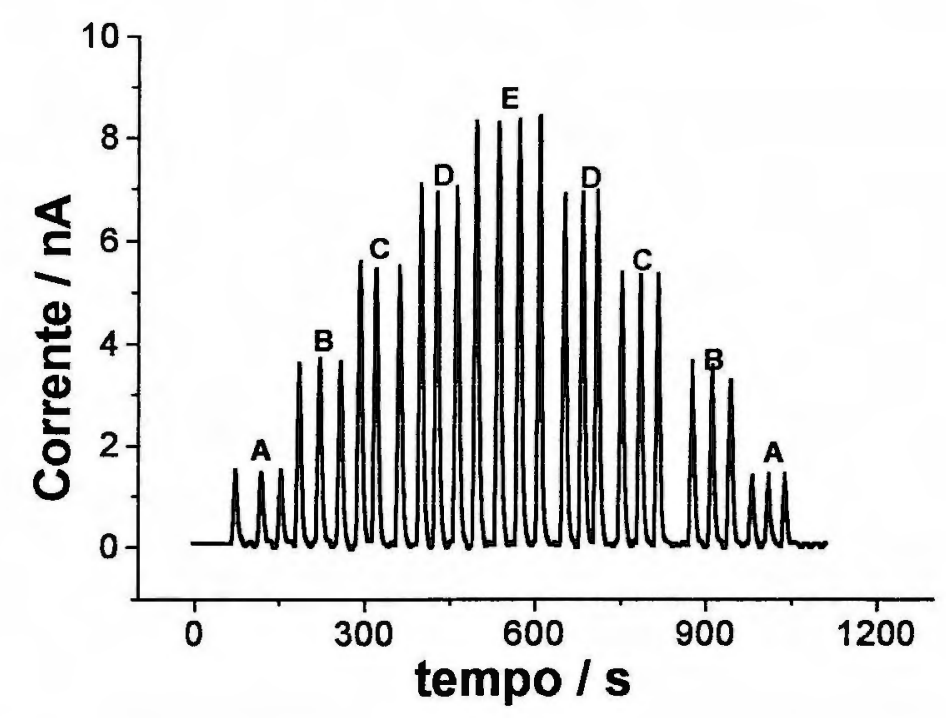

Figura 58 - Resposta amperométrica em fluxo utilizando eletrodo de carbono vítreo modificado com 1 par de depósitos alternados de Co-TRP/ZnTPPS, no $\mathrm{E}=0,75 \mathrm{~V}$ vs. $\mathrm{Ag} / \mathrm{AgCl}$, com injeções consecutivas de (A) 1; (B) 3; (C) 5 ; (D) 7 e (E) $9 \mu \mathrm{mol} / \mathrm{L}$ de $\mathrm{NO}_{2}^{-}$. Solução carregadora acetato de sódio $0,1 \mathrm{~mol} / \mathrm{L}(\mathrm{pH} 8)$ contendo $\mathrm{NaClO}_{4} 0,2 \mathrm{~mol} / \mathrm{L}$. Vazão do fluxo carregador = $2,4 \mathrm{~cm}^{3} / \mathrm{min}$. Volume da amostra $=130 \mu \mathrm{L}$.

A curva analítica para nitrito (figura 59) apresentou equação I (nA) $=0,49+$ $0,90 \mathrm{C} \mathrm{e} \mathrm{r}^{2}=0,99936$, sendo a faixa de concentração de nitrito de 1 a $9 \mu \mathrm{mol} / \mathrm{L}$.

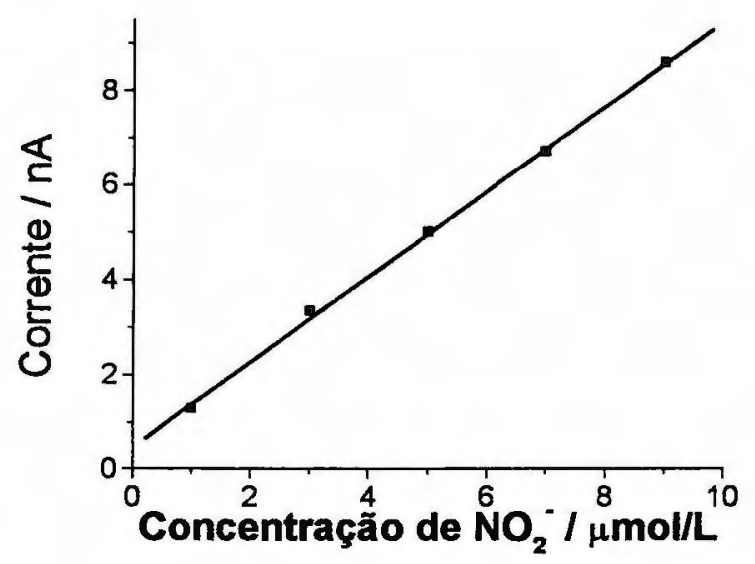

Figura 59 - Curva analítica para nitrito obtida com dados da figura 58. 


\subsubsection{Repetibilidade e Linearidade do Método em $\mathrm{pH} 8$}

Foram realizados ensaios para determinar a repetibilidade do método (figura 60) utilizando solução de acetato de sódio $0,1 \mathrm{~mol} / \mathrm{L}(\mathrm{pH} 8)$ contendo perclorato de sódio $0,2 \mathrm{~mol} / \mathrm{L}$ e com estes resultados foi possível calcular um desvio de $1,5 \%$. $\mathrm{O}$ limite de deteç̧ão observado foi de $0,1 \mu \mathrm{mol} / \mathrm{L}$.

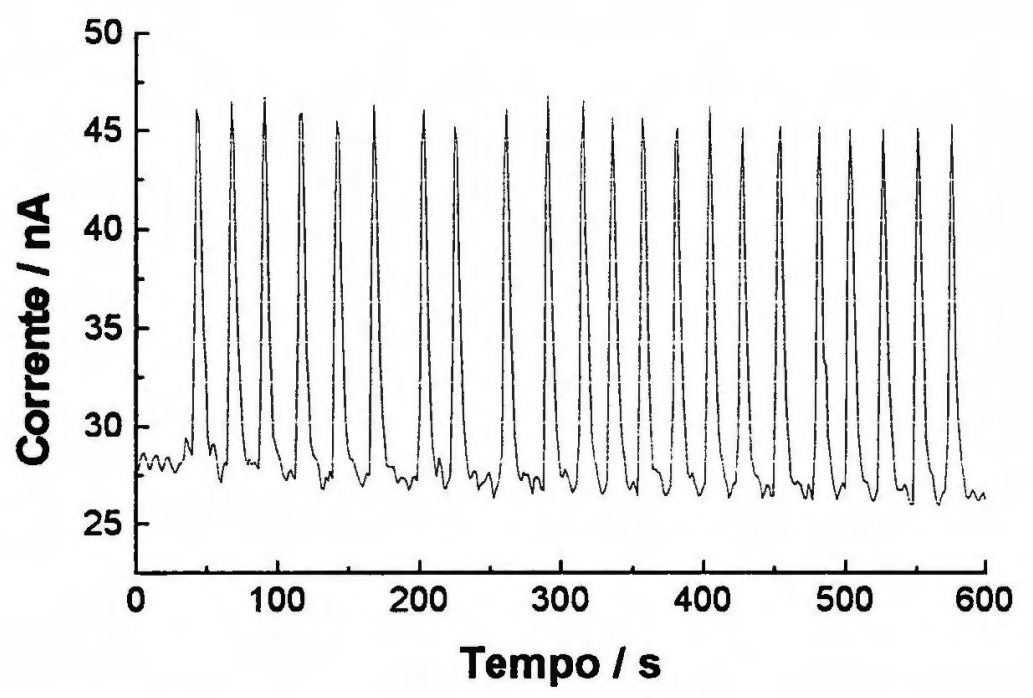

Figura 60 - Fiagramas obtidos para determinar a repetibilidade do método. Como eletrodo de trabalho foi usado carbono vítreo modificado com 1 par de depósito alternado de Co-TRP/Zn-TPPS, eletrodo auxiliar de aço inoxidável, eletrodo de referência $\mathrm{Ag} / \mathrm{AgCl}$ em solução acetato de sódio $0,1 \mathrm{~mol} / \mathrm{L}$ (pH 8) contendo $\mathrm{NaClO}_{4} 0,2 \mathrm{~mol} / \mathrm{L}$ e $5 \mu \mathrm{mol} / \mathrm{L}$ de nitrito.

Para determinar a linearidade do método foram realizados ensaios em fluxo, injetando soluções de acetato de sódio $0,1 \mathrm{~mol} / \mathrm{L}(\mathrm{pH} 8)$ contendo perclorato de sódio $0,2 \mathrm{~mol} / \mathrm{L}$ e $1,10,100$ e $1000 \mu \mathrm{mol} / \mathrm{L}$ ao fluxo carregador.

Os resultados podem ser observados na figura 61, sendo que $r^{2}=0,99994$. Com estes resultados percebe-se que a linearidade é muito boa para uma ampla faixa de concentração de nitrito. 


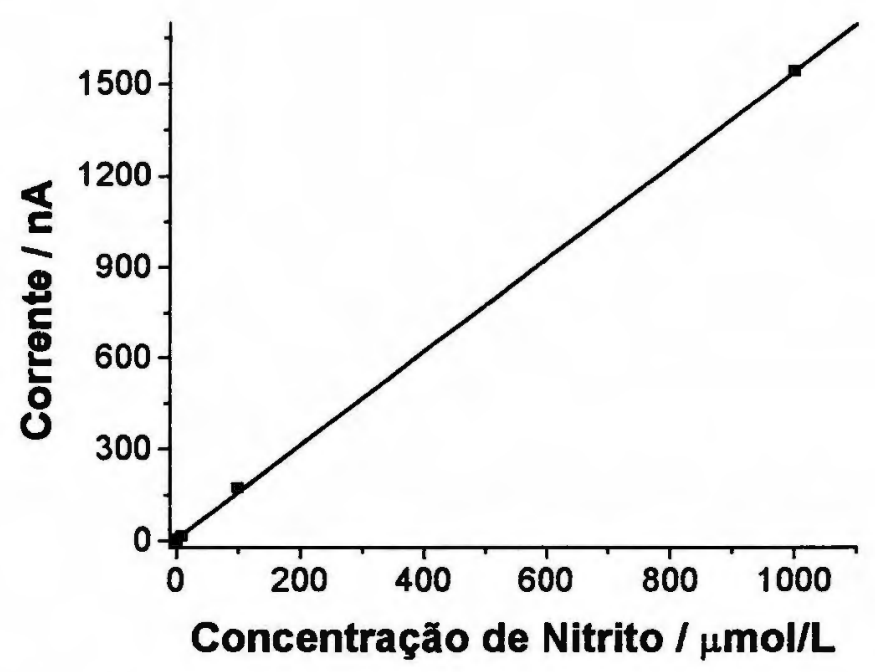

Figura 61 - Curva para demonstrar a linearidade do método.

\subsubsection{Preparo das Amostras Reais}

Foram realizados ensaios em três tipos de amostras reais: saliva, água mineral e carne bovina salgada curada e seca. Em todas as amostras foram realizadas diluições, pois todas apresentavam concentrações altas se comparados os valores com a faixa de trabalho escolhida.

Já para as amostras de carne curada foram utilizados dois procedimentos diferentes para a preparação das soluções. $O$ primeiro procedimento foi a extração dos sais impregnados na referida carne, utilizando solução acetato de sódio $0,1 \mathrm{~mol} / \mathrm{L}$ (pH 8) contendo perclorato de sódio $0,2 \mathrm{~mol} / \mathrm{L}$. No segundo procedimento foi realizada a extração e a desproteinização da amostra conforme metodologia descrita por Lara et al [71] com posterior diluição da amostra em solução acetato (pH 8).

Foram realizados dois tipos de procedimento de tratamento da amostra de carne curada para verificar se as proteínas interfeririam no ensaio com este eletrodo modificado. 


\subsubsection{Resultados das Amostras Reais[77]}

Os ensaios das amostras reais foram realizados logo após a obtenção de dados para a construção de cada curva analítica.

Os resultados de nitrato foram calculados descontando os valores de pico de corrente de nitrito visto que, ao determinar nitrato, determina-se em conjunto nitrito.

Tabela 4 - Resultados da concentração de nitrato e nitrito, obtidos por meio de ensaios amperométricos e espectrofotométricos em amostras de água mineral e de saliva.

Amostras Nitrito $(\mu \mathrm{mol} / \mathrm{L})$

Nitrato $(\mu \mathrm{mol} / \mathrm{L})$

\begin{tabular}{cccccc}
\hline & A & E-VIS & A & E-VIS & Especificação \\
\hline Saliva & 18,9 & 19,4 & 45,5 & 46,6 & - \\
\hline Amostra 1* & - & - & 51,5 & 53,6 & 50 \\
\hline Amostra 2* & - & - & 139,1 & 138,3 & 140 \\
\hline Amostra 3* & - & - & 253,5 & 250,4 & 240 \\
\hline Amostra 4* & - & - & 117,0 & 113,1 & 100 \\
\hline Amostra 5* & - & - & 318,9 & 316,8 & 330 \\
\hline
\end{tabular}

$\mathrm{A}=$ amperometria; $\mathrm{E}-\mathrm{Vis}$ = espectrofotometria no vísivel; * água mineral.

Tabela 5 - Resultados da concentração de nitrato e nitrito, obtidos por meio de ensaios amperométricos e espectrofotométricos em amostra de carne curada.

Amostras Nitrito (mmol/Kg) Nitrato (mmol/Kg)

\begin{tabular}{ccccc}
\hline & $\mathbf{A}$ & E-VIS & $\mathbf{A}$ & E-VIS \\
\hline Extração & 1,12 & 1,16 & 11,04 & 11,81 \\
\hline Extração + Desproteinização & 1,32 & 1,45 & 12,84 & 12,20 \\
\hline
\end{tabular}

$\mathrm{A}=$ amperometria; $\mathrm{E}-\mathrm{Vis}=$ espectrofotometria no vísivel 
Comparando-se os resultados apresentados nas tabelas 4 e 5, percebe-se similaridade dos mesmos, portanto a aplicabilidade desta metodologia é viável. Além disto, os valores obtidos pelos dois métodos - espectrofotométrico e amperométrico - estão próximos das prováveis concentrações que são indicadas nos rótulos das águas minerais analisadas.

Com os resultados para nitrato obtidos com o método de Griess e com o método amperométrico construiu-se o gráfico que compara os resultados desses ensaios, o qual é apresentado na figura 62.

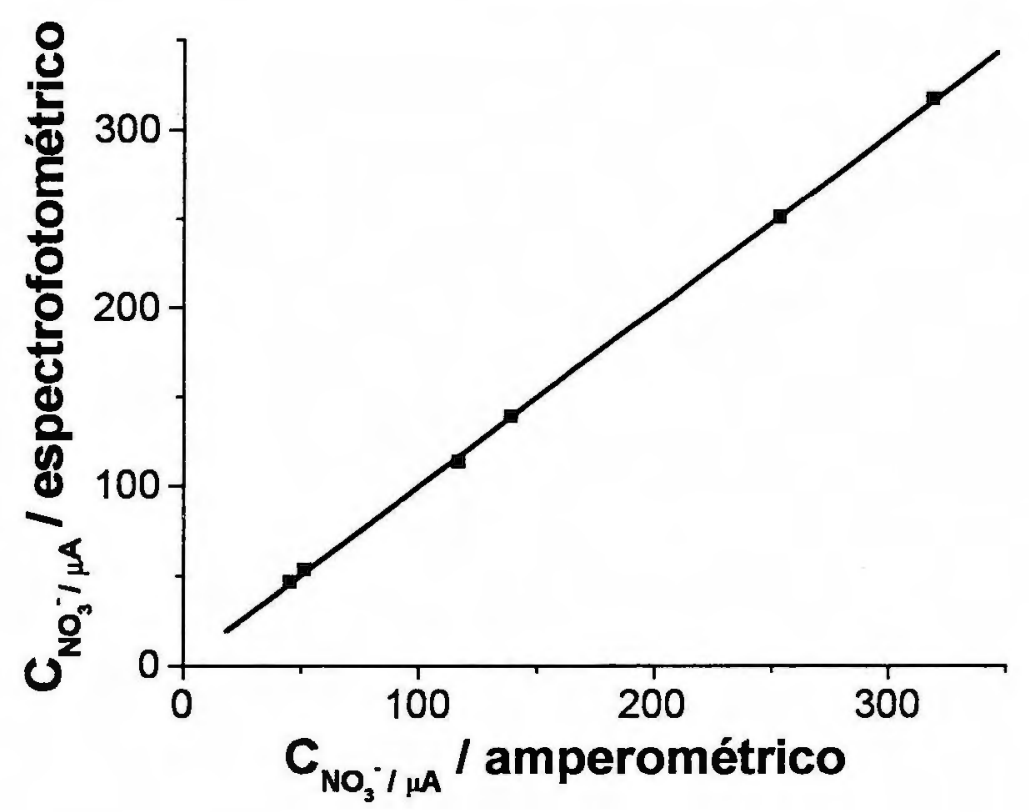

Figura 62 - Gráfico que compara os métodos de Griess e amperométrico utilizando os resultados obtidos com a determinação de nitrato.

Os resultados mostram que nos dois métodos encontrou-se quantidades muito próximas de analito, sendo que o coeficiente angular da reta é de 0,9864 . Com estes resultados e os desvios entre os métodos apresentados na tabela 6 , verifica-se a boa confiabilidade do método amperométrico proposto. 
Tabela 6 - Valores dos desvios encontrados entre o método de Griess e o amperométrico.

Amostra Desvio / \%

\begin{tabular}{cc}
\hline Saliva & $-1,18$ \\
\hline Amostra 1* & $-1,96$ \\
\hline Amostra 2* & $+0,29$ \\
\hline Amostra 3* & $+0,62$ \\
\hline Amostra 4* & $+1,72$ \\
\hline Amostra 5* & $+0,33$ \\
\hline Extração\& & $-3,26$ \\
\hline Extração + Desproteinização* & $+2,62$ \\
\hline Desvio médio & 1,50
\end{tabular}

* água mineral; *carne bovina salgada curada. 


\section{CONCLUSÕES}

Pela observação da figura 26 , pode-se verificar que realmente há a necessidade da utilização de perclorato de sódio como contra-íon, pois somente pares de depósitos alternados de Co-TRP/Zn-TPPS não são suficientes para minimizar de forma eficaz a solubilização das porfirinas.

Nota-se, na figura 27, que o processo eletroquímico envolvendo a oxidação do $\mathrm{NO}_{2}{ }^{-}$é observado de forma mais eficaz em eletrodo de carbono vítreo modificado com Co-TRP/Zn-TPPS do que em relação ao mesmo eletrodo sem modificação, visto que ocorre a intensificação de corrente.

Com os resultados apresentados na figura 29 e o gráfico apresentado na figura 30, que trata do número de pares de depósitos alternados, nota-se que 1 par de depósito alternado de Co-TRP/Zn-TPPS é a melhor opção de modificação, visto que com 1 par a intensidade de corrente para nitrito é aproximadamente duas vezes maior do que aquela observada para 3 pares de depósitos alternados. Ainda nesta figura percebe-se o decaimento exponencial quando aumenta-se o número de pares de depósitos alternados.

Os ensaios que informam sobre a estabilidade deste filme e que são apresentados na figura 38, demonstram que os resultados são promissores visto que, após 40 horas de uso, o eletrodo modificado apresentou diminuição na intensidade de sinal na ordem de $7 \%$ provocado provavelmente pela solubilização do filme. Este resultado pode ser considerado excelente.

Outros ensaios importantes realizados foram aqueles para verificar a homogeneidade e permeabilidade do filme e que são apresentados na figura 33 . Nestes resultados percebe-se que filmes mais espessos são menos permeáveis e estes resultados são concordantes com aqueles previstos no trabalho de eletrodos modificados com Ni-TRP, que indicam que a permeabilidade do filme diminui devido ao arranjo compacto das moléculas do filme[56]. 
Sabe-se, pela literatura, que a cinética de reação do $\left[\mathrm{Fe}(\mathrm{CN})_{6}\right]^{4}$ é rápida e isto ocorre mesmo com o eletrodo modificado com 1 par de depósitos alternados de CoTRP/Zn-TPPS, conforme pode-se verificar na figura 40 e no gráfico de I x $\omega^{1 / 2}$ que é apresentado na figura 41.

Entretanto, pela análise da figura 42 e do gráfico apresentado na figura 43B percebe-se que o transporte de material até a superfície do eletrodo não é o fator limitante para a oxidação do nitrito. A cinética de reação para este íon é lenta quando utilizam-se eletrodos não modificados e este fato se confirma para eletrodos modificados. Com estes resultados pode-se afirmar que o processo limitante para 0 nitrito é a transferência de elétrons no interior do filme que recobre o eletrodo.

Os resultados obtidos amperometricamente para a quantificação de nitrato e nitrito em saliva, água mineral e em carne curada, podem ser considerados bons. Esta conclusão baseia-se na observação dos resultados apresentados nas tabelas $4 \mathrm{e}$ 5 , bem como na confiabilidade do método proposto, quando observa-se o valor do desvio médio (tabela 6) obtido entre os métodos espectrofotométrico e o amperométrico na determinação de nitrato e da comparação gráfica (figura 62) entre os dois métodos.

Segundo a legislação vigente as concentrações máximas permitidas de nitrato e nitrito em águas de mananciais são respectivamente $220 \mu \mathrm{mol} / \mathrm{L}$ e $30 \mu \mathrm{mol} / \mathrm{L}$, ambos expressos em $\mathrm{N}$ [78]. Os resultados indicaram que o limite de detecção para nitrito é de $0,2 \mu \mathrm{mol} / \mathrm{L}$ expresso em $\mathrm{N}$, sendo estes valores muito abaixo dos limites permitidos pela legislação. 


\section{PERSPECTIVAS FUTURAS}

(4) Otimizar o sistema FIA proposto.

Neste sistema pode-se realizar estudo minucioso alterando dois fatores importantes: o volume da alça de amostragem e a vazão do fluxo carregador. Com a otimização do sistema pode-se obter melhores resultados para aumentar a sensibilidade do método.

$\rightarrow$ Utilizar microeletrodos modificados com pares de depósitos alternados de Co-TRP/Zn-TPPS na determinação quantitativa de nitrato e nitrito.

Com o advento da fabricação de microeletrodos, ganho adicional em sensibilidade pôde ser verificado uma vez que ao elevado fluxo de material originado pela difusão convergente associa-se a efetiva discriminação de processos capacitivos em razão dos baixos valores da capacitância da dupla camada elétrica. Desta forma, a razão sinal faradaico/ruído atinge valores mais favoráveis justificando o emprego de microeletrodos como sensores amperométricos, observando-se como conseqüência a melhoria nos limites de detecção nas determinações analíticas.

Os resultados obtidos até o momento utilizando eletrodos com dimensões convencionais modificados com pares de depósitos alternados de Co-TRP/Zn-TPPS são bastante favoráveis. A utilização de microeletrodos modificados com estas metaloporfirinas pode melhorar ainda mais a sensibilidade das determinações analíticas.

Theterminar quantitativamente nitrato e nitrito em águas do Ribeirão dos Pires.

Este ribeirão está localizado no município de Ribeirão Pires na Região do Grande $\mathrm{ABC}$ e corta o município ao qual cedeu o nome. Tem sua nascente no bairro do Pilar Velho e faz parte da bacia hidrográfica do Reservatório da Billings. 
Os esgotos do núcleo central do município são tratados pelo processo anaeróbico de fluxo ascendente, antes de serem depositados neste rio. Esta estação de tratamento de esgotos (ETE) tem como capacidade máxima o atendimento de esgotos produzidos por 40 mil habitantes, porém devido a problemas operacionais a ETE está trabalhando com $50 \%$ da capacidade máxima, ou seja tratando somente o esgotos produzido por 20 mil habitantes. Segundo o senso de 1996, o município tem mais de 100 mil habitantes.

Este processo de tratamento de esgotos visa somente a eliminação da matéria orgânica e sólidos, não havendo assim preocupação de minimizar a contaminação por outros poluentes.

O Ribeirão dos Pires recebe ainda dejetos industriais, como por exemplo, de empresas que produzem embutidos e que utilizam como um dos conservantes desses alimentos o nitrito de sódio. Este ribeirão como outros rios, riachos e córregos de municípios da região deságuam na Represa Billings que é uma das poucas fontes de mananciais da Grande São Paulo.

Devido a estes fatores e a problemas ocasionados com concentrações relativamente altas de nitrato e nitrito em águas mananciais, torna-se necessário o monitoramento destes íons no referido riacho. 


\section{REFERÊNCIAS BIBLIOGRÁFICAS}

1. A . W. Hayes (Ed.), Principles and Methods of Toxicology, $2^{\text {nd }}$ Edition, Raven Press, New York, 1989, p. 20-21.

2. P. Bennett, Terra: Uma Incrivel Máquina de Reciclagem (Coleção Desafios), Ed. Moderna, São Paulo, 1996, p. 16.

3. B. L. Battalha e A. C. Parlatore, Controle da Qualidade da Água para Consumo Humano - Bases Conceituais e Operacionais, $1^{\text {a }}$ Edição, CETESB, São Paulo, 1993, p. 117.

4. Tecnoalimenti, Tox Data Food - Toxicological survey in food field - Dati tossicologici di interesse alimentare, $1^{\text {st }}$ Edition, Organizzazione Editoriale Medico Farmaceutica, Via Edolo 42 - Milano, 1991, p. 205.

5. R. J. M. Niesink, J. de Vries and M. A. Hollinger, Toxicology - Principles and Applications, $1^{\text {st }}$ Edition, CRC Press, Boca Raton - Florida, 1996, p. 647-648-652.

6. G. M. Rand (Ed.), Fundamentals of Aquatic Toxicology - Effects, Environmental Fate, and Risk Assessment, $2^{\text {nd }}$ Edition, Washington, 1995, p. 423.

7. C. D. Klaassen (Ed.), Casarett and Doull's Toxicology - The Basic Science of Poisons, $5^{\text {th }}$ Editon, McGraw-Hill, New York, 1996, p. 96

8. G. H. Jeffery(Ed.), Vogel's Textbook of Quantitative Chemical Analysis, Longman, London, $5^{\text {th }}$ Edition., 1989, p.702. 
9. M. A. H. Franson (Ed.), Standard Methods for the Examination of Water and Wastewater, $19^{\text {th }}$ Edition, American Public Health Association, Washington, 1995 , p. 4-83

10. P. Cunniff(Ed.), Official Methods of Analysis of AOAC International, $16^{\text {th }}$ Edition, Vol.1, Chapter 11, AOAC, Virginia, 1995, p. 10.

11. M. Czae and J. Wang, Talanta, 50, 1999, 921.

12. J. Osteryoung, Science, 218, 1982, 261.

13. D. H. Evans, K. M. O'Connell, R. A. Petersen and M. J. Kelly, Journal of Chemical Education, , 60(4),1983 290.

14. G. A. Mabbott, Journal of Chemical Education, 60(9), 1983, 697.

15. P. T. Kissinger and W. R. Heineman, Journal of Chemical Education, 60(9), 1983, 702.

16. J. J. Van Benschoten, J. Y. Lewis, W. R. Heineman, D. A. Roston and P. T. Kissinger, Journal of Chemical Education, 1983, 60(9), 772.

17. A. M. O. Brett and C. M. A. Brett, Electrochemistry: Principles, Methods and Applications, $1^{\text {st }}$ Edition, Oxford University Press, New York, 1993, p. $339-340$.

18. V. S. Bagotzky, Fundamentals of Electrochemistry, $1^{\text {st }}$ Edition, Plenum Press, New York, 1993, p. 503.

19. J. Ruzicka and E. H. Hansen, Analytica Chimica Acta, 78, 1975, 145. 
20. J. Ruzicka and E. H. Hansen, Analytica Chimica Acta. 179, 1986, 1.

21. J. Ruzicka and E. H. Hansen, Flow Injection Analysis (Chemical Analysis), v. 62, $2^{\text {nd }}$ Edition, John Wiley \& Sons, Inc, New York, 1988, p. 20.

22. J. Ruzicka and E. H. Hansen, Analytica Chimica Acta, 99, 1978, 37.

23. Z. Fang, Flow Injection Separation and Preconcentration, $1^{\text {st }}$ Edition, VCH Publishers, Inc., New York, 1993.

24. J. Ruzicka, E. H. Hansen and H. Mosbaek, Analytica Chimica Acta, 92, 1977, 235.

25. E. H. Hansen, Analytica Chimica Acta, 308, 1995, 3.

26. B. Karlberg and G. E. Pacey, Flow Injection Analysis - A Practical Guide, $1^{\text {st }}$ Edition. Elsevier Science Publishing Company Inc., New York, 1989.

27. K. Araki, L. Angnes, C. M. N. Azevedo and H. E. Toma. Journal of Electroanalytical Chemistry, 397, 1995, 205.

28. R. W. Murray, Accounts of Chemical Research, 13, 1980, 135.

29. R. W. Murray, A. G. Ewing and R. A. Durrst, Analytical Chemistry, 59(5), $1987,379 \mathrm{~A}$.

30. J. Zak and T. Kuwana, Journal of Electroanalytical Chemistry, 150, 1983, 645. 
31. A. J. Bard, Journal of Chemical Education, 60(4), 1983, 302.

32. J. A. Cox, R. K. Jaworski and P. J. Kulesza, Electroanalysis, 3, 1991, 869.

33. J. Wang, A. Brennsteiner, L. Angnes, N. Bitsh, Analytical Chemistry, 64, 1992, 151.

34. N. D. Popovic, J. A. Cox and D. C. Johnson, Journal Electroanalytical Chemistry, 455, 1998, 153.

35. J. R. C. da Rocha, L. Kosminsky, T. R. L. C. Paixão and M. Bertotti, Electroanalysis, 13(2), 2001. 155.

36. E. Lust, A. Jänes, K. Lust and R. Pullerits, Journal Electroanalytical Chemistry, 431, 1997, 183.

37. J. R. C. da Rocha, M. Bertotti, K. Araki and H. E. Toma, Kinetics of the Electrochemical Oxidation of Nitrite at Tetraruthenated Porphyrin Modified Electrodes, Electrochimica Acta, Submetido para publicação.

38. K. Araki, L. Angnes, C. M. N. Azevedo and H. E. Toma, Journal of Electroanalytical Chemistry, 397, 1997, 205.

39. P. Bertocchi, D. Compagnone and G. Palleschi, Bioensors \& Bioelectronics, 11(1-2), 1996, 1.

40. A. M. O. Brett, S. H. P. Serrano, I. Gutz and M. A. La-Scalea, Bioelectrochemestry and Bioenergetics, 42(2), 1997, 175. 
41. A. M. O. Brett, T. R. A. Macedo, D. Raimundo, M. H. Marques, S. H. P. Serrano, Biosensors \& Bioelectronics, 13(7-8), 1998, 861.

42. Jing-Na Ni, Huang-Xian Ju, Hong-Yuan Chen and Dónal Leech, Analytica Chimica Acta, 378, 1999, 151.

43. W. W. Kubiak and J. Wang, Analytica Chimica Acta, 329, 1996, 181.

44. D. Dolphin (Ed.), The Porphyrins - Structure and Synthesis - Part B, Vol. 2, $1^{\text {st }}$ Edition, Academic Press, New York, 1978.

45. L. R. Milgrom, The Colours of Life - An Introduction to the Chemistry of Porphirins and Related Compounds, $1^{\text {st }}$ Edition, Oxford University Press, New York, 1997.

46. N. L. Allinger, M. P. Cava, D. C. de Jongh, C. R. Johnson, N. A. Lebel and C. L. Stevens, Organic Chemistry, $2^{\text {nd }}$ Edition, Worth Publishers, Inc., New York. 1976, p. 692.

47. J. Rudijk and E. Bouwman, Bioinorganic Catalysis, $2^{\text {nd }}$ Edition, Marcel Dekker, Inc., New York, 1999, p. 326.

48. D. Dolphin (Ed.), The Porphyrins - Structure and Synthesis-Part A, Vol. 1, $1^{\text {st }}$ Edition, Academic Press, New York, 1978.

49. B. Kräutler, Chimia, 41, 1987, 277.

50. K. Kalyanasundaram, Photochemistry of Polypyridine and Porphyrin Complexes, Chapter 12, Academic Press, London, 1992. 
51. A. S. Ito, G. C. Azzellini, S. C. Silva, O. Serra and A. G. Szabo, Biophisical Chemistry, 45(1). 1992. 79.

52. K. Araki, L. Angnes and H. E. Toma, Advanced Materials, 7(6), 1995, 554.

53. A. S. Ito, G. C. Azzellini, S. C. Silva, O. Serra and A. G. Szabo, Biophisical Chemistry, 45(3). 1993. 305.

54. Y. Ridente, G. C. Azzellini and A. S. Ito, Pigment Cell Research, 6(3). 1993. 134.

55. A. Archut, G. C. Azzellini, V. Balzam, L. De Cola and F. Vogtle, Journal of the American Chemical Society, 120(47), 1998. 12187.

56. F. Vogtle, M. Plevoets, M. Nieger, G. C. Azzellini, A. Credi, L. De Cola, V. Demarchi, M. Venturi and V. Balzani, Journal of the American Chemical Society, 121(26), 1999. 6290.

57. K. Araki, M. J. Wagner and M. S. Wrighton, Langmuir, 12, 1996, 5393.

58. R. C. Rocha, K. Araki and H. E. Toma, Inorganica Chimica Acta, 285, 1999, 197.

59. C. M. N. Azevedo, K. Araki, H. E. Toma and L. Angnes, Analytica Chimica Acta, 387, 1999, 175.

60. H. E. Toma and K. Araki, Coordination Chemistry Reviews, 196, 2000, 307.

61. R. J. Elliott and A. G. Porter, Analyst, 66, 1971, 522. 
62. J. C. Fanning. Coordination Chemistry Review, 199. 2000. 159.

63. T. J. Chow and M. S. Johnstone, Analytica Chimica Acta, 27, 1962, 441.

64. A. W. Morris and J. P. Riley, Analytica Chimica Acta, 29, 1963, 272.

65. J. D. H. Strickland and T. R. Parsons, A Practical Handbook of Seawater Analysis, Fisheries Research Board of Canada, Ottawa, 1968, p. 71.

66. K. Grasshoff, M. Ehrhardt and K. Kremling(Ed.), Methods of Seawater Analysis, $2^{\text {nd }}$ Edition, Verlag Chemie, Federal Republic of Germany, 1983, p.145.

67. V. Mori and M. Bertotti, Analytical Letters, 32, 1999, 25.

68. C. M. N. Azevedo, K. Araki, L. Angnes and H. E. Toma, Eletroanalysis, 10(7), 1998, 467.

69. Dissertação de Mestrado, R.M. Liegel, Porfirinas e Metaloporfirinas Catiônicas Aquossolúveis: Síntese e Caracterização de Derivados Benzilpiridinio Substituidos, IQ-USP, 1996, p. 29.

70. R. C. Silva e I. G. de Souza, Química Nova, 21(4), 1998, 477.

71. W. H. Lara, M. Y. Takahashi e N. Silveira, Revista do Instituto Adolfo Lutz, 38(2), 1978, 167.

72. C. D. Usher and G. M. Telling, Journal Science, Food and Agriculture, 2, 1975, 1793. 
73. A. M. O. Brett and C. M. A. Brett, Electrochemistry: Principles, Methods and Applications, $1^{\text {st }}$ Edition, Oxford University Press, New York, 1993, p. 99.

74. Tese de Doutorado, C. M. N. Azevedo, Desenvolvimento de Eletrodos Modificados e Métodos Analíticos, IQ-USP, 1999, p. 16.

75. A J. Bard and L.R. Faulkner, Electrochemical Methods - Fundamentals and Applications, $1^{\text {st }}$ Edition, John Wiley \& Sons, Inc. New York, 1980, p.151292.

76. S. M. Silva, C. R. Alves, S. A. S. Machado, L. H. Mazo and L. A. Avaca, Eletroanalysis, 8(11), 1996, 1055.

77. J. R. C. Rocha, K. Araki, L. Angnes, H. E. Toma and M. Bertotti, Flow Injection Determination of Nitrite and Nitrate by Amperometric Detection Using Tetraruthenated Porphyrin Modified Electrodes, Analytica Chimica Acta, Submetido para publicação.

78. Legislação: regiões metropolitanas, proteção de mananciais, zoneamento industrial (atualizada até dezembro/1995), CETESB/Secretária do Meio Ambiente, São Paulo, 1995. 